Received 7 July; accepted 21 September 1998

Dalbey, R. E., Lively, M. O., Bron, S. \& van Dijl, J. M. The chemistry and enzymology of the type signal peptidases. Protein Sci. 6, 1129-1138 (1997).

2. Kuo, D. W. et al. Escherichia coli leader peptidase: production of an active form lacking a requirement for detergent and development of peptide substrates. Arch. Biochem. Biophys. 303, 274-280 (1993).

Tschantz, W. R. et al. Characterization of a soluble, catalytically active form of Escherichia coli leader peptidase: requirement of detergent or phospholipid for optimal activity. Biochemistry 34, 3935-3941 (1995).

4. Allsop, A. E. et al. in Anti-Infectives, Recent Advances in Chemistry and Structure-Activity Relationships (eds Bently, P. H. \& O’Hanlon, P. J.) 61-72 (R. Soc. Chem., Cambridge, 1997).

Black, M. T. \& Bruton, G. Inhibitors of bacterial signal peptidases. Curr. Pharm. Des. 4, 133-154 (1998)

6. Date, T. Demonstration by a novel genetic technique that leader peptidase is an essential enzyme in Escherichia coli. J. Bacteriol. 154, 76-83 (1983).

7. Whitely, P. \& von Heijne, G. The DsbA-DsbB system affects the formation of disulfide bonds in periplasmic but not in intramembraneous protein domains. FEBS Lett. 332, 49-51 (1993).

8. Peat, T. S. et al. Structure of the UmuD' protein and its regulation in response to DNA damage. Nature 380, 727-730 (1996)

9. Paetzel, M. et al. Crystallization of a soluble, catalytically active form of Escherichia coli leader peptidase. Proteins Struct. Funct. Genet. 23, 122-125 (1995).

10. van Klompenburg, W. et al. Phosphatidylethanolamine mediated insertion of the catalytic domain of leader peptidase in membranes. FEBS Lett. 431, 75-79 (1998).

11. Kim, Y. T., Muramatsu, T. \& Takahashi, K. Identification of Trp 300 as an important residue for Escherichia coli leader peptidase activity. Eur. J. Biochem. 234, 358-362 (1995).

12. Landolt-Marticorena, C., Williams, K. A., Deber, C. M. \& Reithmeirer, R. A. Non-random distribution of amino acids in the transmembrane segments of human type I single span membrane proteins. J. Mol. Biol. 229, 602-608 (1993).

13. James, M. N. G. in Proteolysis and Protein Turnover (eds Bond, J. S. \& Barrett, A. J.) 1-8 (Portland, Brookfield, VT, 1994).

14. Strynadka, N. C. J. et al. Molecular structure of the acyl-enzyme intermediate in $\beta$-lactamase at $1.7 \AA$ resolution. Nature 359, 393-400 (1992)

15. Manard, R. \& Storer, A. C. Oxyanion hole interactions in serine and cysteine proteases. Biol. Chem. Hoppe-Seyler 373, 393-400 (1992).

16. Nicolas, A. et al. Contribution of cutinase Ser 42 side chain to the stabilization of the oxyanion transition state. Biochemistry 35, 398-410 (1996).

17. Paetzel, M. et al. Use of site-directed chemical modification to study an essential lysine in Escherichia coli leader peptidase. J. Biol. Chem. 272, 9994-10003 (1997).

18. Paetzel, M. \& Dalbey, R. E. Catalytic hydroxyl/amine dyads with serine proteases. Trends Biochem. Sci 22, 28-31 (1997)

19. von Heijne, G. Signal sequences. The limits of variation. J. Mol. Biol. 184, 99-105 (1985).

20. Izard, J. W. \& Kendall, D. A. Signal peptides: exquisitely designed transport promoters. Mol. Microbiol. 13, 765-773 (1994)

21. Matthews, B. W. Solvent content of protein crystals. J. Mol. Biol. 33, 491-497 (1968).

22. Otwinowski, Z. in DENZO (eds Sawyer, L., Isaacs, N. \& Baily, S.) 56-62 (SERC Daresbury Laboratory, Warrington, UK, 1993)

23. Collaborative Computational Project No. 4 The CCP4 suite: programs for protein crystallography. Acta Crystallogr. D 50, 760-763 (1994).

24. Jones, T. A., Zou, J. Y., Cowan, S. W. \& Kieldgaard, M. Improved methods for building protein model in electron density maps and the location of errors in these models. Acta Crystallogr. A 47, 110-119 (1991). 25. Brunger, A. T. X-PLOR: A System for X-ray Crystallography and NMR (Version 3.1) (Yale Univ. Press, New Haven, 1987).
26. Tronrud, D. E Conjugate-direction minimization: an improved method for the refinement of macromolecules. Acta Crystallogr. A 48, 912-916 (1992).

27. Wolfe, P. B., Wickner, W. \& Goodman, J. M. Sequence of the leader peptidase gene of Escherichia coli and the orientation of leader peptidase in the bacterial envelope. J. Biol. Chem. 258, 12073-12080 (1983).

28. Kraulis, P. G. Molscript: a program to produce both detailed and schematic plots of protein structures. J. Appl. Crystallogr. 24, 946-950 (1991)

29. Nicholls, A., Sharp, K. A. \& Honig, B. Protein folding and association: insights from the interfacial and the thermodynamic properties of hydrocarbons. Proteins Struct. Funct. Genet. 11, 281-296 (1991).

30. Meritt, E. A. \& Bacon, D. J. Raster3D: photorealistic molecular graphics. Methods Enzymol. 277, 505524 (1997).

Acknowledgements. We thank SmithKlineBeecham Pharmaceuticals for penem inhibitor; R. M. Sweet for use of beamline X12C (NSLS, Brookhaven National Laboratory); G. Petsko for the ethylmercury phosphate; M. N. G. James for access to equipment for characterization of earlier crystal forms of SPase; and S. Mosimann and S. Ness for discussions. This work was supported by the Medical Research Council of Canada, the Canadian Bacterial Diseases Network of Excellence, and British Columbia Medical Research Foundation grants to N.C.J.S. M.P. is funded by an MRC of Canada post-doctoral fellowship, N.C.J.S. by an MRC of Canada scholarship, and R.E.D. by the NIH and the American Heart Association.

Correspondence and requests for materials should be addressed to N.C.J.S. (e-mail: natalie@byron. biochem.ubc.ca).

\section{errata}

\section{Reconciling the spectrum of Sagittarius $A$ * with a two-temperature plasma model}

\section{Rohan Mahadevan}

Nature 394, 651-653 (1998)

A misleading typographical error was introduced into the second sentence of the bold introductory paragraph of this Letter: the word "infrared" should be "inferred".

\title{
Deciphering the biology of Mycobacterium tuberculosis from the complete genome sequence
}

S. T. Cole, R. Brosch, J. Parkhill, T. Garnier, C. Churcher, D. Harris, S. V. Gordon, K. Eiglmeier, S. Gas, C. E. Barry III,
F. Tekaia, K. Badcock, D. Basham, D. Brown, T. Chillingworth, R. Connor, R. Davies, K. Devlin, T. Feltwell, S. Gentles, N. Hamlin, S. Holroyd, T. Hornsby, K. Jagels, A. Krogh, J. McLean, S. Moule, L. Murphy, K. Oliver, J. Osborne, M. A. Quail, M.-A. Rajandream, J. Rogers, S. Rutter, K. Seeger, J. Skelton, R. Squares, S. Squares, J. E. Sulston, K. Taylor, S. Whitehead \& B. G. Barrell

Nature 393, 537-544 (1998)

As a result of an error during film output, Table 1 was published with some symbols missing. The correct version can be found at http://www.sanger.ac.uk and is reproduced again here (following pages).

Also, in Fig. 2, we incorrectly labelled Rv0649 as fadD37 instead of fabD2. Two of the genes for mycolyl transferases were inverted: Rv0129c encodes antigen 85C and not 85C' as stated, whereas Rv3803c codes for the secreted protein MPT51 and not antigen 85C (Infect. Immun. 59, 372-382; 1991); Rv3803c is now designated $f b p D$. We thank Morten Harboe and Harald Wiker for drawing this to our attention.

The sequence of Rv0746 from M. bovis BCG-Pasteur presented in Fig. 5b was incorrect and should have shown a 16-codon deletion instead of 29, as indicated here:

H37RV . . . . GSGAPGGAGGAAGLWGTGGAGGAGGSSAGGGGAGGAGGAGGWLLGDGGAGGIGGAST . . .

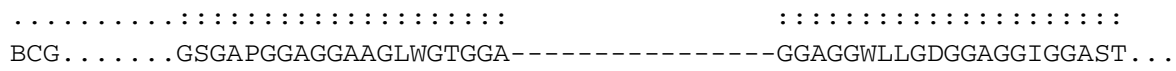




\begin{tabular}{|c|c|c|c|c|c|}
\hline \multirow{2}{*}{\multicolumn{3}{|c|}{ A. Degradation }} & Rv2831 & $\operatorname{ech} A 16$ & $\begin{array}{l}\text { superfamily } \\
\text { enoyl-CoA hydratase/isomerase } \\
\text { superfamily }\end{array}$ \\
\hline & & & & & $\begin{array}{l}\text { superfamily } \\
\text { enoyl-CoA hydratase/isomerase }\end{array}$ \\
\hline $\begin{array}{l}\text { Rv0186 } \\
\text { Rv2202c }\end{array}$ & & $\begin{array}{l}\beta \text {-glucosidase } \\
\text { carbohydrate kinase }\end{array}$ & Rv3039c & echA17 & $\begin{array}{l}\text { enoyl-CoA hydratase/isomerase } \\
\text { superfamily }\end{array}$ \\
\hline $\begin{array}{l}\text { Rv0727c } \\
\text { Rv1731 }\end{array}$ & fucA & $\begin{array}{l}\text { L-fuculose phosphate aldolase } \\
\text { succinate-semialdehyde dehydro- }\end{array}$ & Rv3373 & $\operatorname{echA18}$ & $\begin{array}{l}\text { enoyl-CoA hydratase/isomerase } \\
\text { superfamily, } \mathrm{N} \text {-term }\end{array}$ \\
\hline & & & Rv3374 & $\operatorname{ech} A 18^{\prime}$ & enoyl-COA hydratase/isomer \\
\hline Rv0234c & $g a b D 2$ & $\begin{array}{l}\text { succinate-semialdehyde dehydro- } \\
\text { genase }\end{array}$ & Rv3516 & & $\begin{array}{l}\text { superfamily, C-term } \\
\text { enoyl-CoA hydratase/isomera }\end{array}$ \\
\hline Zv0501 & galE1 & UDP-glucose 4-epimerase & & & superfamily \\
\hline $\begin{array}{l}\text { Rv0536 } \\
\text { Rv0620 }\end{array}$ & $\begin{array}{l}\text { galE2 } \\
\text { galK }\end{array}$ & $\begin{array}{l}\text { UDP-glucose 4-epimerase } \\
\text { galactokinase }\end{array}$ & Rv3550 & echA2O & $\begin{array}{l}\text { enoyl-CoA hydratase/isomer } \\
\text { superfamily }\end{array}$ \\
\hline Rv0619 & galt & $\begin{array}{l}\text { galactose-1-phosphate uridylyl- } \\
\text { transferase C-term }\end{array}$ & Rv3774 & echA21 & $\begin{array}{l}\text { enoyl-CoA hydratase/isomeras } \\
\text { superfamily }\end{array}$ \\
\hline Rv0618 & galt & $\begin{array}{l}\text { galactose-1-phosphate uridylyl- } \\
\text { transferase N-term }\end{array}$ & Rv0859 & $\mathrm{fad} A$ & $\begin{array}{l}\beta \text { oxidation complex, } \beta \text { subunit } \\
\text { (acetyl-CoA C-acetyltransferase }\end{array}$ \\
\hline Rv0993 & gall & $\begin{array}{l}\text { UTP-glucose-1-phosphate uridylyl- } \\
\text { transferase }\end{array}$ & $\begin{array}{l}\text { Rv0243 } \\
\text { Rv1074c }\end{array}$ & $\begin{array}{l}f a d A 2 \\
\text { fadA3 }\end{array}$ & $\begin{array}{l}\text { acetyl-COA C-acetyltransferase } \\
\text { acetyl-CoA C-acetyltransferase }\end{array}$ \\
\hline Rv3696c & $g l p K$ & $\begin{array}{l}\text { ATP:glycerol 3-phosphotrans- } \\
\text { ferase }\end{array}$ & Rv1323 & fadA4 & $\begin{array}{l}\text { acetyl-CoA C-acetyltransferase } \\
\text { (aka thiL) }\end{array}$ \\
\hline Rv3255c & $\operatorname{man} A$ & mannose-6-phosphate isomerase & Rv3546 & fadA5 & acetyl-CoA C-acetyltransferase \\
\hline Rv3441c & $m r s A$ & $\begin{array}{l}\text { phosphoglucomutase or phospho- } \\
\text { mannomutase }\end{array}$ & $\begin{array}{l}\text { Rv3556c } \\
\text { Rv0860 }\end{array}$ & $\begin{array}{l}f a d A 6 \\
f a d B\end{array}$ & $\begin{array}{l}\text { acetyl-CoA C-acetyltransferase } \\
\beta \text { oxidation complex, } \alpha \text { subunit }\end{array}$ \\
\hline Rv0118c & $O X C A$ & oxalyl-CoA decarboxylase & & & (multiple activities) \\
\hline Rv3068c & $\operatorname{pgmA}$ & phosphoglucomutase & Rv0468 & $\mathrm{fadB2}$ & 3-hydroxyacyl-CoA dehydroge- \\
\hline Rv3257c & pmmA & phosphomannomutase & & & nase \\
\hline Rv3308 & $p m m B$ & nomutase & Rv1715 & $f a d B 3$ & 3-hydroxyacyl-CoA dehydroge- \\
\hline Rv2702 & ppgK & polyphosphate glucokinase & & & nase \\
\hline $\begin{array}{l}\text { Rv0408 } \\
\text { Rv0729 }\end{array}$ & pta & phosphate acetyltransferase & Rv3141 & $\mathrm{fadB} 4$ & $\begin{array}{l}\text { 3-hydroxyacyl-CoA dehydroge- } \\
\text { nase }\end{array}$ \\
\hline Rv1096 & $x y=$ & carbohydrate degrading enzyme & Rv1912c & fadB5 & $\begin{array}{l}\text { 3-hydroxyacyl-CoA dehydroge- } \\
\text { nase }\end{array}$ \\
\hline 2. Amino & acids and & amines & Rv1750c & $f a d D 1$ & acyl-CoA synthase \\
\hline Rv1905c & aao & D-amino a & Rv0270 & $\mathrm{fadD2}$ & acyl-CoA synthase \\
\hline Rv2531c & $a d i$ & ginine decarboxylase & Rv3561 & $\mathrm{fadD} 3$ & acyl-CoA synthase \\
\hline Rv2780 & ald & hydrogenase & Rv0214 & $\mathrm{fadD} 4$ & acyl-CoA synthase \\
\hline Rv1538c & ansA & L-as & Rv0166 & fadD5 & acyl-CoA synthase \\
\hline Rv1001 & $\operatorname{arcA}$ & arginine deiminase & Rv1206 & fadD6 & acyl-CoA synthase \\
\hline Rv0753c & $m m s A$ & $\begin{array}{l}\text { methylmalmonate semialdehyde } \\
\text { dehydrogenase }\end{array}$ & $\begin{array}{l}\text { Rv0119 } \\
\text { Rv0551c }\end{array}$ & $\begin{array}{l}\text { fadD7 } \\
\text { fadD8 }\end{array}$ & $\begin{array}{l}\text { acyl-CoA synthase } \\
\text { acyl-CoA synthase }\end{array}$ \\
\hline Rv0751c & $m m s B$ & $\begin{array}{l}\text { methylmalmonate semialdehyde } \\
\text { oxidoreductase }\end{array}$ & $\begin{array}{l}\text { Rv2590 } \\
\text { Rv0099 }\end{array}$ & $\begin{array}{l}\text { fadD9 } \\
\text { fadD } 10\end{array}$ & $\begin{array}{l}\text { acyl-CoA synthase } \\
\text { acyl-CoA synthase }\end{array}$ \\
\hline Rv1187 & rocA & $\begin{array}{l}\text { pyrroline-5-carboxylate dehydro- } \\
\text { genase }\end{array}$ & $\begin{array}{l}\text { Rv1550 } \\
\text { Rv1549 }\end{array}$ & $\begin{array}{l}\text { fadD11 } \\
\text { fadD } 11^{\prime}\end{array}$ & $\begin{array}{l}\text { acyl-CoA synthase, } N \text {-term } \\
\text { acyl-CoA synthase, C-term }\end{array}$ \\
\hline Rv2322c & rocD1 1 & ornithine aminotransferase & Rv1427c & $\mathrm{fadD} 12$ & acyl-CoA synthase \\
\hline Rv2321c & $\mathrm{rocD2}$ & ornithine aminotransferase & Rv3089 & $f a d D 13$ & acyl-CoA synthase \\
\hline Rv1848 & ureA & $y$ subunit & Rv1058 & $\mathrm{fadD} 14$ & acyl-CoA synthase \\
\hline Rv1849 & ure $B$ & ureas & Rv2187 & $\operatorname{fad} D 15$ & acyl-CoA synthase \\
\hline Rv1850 & ureC & subunit & Rv0852 & $f a d D 16$ & acyl-CoA synthase \\
\hline Rv1853 & ure $D$ & cessory protein & Rv3506 & $f a d D 17$ & -CoA synthase \\
\hline Rv1851 & ureF & urease accessory protein & Rv3513c & $f a d D 18$ & acyl-CoA synthase \\
\hline Rv1852 & ureG & cessory protein & Rv3515c & fadD 19 & acyl-CoA synthase \\
\hline Rv2913c & - & $\begin{array}{l}\text { probable } \mathrm{D} \text {-amino acid } \\
\text { aminohydrolase }\end{array}$ & $\begin{array}{l}\text { Rv1185c } \\
\text { Rv2948c }\end{array}$ & $\begin{array}{l}f a d D 21 \\
f a d D 22\end{array}$ & $\begin{array}{l}\text { acyl-CoA synthase } \\
\text { acyl-CoA synthase }\end{array}$ \\
\hline Rv3551 & - & $\begin{array}{l}\text { possible glutaconate CoA- } \\
\text { transferase }\end{array}$ & Rv3826 & $f a d D 23$ & acyl-CoA synthase \\
\hline & & & Rv1521 & fadD25 & acyl-CoA synthase \\
\hline 3. Fatty ac & & & Rv2930 & $f a d D 26$ & acyl-CoA synthase \\
\hline Rv2501c & $\operatorname{acc} A 1$ & $\begin{array}{l}\text { acetyV/propionyl-CoA carboxylase, } \\
\alpha \text { subunit }\end{array}$ & $\begin{array}{l}\text { Rvo275c } \\
\text { Rv2941 }\end{array}$ & $\begin{array}{l}\text { fadD27 } \\
\text { fadD28 }\end{array}$ & $\begin{array}{l}\text { acyl-CoA synthase } \\
\text { acyl-CoA synthase }\end{array}$ \\
\hline Rv0973c & accA2 & $\begin{array}{l}\text { acety/propionyl-CoA carboxylase, } \\
\alpha \text { subunit }\end{array}$ & $\begin{array}{l}\text { Rv2950c } \\
\text { Rv0404 }\end{array}$ & $\begin{array}{l}f a d D 29 \\
f a d D 30\end{array}$ & $\begin{array}{l}\text { acyl-CoA synthase } \\
\text { acyl-CoA synthase }\end{array}$ \\
\hline Rv2502c & $a c c D 1$ & $\begin{array}{l}\text { acety } / \text { propionyl-CoA carboxylase, } \\
\beta \text { subunit }\end{array}$ & $\begin{array}{l}\text { Rv1925 } \\
\text { Rv3801c }\end{array}$ & $\begin{array}{l}f a d D 31 \\
f a d D 32\end{array}$ & $\begin{array}{l}\text { acyl-CoA synthase } \\
\text { acyl-CoA synthase }\end{array}$ \\
\hline Rv0974c & $\mathrm{accD} 2$ & $\begin{array}{l}\text { acety/propionyl-CoA carboxylase, } \\
\beta \text { subunit }\end{array}$ & $\begin{array}{l}\text { Rv1345 } \\
\text { Rv0035 }\end{array}$ & $\begin{array}{l}f a d D 33 \\
f a d D 34\end{array}$ & $\begin{array}{l}\text { acyl-CoA synthase } \\
\text { acyl-CoA synthase }\end{array}$ \\
\hline Rv3667 & acs & acetyl-CoA synthase & Rv2505c & fadD35 & acyl-CoA synthase \\
\hline Rv3409c & $C h o D$ & cholesterol oxidase & Rv1193 & $f a d D 36$ & acyl-CoA synthase \\
\hline Rv0222 & echAt & $\begin{array}{l}\text { enoyl-CoA hydratase/isomerase } \\
\text { superfamily }\end{array}$ & $\begin{array}{l}\text { Rv0131c } \\
\text { Rv0154c }\end{array}$ & $\begin{array}{l}\text { fadE1 } \\
\text { fadE2 }\end{array}$ & $\begin{array}{l}\text { acyl-COA dehydrogenase } \\
\text { acyl-CoA dehydrogenase }\end{array}$ \\
\hline Rv0456c & echA2 & $\begin{array}{l}\text { enoyl-CoA hydratase/isomerase } \\
\text { superfamily }\end{array}$ & $\begin{array}{l}\text { Rv0215c } \\
\text { Rv0231 }\end{array}$ & $\begin{array}{l}\text { fadE3 } \\
\text { fadE4 }\end{array}$ & $\begin{array}{l}\text { acyl-CoA dehydrogenase } \\
\text { acyl-COA dehydrogenase }\end{array}$ \\
\hline Rv0632c & echA3 & enoyl-CoA hydratase/isomerase & Rv0244c & fadE5 & acyl-COA dehydrogenase \\
\hline & & & Rv0271c & fadE6 & acyl-CoA dehydrogenase \\
\hline Rv0673 & echA4 & enoyl-CoA hydratase/isomerase & Rv0400c & fadE7 & acyl-CoA dehydrogenase \\
\hline & echA5 & merase & & & $\begin{array}{l}\text { acyl-CoA dehydrogena } \\
\text { (aka aidB) }\end{array}$ \\
\hline & & & Rv0752c & & acyl-CoA dehydrogenase \\
\hline Rv0905 & echA6 & enoyl-CoA hydratase/iso & Rv0873 & fadE 10 & acyl-COA dehydrogenase \\
\hline & & & & & acyl-CoA dehydrogenase \\
\hline Rv0971c & echA7 & $\begin{array}{l}\text { enoyl-CoA hydratase/isomerase } \\
\text { superfamily }\end{array}$ & $\begin{array}{l}\text { Rv0975c } \\
\text { Rv1346 }\end{array}$ & $\begin{array}{l}\text { fadE } 13 \\
\text { fadE } 14\end{array}$ & $\begin{array}{l}\text { acyl-CoA dehydrogenase } \\
\text { acyl-COA dehydrogenase }\end{array}$ \\
\hline Rv1070c & echA8 & enoyl-CoA hydratase/isomerase & Rv1467c & fadE 15 & acyl-CoA dehydrogenase \\
\hline & & & & & \\
\hline & echA9 & Iratase/isomerase & $\begin{array}{l}\text { Rv1934c } \\
\text { Rv1933c }\end{array}$ & $\begin{array}{l}\text { fadE } 17 \\
\text { fadE18 }\end{array}$ & $\begin{array}{l}\text { acyl-CoA dehydrogenase } \\
\text { acyl-COA dehydrogenase }\end{array}$ \\
\hline Rv1142c & echA10 & $\begin{array}{l}\text { enoyl-CoA hydratase/isomerase } \\
\text { superfamily }\end{array}$ & Rv2500c & fadE 19 & $\begin{array}{l}\text { acyl-CoA dehydrogenase } \\
\text { (aka } m m g C \text { ) }\end{array}$ \\
\hline Rv1141c & echA11 & $\begin{array}{l}\text { enoyl-CoA hydratase/isomerase } \\
\text { superfamily }\end{array}$ & $\begin{array}{l}\text { Rv2724c } \\
\text { Rv2789c }\end{array}$ & fadE20 & acyl-COA dehydrogenase \\
\hline Rv1472 & echA12 & enoyl-CoA hydratase/isomerase & Rv3061c & fadE22 & acyl-CoA dehydrogenase \\
\hline & & & & & \\
\hline Rv1935c & echA13 & enoyl-CoA hydratase/isomerase & Rv3139 & fadE24 & acyl-CoA dehydrogenase \\
\hline & & & & & acyl-coA denyarogenase \\
\hline & echA14 & enoyl-CoA hydratase/isomerase & Rv3504 & fadE26 & acyl-CoA dehydrogenase \\
\hline & echA15 & $\begin{array}{l}\text { superfamily } \\
\text { enoyl-CoA hydratase/isomerase }\end{array}$ & & $\begin{array}{l}\text { fadE27 } \\
\text { fadE28 }\end{array}$ & $\begin{array}{l}\text { acyl-CoA dehydrogenase } \\
\text { acyl-COA dehydrogenase }\end{array}$ \\
\hline
\end{tabular}

\begin{tabular}{|c|c|c|}
\hline Rv3543c & fadE29 & acyl-CoA dehydrogenase \\
\hline Rv3560c & fadEЗ & acyl-CoA dehydrogenase \\
\hline Rv3562 & fadE31 & acyl-COA dehydrogenase \\
\hline Rv3563 & fadE32 & acyl-CoA dehydrogenase \\
\hline Rv3564 & fadE33 & acyl-CoA dehydrogenase \\
\hline Rv3573c & fadE34 & acyl-CoA dehydrogenase \\
\hline Rv3797 & fadE35 & acyl-CoA dehydrogenase \\
\hline Rv3761c & fadE36 & acyl-CoA dehydrogenase \\
\hline Rv1175c & $\mathrm{fadH}$ & 2,4-Dienoyl-CoA Reductase \\
\hline Rv0855 & far & fatty acyl-CoA racemase \\
\hline Rv1143 & $\mathrm{mor}$ & $\alpha$-methyl acyl-CoA racemase \\
\hline Rv1492 & mutA & $\begin{array}{l}\text { methylmalonyl-CoA mutase, } \beta \\
\text { subunit }\end{array}$ \\
\hline Rv1493 & mutB & $\begin{array}{l}\text { methylmalonyl-CoA mutase, } \alpha \\
\text { subunit }\end{array}$ \\
\hline Rv2504c & $s c o A$ & $\begin{array}{l}\text { 3-oxo acid:CoA transferase, } \alpha \text { sub- } \\
\text { unit }\end{array}$ \\
\hline Rv2503c & $s c o B$ & $\begin{array}{l}\text { 3-oxo acid:Co } A \text { transferase, } \beta \text { sub- } \\
\text { unit }\end{array}$ \\
\hline Rv1136 & - & probable carnitine racemase \\
\hline Rv1683 & - & possible acyl-CoA synthase \\
\hline \multicolumn{3}{|c|}{ 4. Phosphorous compounds } \\
\hline $\operatorname{Rv} 2368 \mathrm{c}$ & phoH & $\begin{array}{l}\text { ATP-binding pho regulon } \\
\text { component }\end{array}$ \\
\hline Rv1095 & phoH2 & PhoH-like protein \\
\hline Rv3628 & ppa & $\begin{array}{l}\text { probable inorganic pyrophos- } \\
\text { phatase }\end{array}$ \\
\hline Rv2984 & ppk & polyphosphate kinase \\
\hline \multirow{2}{*}{\multicolumn{3}{|c|}{$\begin{array}{l}\text { B. Energy metabolism } \\
\text { 1. Glycolysis }\end{array}$}} \\
\hline & & \\
\hline Rv1023 & eno & enolase \\
\hline Rv0363c & $f b a$ & fructose bisphosphate aldolase \\
\hline Rv1436 & gap & $\begin{array}{l}\text { glyceraldehyde 3-phosphate dehy- } \\
\text { drogenase }\end{array}$ \\
\hline Rv0489 & gpm & phosphoglycerate mutase I \\
\hline Rv3010c & pfkA & phosphofructokinase I \\
\hline Rv2029c & $p f k B$ & phosphofructokinase II \\
\hline Rv0946c & pgi & glucose-6-phosphate isomerase \\
\hline Rv1437 & pgk & phosphoglycerate kinase \\
\hline Rv1617 & pykA & pyruvate kinase \\
\hline Rv1438 & tpi & triosephosphate isomerase \\
\hline Rv2419c & - & putative phosphoglycerate mutase \\
\hline Rv3837c & - & putative phosphoglycerate mutase \\
\hline \multicolumn{3}{|c|}{ 2. Pyruvate dehydrogenase } \\
\hline Rv2241 & aceE & $\begin{array}{l}\text { pyruvate dehydrogenase } \mathrm{E} 1 \mathrm{com}- \\
\text { ponent }\end{array}$ \\
\hline Rv3303c & IpdA & dihydrolipoamide dehydrogenase \\
\hline Rv2497c & pdhA & $\begin{array}{l}\text { pyruvate dehydrogenase } \mathrm{E} 1 \mathrm{com} \text { - } \\
\text { ponent } \alpha \text { subunit }\end{array}$ \\
\hline Rv2496c & $p d h B$ & $\begin{array}{l}\text { pyruvate dehydrogenase } E 1 \text { com- } \\
\text { ponent } \beta \text { subunit }\end{array}$ \\
\hline $\begin{array}{l}\text { Rv2495c } \\
\text { Rv0462 }\end{array}$ & pdhC & $\begin{array}{l}\text { dihydrolipoamide acetyltransferase } \\
\text { probable dihydrolipoamide dehy- } \\
\text { drogenase }\end{array}$ \\
\hline \multicolumn{3}{|c|}{ 3. TCA cycle } \\
\hline Rv1475c & acn & aconitate hydratase \\
\hline Rv0889c & citA & citrate synt \\
\hline Rv2498c & citE & citrate lyase \\
\hline Rv1098c & fum & fumarase \\
\hline Rv1131 & gitA1 & citrate synthase 3 \\
\hline Rv0896 & gltA2 & citrate syntl \\
\hline Rv3339c & icd 1 & isocitrate dehydrogenase \\
\hline Rv0066c & icd2 & isocitrate dehydrogenase \\
\hline Rv0794c & lpdB & dihydrolipoamide dehydrogenase \\
\hline Rv1240 & $m a h$ & malate dehydrogenase \\
\hline Rv2967c & pca & pyruvate carboxylase \\
\hline Rv3318 & sdhA & succinate dehydrogenase A \\
\hline Rv3319 & $s d h B$ & succinate dehydrogenase $B$ \\
\hline Rv3316 & sdhc & $\begin{array}{l}\text { succinate dehydrogenase } \mathrm{C} \text { sub- } \\
\text { unit }\end{array}$ \\
\hline Rv3317 & $s d h D$ & $\begin{array}{l}\text { succinate dehydrogenase } D \text { sub- } \\
\text { unit }\end{array}$ \\
\hline Rv1248c & sucA & 2-oxoglutarate dehydrogenase \\
\hline Rv2215 & $s u c B$ & $\begin{array}{l}\text { dihydrolipoamide succinyltrans- } \\
\text { ferase }\end{array}$ \\
\hline Rv0951 & sucC & succinyl-CoA synthase $\beta$ chain \\
\hline Rv0952 & sucD & succinyl-CoA synthase $\alpha$ chain \\
\hline \multicolumn{3}{|c|}{ 4. Glyoxylate bypass } \\
\hline Rv0467 & $a c e A$ & isocitrate lyase \\
\hline Rv1915 & aceAa & isocitrate lyase, $\alpha$ module \\
\hline Rv1916 & $a c e A b$ & isocitrate lyase, $\beta$ module \\
\hline Rv1837c & $g / c B$ & malate synthase \\
\hline Rv3323c & gphA & phosphoglycolate phosphatase \\
\hline \multicolumn{3}{|c|}{ 5. Pentose phosphate pathway } \\
\hline Rv1445c & & $\begin{array}{l}\text { glucose-6-phosphate 1-dehydro- } \\
\text { genase }\end{array}$ \\
\hline Rv1844c & gnd & $\begin{array}{l}\text { 6-phosphogluconate dehydroge- } \\
\text { nase (Gram -) }\end{array}$ \\
\hline Rv1122 & gnd2 & $\begin{array}{l}\text { 6-phosphogluconate dehydroge- } \\
\text { nase (Gram }+ \text { ) }\end{array}$ \\
\hline & & $\begin{array}{l}\text { unknown function, may aid } \\
\text { G6PDH }\end{array}$ \\
\hline
\end{tabular}




\begin{tabular}{|c|c|c|c|c|c|c|c|c|}
\hline Rv2436 & rbsk & ribokinase & Rv3250c & $r u b B$ & rubredoxin $B$ & Rv1878 & $\operatorname{gin} A 3$ & probable glutamine synthase \\
\hline Rv1408 & rpe & ribulose-phosphate 3-epimerase & & & & Rv2860c & $\operatorname{gin} A 4$ & proable glutamine synthase \\
\hline Rv2465c & rpi & phosphopentose isomerase & \multirow{2}{*}{\multicolumn{3}{|c|}{ 7. Miscellaneous oxidoreductases and oxygenases 171}} & Rv2918c & $\operatorname{gin} D$ & uridylyltransferase \\
\hline Rv1448c & tal & transaldolase & & & & Rv2221c & gine & glutamate-ammonia-ligase \\
\hline Rv1449c & $t k t$ & transketolase & \multicolumn{3}{|c|}{ 8. ATP-proton motive force } & & & adenyltransferase \\
\hline Rv1121 & $z w f$ & $\begin{array}{l}\text { glucose-6-phosphate 1-dehydro- } \\
\text { genase }\end{array}$ & $\begin{array}{l}\text { Rv1308 } \\
\text { Rv1304 }\end{array}$ & $\begin{array}{l}\text { atpA } \\
\text { atp } B\end{array}$ & $\begin{array}{l}\text { ATP synthase } \alpha \text { chain } \\
\text { ATP synthase a chain }\end{array}$ & Rv3859c & $g i t B$ & $\begin{array}{l}\text { ferredoxin-dependent glutamate } \\
\text { synthase }\end{array}$ \\
\hline Rv1447c & $z w f 2$ & $\begin{array}{l}\text { glucose-6-phosphate 1-dehydro- } \\
\text { genase }\end{array}$ & $\begin{array}{l}\text { Rv1311 } \\
\text { Rv1310 }\end{array}$ & $\begin{array}{l}\text { atpc } \\
\operatorname{atp} D\end{array}$ & $\begin{array}{l}\text { ATP synthase } \epsilon \text { chain } \\
\text { ATP synthase } \beta \text { chain }\end{array}$ & Rv3858c & gitD & $\begin{array}{l}\text { small subunit of } \mathrm{NADH} \text {-dependent } \\
\text { glutamate synthase }\end{array}$ \\
\hline & & & Rv1305 & atp $E$ & ATP synthase $c$ chain & Rv3704c & $g \operatorname{sh} A$ & possible $\gamma$-glutamylcysteine syn- \\
\hline 6. Respirati & tion & & Rv1306 & atp $F$ & ATP synthase $b$ chain & & & thase \\
\hline a. aerobic & & & Rv1309 & $\operatorname{atp} G$ & ATP synthase $\gamma$ chain & Rv2427c & proA & $\gamma$-glutamyl phosphate reductase \\
\hline Rv0527 & $\operatorname{ccs} A$ & $\begin{array}{l}\text { cytochrome } c \text {-type biogenesis } \\
\text { protein }\end{array}$ & Rv1307 & atpH & ATP synthase $\delta$ chain & $\begin{array}{l}\text { Rv2439c } \\
\text { Rv0500 }\end{array}$ & $\begin{array}{l}\text { proB } \\
\text { proc }\end{array}$ & $\begin{array}{l}\text { glutamate } 5 \text {-kinase } \\
\text { pyrroline-5-carboxylate reductase }\end{array}$ \\
\hline Rv0529 & $\operatorname{ccs} B$ & $\begin{array}{l}\text { cytochrome } c \text {-type biogenesis } \\
\text { protein }\end{array}$ & \multicolumn{5}{|c|}{$\begin{array}{l}\text { C. Central intermediary metabolism } \\
\text { 1. General }\end{array}$} & \\
\hline Rv1451 & $\operatorname{cta} B$ & $\begin{array}{l}\text { cytochrome coxidase assembly } \\
\text { factor }\end{array}$ & $\begin{array}{l}\text { Rv2589 } \\
\text { Rv3432c }\end{array}$ & $\begin{array}{l}\operatorname{gabT} T \\
\operatorname{gadB}\end{array}$ & $\begin{array}{l}\text { 4-aminobutyrate aminotransferase } \\
\text { glutamate decarboxylase }\end{array}$ & Rv3708c & asd & $\begin{array}{l}\text { aspartate semialdehyde dehydro- } \\
\text { genase }\end{array}$ \\
\hline Rv2200c & $\operatorname{ctaC}$ & cytochrome $c$ oxidase chain II & Rv1832 & gcvB & glycine decarboxylase & Rv3709c & ask & aspartokinase \\
\hline Rv3043c & $\operatorname{cta} D$ & $\begin{array}{l}\text { cytochrome } c \text { oxidase poly- } \\
\text { peptide I }\end{array}$ & $\begin{array}{l}\text { Rv1826 } \\
\text { Rv2211c }\end{array}$ & $\begin{array}{l}\text { gcvH } \\
\text { gcvT }\end{array}$ & $\begin{array}{l}\text { glycine cleavage system } \mathrm{H} \text { protein } \\
\mathrm{T} \text { protein of glycine cleavage }\end{array}$ & $\begin{array}{l}\text { Rv22201 } \\
\text { Rv3565 }\end{array}$ & $\begin{array}{l}a s n B \\
a s p B\end{array}$ & $\begin{array}{l}\text { asparagine synthase } B \\
\text { aspartate aminotransferase }\end{array}$ \\
\hline Rv2193 & $\operatorname{cta} E$ & $\begin{array}{l}\text { cytochrome coxidase poly- } \\
\text { peptide III }\end{array}$ & Rv1213 & $g / g C$ & $\begin{array}{l}\text { system } \\
\text { glucose-1-phosphate adenylyl- }\end{array}$ & $\begin{array}{l}\text { Rv0337c } \\
\text { Rv2753c }\end{array}$ & $\begin{array}{l}\text { aspC } \\
\text { dapA }\end{array}$ & $\begin{array}{l}\text { aspartate aminotransferase } \\
\text { dihydrodipicolinate synthase }\end{array}$ \\
\hline Rv1542c & $g l b N$ & hemoglobin-like, oxygen carrier & & & transferase & Rv2773c & dapB & dihydrodipicolinate reductase \\
\hline $\begin{array}{l}\text { Rv2470 } \\
\text { Rv2249c }\end{array}$ & $\begin{array}{l}g l b O \\
g l p D 1\end{array}$ & $\begin{array}{l}\text { hemoglobin-like, oxygen carrier } \\
\text { glycerol-3-phosphate dehydroge- }\end{array}$ & $\mathrm{Rv} 3842 \mathrm{c}$ & $g / p Q 1$ & $\begin{array}{l}\text { glycerophosphoryl diester phos- } \\
\text { phodiesterase }\end{array}$ & Rv1202 & dapE & $\begin{array}{l}\text { succinyl-diaminopimelate desuc- } \\
\text { cinylase }\end{array}$ \\
\hline Rv3302c & $g / p D 2$ & $\begin{array}{l}\text { nase } \\
\text { glycerol-3-phosphate dehydroge- }\end{array}$ & Rv0317c & glpQ2 & $\begin{array}{l}\text { glycerophosphoryl diester phos- } \\
\text { phodiesterase }\end{array}$ & Rv2141c & dapE2 & $\begin{array}{l}\text { ArgE/DapE/Acy } 1 / \mathrm{Cpg} 2 / \mathrm{yscS} \\
\text { family }\end{array}$ \\
\hline & & -pinspilate cenyuruge- & Rv3566c & nhoA & $\mathrm{N}$-hydroxyarylamine o-acetyltrans- & Rv2726c & dapF & diaminopimelate epimerase \\
\hline Rv0694 & $\| d D 1$ & $\begin{array}{l}\text { L-lactate dehydrogenase } \\
\text { (cytochrome) }\end{array}$ & Rv0155 & pntAA & $\begin{array}{l}\text { ferase } \\
\text { pyridine transhydrogenase sub- }\end{array}$ & $\begin{array}{l}\text { Rv1293 } \\
\text { Rv3341 }\end{array}$ & $\begin{array}{l}\text { IysA } \\
\text { metA }\end{array}$ & $\begin{array}{l}\text { diaminopimelate decarboxylase } \\
\text { homoserine } o \text {-acetyltransferase }\end{array}$ \\
\hline Rv1872c & IIdD2 & L-lactate dehydrogenase & & & unit $\alpha 1$ & Rv1079 & metB & cystathionine $\gamma$-synthase \\
\hline Rv1854c & $n a h$ & probable NADH dehydrogenase & Rv0156 & pntAB & pyridine transhydrogenase sub- & Rv3340 & metc & cystathio \\
\hline Rv3145 & nUOA & NADH dehydrogenase chain A & & & unit $\alpha 2$ & Rv1133c & metE & 5-methyltetrahydropteroyltrigluta- \\
\hline Rv3146 & nuoB & $\mathrm{NADH}$ dehydrogenase chain $\mathrm{B}$ & Rv0157 & pntB & pyridine transhydrogenase & & & mate-homocysteine methyltrans- \\
\hline Rv3147 & nuoc & $\mathrm{NADH}$ dehydrogenase chain $\mathrm{C}$ & & & subur & & & ferase \\
\hline $\begin{array}{l}\text { Rv3148 } \\
\text { Rv3149 }\end{array}$ & $\begin{array}{l}\text { nUOD } \\
\text { nUOE }\end{array}$ & $\begin{array}{l}\text { NADH dehydrogenase chain D } \\
\text { NADH dehydrogenase chain } E\end{array}$ & Rv1127c & $p p d K$ & $\begin{array}{l}\text { similar to pyruvate, phosphate } \\
\text { dikinase }\end{array}$ & Rv2124c & $\mathrm{metH}$ & $\begin{array}{l}\text { 5-methyltetrahydrofolate-homo- } \\
\text { cysteine methyltransferase }\end{array}$ \\
\hline Rv3150 & nuof & $\mathrm{NADH}$ dehydrogenase chain $\mathrm{F}$ & & & & Rv1392 & metk & $S$-adenosylmethionine synthase \\
\hline Rv3151 & nUoG & ydrogenase chain $G$ & 2. Glucone & eogenesis & & Rv0391 & $m e t Z$ & cinylhomoserine sulfhy- \\
\hline Rv3152 & nuoH & $\mathrm{NADH} d$ & Rv0211 & pckA & phosphoenolpyruvate carboxy- & & & \\
\hline Rv3153 & nuol & NADH dehydrogenase chain I & & & kinas & Rv1294 & thra & homoserine dehydrogenase \\
\hline Rv3154 & nuod & hydrogenase chain $\mathrm{J}$ & Rvo069c & $s d a A$ & L-serine dehydratase 1 & Rv1296 & thrB & \\
\hline Rv3155 & nuok & $\mathrm{NADH}$ dehydrogenase chain $\mathrm{K}$ & & & & Rv1295 & thre & homoserine synthase \\
\hline Rv3156 & nuol & $\mathrm{NADH}$ & 3. Sugar $n$ & hucleotides & & & & \\
\hline Rv3157 & nuom & $\mathrm{NADH}$ dehydrogenase chain $\mathrm{M}$ & Rv1512 & epiA & nucleotide sugar epimerase & 3. Serine $f$ & amily & \\
\hline Rv3158 & nUON & $\mathrm{NADH}$ dehydrogenase chain $\mathrm{N}$ & Rv3784 & epiB & probable UDP-galactose 4- & Rv0815c & CYSA2 & thiosulfate sulfurtransferase \\
\hline Rv2195 & qcrA & $\begin{array}{l}\text { Rieske iron-sulphur component of } \\
\text { ubiQ-cytB reductase }\end{array}$ & Rv1511 & & $\begin{array}{l}\text { epimerase } \\
\text { GDP-mannose } 4,6 \text { dehydrata }\end{array}$ & $\begin{array}{l}\text { Rv3117 } \\
\text { Rv2335 }\end{array}$ & $\begin{array}{l}\text { CYSA3 } \\
\text { CYSE }\end{array}$ & $\begin{array}{l}\text { thiosulfate sulfurtransferase } \\
\text { serine acetyltransferase }\end{array}$ \\
\hline Rv2196 & $q a r B$ & $\begin{array}{l}\text { cytochrome } \beta \text { component of ubiQ- } \\
\text { cyt } B \text { reductase }\end{array}$ & Rv0334 & $\begin{array}{l}g m a A \\
r m i A\end{array}$ & $\begin{array}{l}\text { glucose-1-phosphate thymidyl- } \\
\text { transferase }\end{array}$ & $\begin{array}{l}\text { RV2335 } \\
\text { Rv0511 }\end{array}$ & $\begin{array}{l}\text { Cyst } \\
\text { cysG }\end{array}$ & $\begin{array}{l}\text { serine aceylytransterase } \\
\text { uroporphyrin-III } c \text {-methyltrans- } \\
\text { ferase }\end{array}$ \\
\hline Rv2194 & qcrC & $\begin{array}{l}\text { cytochrome } b / c \text { component of } \\
u b i Q \text {-cytB reductase }\end{array}$ & Rv3264c & ImIA2 & $\begin{array}{l}\text { glucose-1-phosphate thymidyl- } \\
\text { transferase }\end{array}$ & Rv2847c & cysG2 & $\begin{array}{l}\text { multifunctional enzyme, siroheme } \\
\text { synthase }\end{array}$ \\
\hline & & & Rv34 & $r m i B$ & dTDP-glucose 4,6-dehydratase & Rv2334 & cysk & cysteine synthase $A$ \\
\hline b. anaerobi & & & Rv3634c & $r m i B 2$ & ucose 4,6 & Rv1336 & cysm & cyste \\
\hline Rv2392 & $\mathrm{cysH}$ & 3'-phosphoadenylylsulfate (PAPS) & Rv3 $3468 \mathrm{c}$ & rmiB3 & dTDP-glucose 4,6-dehydratase & Rv1077 & cysM2 & 3-synthase \\
\hline & & reduc & Rv3465 & $\mathrm{rmic}$ & -dehydrorhamnose & Rv0848 & cysM3 & cysteine synthase \\
\hline Rv2899c & $f d h D$ & affects formate dehydrogenase $-\mathrm{N}$ & & & pimerase & Rv1093 & glyA & ymethyltransferase \\
\hline Rv2900c & fahF & $\begin{array}{l}\text { molybdopterin-containing oxidore- } \\
\text { ductase }\end{array}$ & Rv3266c & $r m i D$ & $\begin{array}{l}\text { dTDP-4-dehydrorhamnose } \\
\text { reductase }\end{array}$ & $\begin{array}{l}\text { Rv0070c } \\
\text { Rv2996c }\end{array}$ & $\begin{array}{l}\text { glyA2 } \\
\text { serA }\end{array}$ & $\begin{array}{l}\text { serine hydroxymethyltransferase } \\
\text { D-3-phosphoglycerate dehydro- }\end{array}$ \\
\hline Rv1552 & frolA & fumarate reductase flavoprotein & Rv0322 & $u d g A$ & UDP-glucose & & & genase \\
\hline Rv1553 & $f r d B$ & $\begin{array}{l}\text { subunit } \\
\text { fumarate reductase iron sulphur }\end{array}$ & & & $\begin{array}{l}\text { ogenase/GDP-mannose 6- } \\
\text { ogenase }\end{array}$ & Rv0505c & $\operatorname{ser} B$ & $\begin{array}{l}\text { probable phosphoserine phos- } \\
\text { phatase }\end{array}$ \\
\hline & & protein & Rv3265c & $w b b L$ & The lal transtarase & $\mathrm{Rv} 3042 \mathrm{c}$ & serB2 & C-term similar to phosphoserine \\
\hline Rv1554 & fralC & fumarate reductase $15 \mathrm{kD}$ anchor & Rv1525 & $w b b L 2$ & dTDP-rhamnosyl tr & & & \\
\hline & frad & $\begin{array}{l}\text { protein } \\
\text { fumarate reductase } 13 \mathrm{kD} \text { anchor } \\
\text { protein }\end{array}$ & Rv3400 & sugars & probable $\beta$-phosphoglucomutase & Rv0884c & serc & phosphoserine aminotransferase \\
\hline Rv1161 & & $\begin{array}{l}\text { protein } \\
\text { nitrate reductase } \alpha \text { subunit }\end{array}$ & $\begin{array}{l}\text { 4. Amino s } \\
\text { Rv3436c }\end{array}$ & $\begin{array}{l}\text { sugars } \\
\text { gims }\end{array}$ & & $\begin{array}{l}\text { 4. Aromat } \\
\text { Rv3227 }\end{array}$ & aroA & amily \\
\hline Rv1162 & narH & nitrate reducta & & & phosphate aminotransferase & & $\operatorname{aroA}$ & mate \\
\hline Rv1164 & narl & nitrate & & & & Rv2538c & $\operatorname{aroB}$ & synthase \\
\hline Rv1163 & narj & nitrat & 5. Sulphur & metabol & & Rv2537c & aroD & Iratase \\
\hline Rv1736c & narX & fused & Rv0711 & atsA & arylsulfatase & Rv2552c & aroE & \\
\hline Rv2391 & nirA & reductase/sulphite & Rv3299c & atsB & ylsulfatase & Rv2540c & arof & chorismate synthase \\
\hline & & & & ats $D$ & ylsulfatase & Rv2178c & aroG & \\
\hline Rv0252 & nirB & durtom flounongtoin & Rv3077 & atsF & ylsulfatase & Rv2539c & arok & sh \\
\hline Rv0253 & nirD & probable nitrite reductase small & Rv0296c & ats $G$ & proable arylsulfatase & Rv3838c & pheA & ephenate dehydratase \\
\hline & & subunit & Rv3796 & atsH & proable arylsulfatase & Rv1613 & $\operatorname{trpA}$ & $\mathrm{n}$ synthase $\alpha$ chain \\
\hline & & & & cys $D$ & ATP:sulphurylase subunit 2 & Rv1612 & $\operatorname{trpB}$ & tryptophan synthase $\beta$ chain \\
\hline Electron & transport & & Rv1286 & cysN & ATP:sulphurylase subunit 1 & Rv1611 & $\operatorname{trpC}$ & indole-3-glycerol phosphate \\
\hline & ackA & acetate kinase & & cys $Q$ & homologue of M.leprae cys $Q$ & & & \\
\hline Rv1623c & appC & $\begin{array}{l}\text { cytochrome } b d-/ / \text { oxidase } \\
\text { subunit I }\end{array}$ & $\begin{array}{l}\text { Rv3248c } \\
\text { Rv3283 }\end{array}$ & $\begin{array}{l}\text { sahH } \\
\text { sseA }\end{array}$ & $\begin{array}{l}\text { adenosylhomocysteinase } \\
\text { thiosulfate sulfurtransferase }\end{array}$ & Rv2192c & $\operatorname{trpD}$ & $\begin{array}{l}\text { anthranilate phosphoribosyltrans- } \\
\text { ferase }\end{array}$ \\
\hline Rv1622c & $c y d B$ & $\begin{array}{l}\text { cytochrome } d \text { ubiquinol oxidase } \\
\text { subunit II }\end{array}$ & $\begin{array}{l}\text { Rv2291 } \\
\text { Rv3118 }\end{array}$ & $\begin{array}{l}s s e B \\
s s e C\end{array}$ & $\begin{array}{l}\text { thiosulfate sulfurtransferase } \\
\text { thiosulfate sulfurtransferase }\end{array}$ & Rv1609 & $\operatorname{trp} E$ & $\begin{array}{l}\text { anthranilate synthase } \\
\text { component I }\end{array}$ \\
\hline Rv1620c & cydC & $\mathrm{ABC}$ & Rvo814c & $\mathrm{sseC} 2$ & thiosulfate sulfurtransferase & Rv2386c & $\operatorname{trpE2}$ & synthase \\
\hline Rv1621c & cydD & $A B C$ & Rv3762c & - & probable alkyl sulfatase & & & \\
\hline Rv2007c & $f d x A$ & & & & & Rv3754 & tyra & prephenate dehydrogenase \\
\hline Rv3554 & $f d x B$ & & & & & & & \\
\hline Rv1177 & $f d x C$ & ferre & 1. Glutama & ate family & & 5. Histidine & & \\
\hline $\operatorname{Rv} 3503 c$ & $f d x D$ & rredoxin & Rv1654 & $\arg B$ & acetylglutamate kinase & Rv1603 & hisA & bosylformimino-5- \\
\hline Rv3029c & $f i x A$ & $\begin{array}{l}\text { electron transfer flavoprotein } \\
\beta \text { subunit }\end{array}$ & RVI002 & $\arg C$ & $\begin{array}{l}\mathrm{N} \text {-acetyl- } \gamma \text {-glutamyl-phosphate } \\
\text { reductase }\end{array}$ & & & $\begin{array}{l}\text { aminoimidazole carboxamide } \\
\text { ribonucleotide isomerase }\end{array}$ \\
\hline $\operatorname{Rv} 3028 c$ & fix $B$ & $\begin{array}{l}\text { electron transfer flavoprotein } \alpha \\
\text { subunit }\end{array}$ & $\begin{array}{l}\text { Rv1655 } \\
\text { Rv1656 }\end{array}$ & $\begin{array}{l}\arg D \\
\arg F\end{array}$ & $\begin{array}{l}\text { acetylornithine aminotransferase } \\
\text { ornithine carbamoyltransferase }\end{array}$ & Rv1601 & hisB & $\begin{array}{l}\text { imidazole glycerol-phosphate } \\
\text { dehydratase }\end{array}$ \\
\hline Rv310 & fpra & $\begin{array}{l}\text { adrenodoxin and NADPH ferre- } \\
\text { doxin reductase }\end{array}$ & $\begin{array}{l}\text { Rv1658 } \\
\text { Rv1659 }\end{array}$ & $\begin{array}{l}\arg G \\
\operatorname{arghH}\end{array}$ & $\begin{array}{l}\text { arginosuccinate synthase } \\
\text { arginosuccinate lyase }\end{array}$ & Rv1600 & hisc & $\begin{array}{l}\text { histidinol-phosphate aminotrans- } \\
\text { ferase }\end{array}$ \\
\hline Rv088e & fprB & $\begin{array}{l}\text { ferredoxin, ferredoxin-NADP } \\
\text { reductase }\end{array}$ & $\begin{array}{l}\text { Rv1653 } \\
\text { Rv2220 }\end{array}$ & $\arg J$ & $\begin{array}{l}\text { glutamate } \mathrm{N} \text {-acetyltransferase } \\
\text { glutamine synthase class I }\end{array}$ & Rv3772 & hisC2 & $\begin{array}{l}\text { histidinol-phosphate aminotrans- } \\
\text { ferase }\end{array}$ \\
\hline Rv3251c & rubA & rubredoxin $\mathrm{A}$ & Rv2222c & $\operatorname{gin} A 2$ & glutamine synthase class II & Rv1599 & hisD & histidinol dehydrogenase \\
\hline
\end{tabular}




\begin{tabular}{|c|c|c|}
\hline Rv1605 & hisF & $\begin{array}{l}\text { imidazole glycerol-phosphate } \\
\text { synthase }\end{array}$ \\
\hline $\begin{array}{l}\text { Rv2121c } \\
\text { Rv1602 }\end{array}$ & $\begin{array}{l}\text { hisG } \\
\text { hisH }\end{array}$ & $\begin{array}{l}\text { ATP phosphoribosyltransferase } \\
\text { amidtransferase }\end{array}$ \\
\hline $\begin{array}{l}\text { Rv1602 } \\
\text { Rv2122c }\end{array}$ & $\begin{array}{l}\text { hisH } \\
\text { hisl }\end{array}$ & $\begin{array}{l}\text { amidotransferase } \\
\text { phosphoribosyl-AMP cyclohydro- } \\
\text { lase }\end{array}$ \\
\hline Rv1606 & his/2 & $\begin{array}{l}\text { probable phosphoribosyl-AMP } 1,6 \\
\text { cyclohydrolase }\end{array}$ \\
\hline Rv0114 & - & similar to HisB \\
\hline \multicolumn{3}{|c|}{ 6. Pyruvate family } \\
\hline Rv3423c & alr & alanine racemase \\
\hline \multicolumn{3}{|c|}{ 7. Branched amino acid family } \\
\hline Rv1559 & INA & threonine deaminase \\
\hline Rv3003c & ivB & $\begin{array}{l}\text { acetolactate synthase I large sub- } \\
\text { unit }\end{array}$ \\
\hline Rv3470c & ilvB2 & $\begin{array}{l}\text { acetolactate synthase large sub- } \\
\text { unit }\end{array}$ \\
\hline Rv3001c & illVC & ketol-acid reductoisomerase \\
\hline Rv0189c & $i N D$ & dihydroxy-acid dehydratase \\
\hline Rv2210c & INE & $\begin{array}{l}\text { branched-chain-amino-acid } \\
\text { transaminase }\end{array}$ \\
\hline Rv1820 & iNG & acetolactate synthase \| \\
\hline Rv3002c & $i V N$ & $\begin{array}{l}\text { acetolactate synthase I small sub- } \\
\text { unit }\end{array}$ \\
\hline Rv3509c & $\operatorname{in} X$ & $\begin{array}{l}\text { probable acetohydroxyacid syn- } \\
\text { thase I large subunit }\end{array}$ \\
\hline Rv3710 & leuA & $\alpha$-isopropyl malate synthase \\
\hline Rv2995c & leuB & 3-isopropylmalate dehydrogenase \\
\hline Rv2988c & leuC & $\begin{array}{l}\text { 3-isopropylmalate dehydratase } \\
\text { large subunit }\end{array}$ \\
\hline Rv2987c & leuD & $\begin{array}{l}\text { 3-isopropylmalate dehydratase } \\
\text { small subunit }\end{array}$ \\
\hline \multicolumn{3}{|c|}{ E. Polyamine synthesis } \\
\hline Rv2601 & $s p e E$ & spermidine synthase \\
\hline \multicolumn{3}{|c|}{$\begin{array}{l}\text { F. Purines, pyrimidines, nucleosides and nucleotides } \\
\text { 1. Purine ribonucleotide biosynthesis }\end{array}$} \\
\hline Rv1389 & $g m k$ & putative guanylate kinase \\
\hline Rv3396c & guaA & GMP synthase \\
\hline Rv1843c & guaB1 & $\begin{array}{l}\text { inosine-5'-monophosphate dehy- } \\
\text { drogenase }\end{array}$ \\
\hline Rv3411c & guaB2 & $\begin{array}{l}\text { inosine-5'-monophosphate dehy- } \\
\text { drogenase }\end{array}$ \\
\hline Rv3410c & guaB3 & $\begin{array}{l}\text { inosine-5'-monophosphate dehy- } \\
\text { drogenase }\end{array}$ \\
\hline Rv1017c & prsA & $\begin{array}{l}\text { ribose-phosphate pyrophosphoki- } \\
\text { nase }\end{array}$ \\
\hline Rv0357c & purA & adenylosuccinate synthase \\
\hline Rv0777 & purB & adenylosuccinate lyase \\
\hline Rv0780 & purc & $\begin{array}{l}\text { phosphoribosylaminoimidazole- } \\
\text { succinocarboxamide synthase }\end{array}$ \\
\hline Rv0772 & purD & $\begin{array}{l}\text { phosphoribosylamine-glycine lig- } \\
\text { ase }\end{array}$ \\
\hline Rv3275c & purE & $\begin{array}{l}\text { phosphoribosylaminoimidazole } \\
\text { carboxylase }\end{array}$ \\
\hline Rvo808 & purF & amidophosphoribosyltransferase- \\
\hline Rv0957 & purH & $\begin{array}{l}\text { phosphoribosylaminoimidazole- } \\
\text { carboxamide formyltransferase }\end{array}$ \\
\hline Rv3276c & purk & $\begin{array}{l}\text { phosphoribosylaminoimidazole } \\
\text { carboxylase ATPase subunit }\end{array}$ \\
\hline Rv0803 & purL & $\begin{array}{l}\text { phosphoribosylformylglycin- } \\
\text { amidine synthase II }\end{array}$ \\
\hline Rv0809 & purM & $\begin{array}{l}\text { 5'-phosphoribosyl-5-aminoimida- } \\
\text { zole synthase }\end{array}$ \\
\hline Rv0956 & purN & $\begin{array}{l}\text { phosphoribosylglycinamide } \\
\text { formyltransferase I }\end{array}$ \\
\hline Rv0788 & purQ & $\begin{array}{l}\text { phosphoribosylformylglycin- } \\
\text { amidine synthase I }\end{array}$ \\
\hline Rv0389 & purT & $\begin{array}{l}\text { phosphoribosylglycinamide } \\
\text { formyltransferase II }\end{array}$ \\
\hline Rv2964 & purU & $\begin{array}{l}\text { formyltetrahydrofolate deformy- } \\
\text { lase }\end{array}$ \\
\hline \multicolumn{3}{|c|}{ 2. Pyrimidine ribonucleotide biosynthesis } \\
\hline Rv1383 & carA & $\begin{array}{l}\text { carbamoyl-phosphate synthase } \\
\text { subunit }\end{array}$ \\
\hline Rv1384 & carB & $\begin{array}{l}\text { carbamoyl-phosphate synthase } \\
\text { subunit }\end{array}$ \\
\hline Rv1380 & pyrB & aspartate carbamoyltransferase \\
\hline Rv1381 & pyrc & dihydroorotase \\
\hline Rv2139 & pyro & dihydroorotate dehydrogenase \\
\hline Rv1385 & pyrF & $\begin{array}{l}\text { orotidine } 5^{\prime} \text {-phosphate decarboxy- } \\
\text { lase }\end{array}$ \\
\hline & pyrG & CTP synthase \\
\hline Rv2883c & pyrH & uridylate kinase \\
\hline Rv0382c & umpA & $\begin{array}{l}\text { probable uridine } 5 \text {-monophos- } \\
\text { phate synthase }\end{array}$ \\
\hline \multicolumn{3}{|c|}{ 3. 2'-deoxyribonucleotide metabolism } \\
\hline & $d c d$ & $\begin{array}{l}\text { deoxycytidine triphosphate } \\
\text { deaminase }\end{array}$ \\
\hline Rv2697c & $d u t$ & deoxyuridine triphosphatase \\
\hline & $n r d B$ & $\begin{array}{l}\text { ribonucleoside-diphosphate } \\
\text { reductase B2 (eukaryotic-like) }\end{array}$ \\
\hline Rv305 & $n r d E$ & $\begin{array}{l}\text { ribonucleoside diphosphate } \\
\text { reductase } \alpha \text { chain }\end{array}$ \\
\hline Rv1981c & $n r d F$ & ribonucleotide reductase small \\
\hline
\end{tabular}

\begin{tabular}{|c|c|c|}
\hline \multirow[b]{2}{*}{ Rv3048c } & \multirow[b]{2}{*}{$n r d G$} & \multirow[b]{2}{*}{$\begin{array}{l}\text { subunit } \\
\text { ribonucleoside-diphosphate small } \\
\text { subunit }\end{array}$} \\
\hline & & \\
\hline Rv3053c & $n r d H$ & $\begin{array}{l}\text { glutaredoxin electron transport } \\
\text { component of NrdEF system }\end{array}$ \\
\hline Rv3052c & nrdl & $\mathrm{Nrdl} / \mathrm{YgaO} /$ mmaA family \\
\hline Rv3247c & tmk & thymidylate kinase \\
\hline Rv2764c & thy A & thymidylate synthase \\
\hline Rv0570 & nrdZ & ribonucleotide reductase, class II \\
\hline Rv3752c & - & $\begin{array}{l}\text { probable cytidine/deoxycytidylate } \\
\text { deaminase }\end{array}$ \\
\hline \multicolumn{3}{|c|}{ 4. Salvage of nucleosides and nucleotides } \\
\hline Rv3313c & $a d d$ & probable adenosine deaminase \\
\hline Rv2584c & apt & $\begin{array}{l}\text { adenine phosphoribosyltrans- } \\
\text { ferases }\end{array}$ \\
\hline Rv3315c & $c d d$ & probable cytidine deaminase \\
\hline Rv3314c & deoA & thymidine phosphorylase \\
\hline Rv0478 & deoc & deoxyribose-phosphate aldolase \\
\hline Rv3307 & $d e o D$ & $\begin{array}{l}\text { probable purine nucleoside phos- } \\
\text { phorylase }\end{array}$ \\
\hline Rv3624c & hpt & $\begin{array}{l}\text { probable hypoxanthine-guanine } \\
\text { phosphoribosyltransferase }\end{array}$ \\
\hline Rv3393 & iunH & $\begin{array}{l}\text { probable inosine-uridine } \\
\text { preferring nucleoside hydrolase }\end{array}$ \\
\hline Rv0535 & pnp & $\begin{array}{l}\text { phosphorylase from Pnp/MtaP } \\
\text { family } 2\end{array}$ \\
\hline $\operatorname{Rv} 3309 c$ & upp & uracil phophoribosyltransferase \\
\hline
\end{tabular}

5. Miscellaneous nucleoside/nucleotide reactions

Rv0733 adk probable adenylate kinase

$\begin{array}{lll}\text { Rv2364c } & \text { bex } & \text { GTobable adenylate kinase } \\ & & \text { GTPinding protein of Era/ThdF }\end{array}$ family

Rv1712 cmk cytidylate kinase

Rv2344c dgt probable deoxyguanosine

triphosphate hydrolase

Rv2727c miaA tRNA $\delta(2)$-isopentenylpyrophostRNA $\delta(2)$-isopentent
phate transferase

Rv2445c ndkA nucleoside diphosphate kinase

Rv2440c obg Obg GTP-binding protein

Rv2583c relA (p)ppGpp synthase I

G. Biosynthesis of cofactors, prosthetic groups and

carriers

1. Biotin

Rv1568 bioA

Rv1589 bioB

Rv1570 bioD

Rv1569 biof

Rv0032 biof2

Rv3279c birA

$\begin{array}{ll}\text { Rv3279c } & \text { birA } \\ \text { Rv1442 } & \text { bisC }\end{array}$

Rv0089 -

adenosylmethionine-8-amino-7oxononanoate aminotransferase biotin synthase

dethiobiotin synthase

8-amino-7-oxononanoate

synthase

C-terminal similar to $B$. subtilis BioF

2. Folic acid

Rv2763c dfrA

Rv2447c folC

Rv3356c folD

Rv3609c fole

Rv3606c folk

biotin apo-protein ligase

biotin sulfoxide reductase possible bioC biotin synthesis gene

Rv3608c folP

Rv1207 folP2

Rv3607c folX

Rv0013 pabA

Rv1005c pabB

Rv0812 pabC

dihydrofolate reductase

folylpolyglutamate synthase methylenetetrahydrofolate dehydrogenase

GTP cyclohydrolase

7,8-dihydro-6-hydroxymethylpterin pyrophosphokinase

dihydropteroate synthase

dihydropteroate synthase

may be involved in folate biosynthesis

$p$-aminobenzoate synthase glutamine amidotransferase

3. Lipoate

Rv2218 lipA
Rv2217

$p$-aminobenzoate synthase

aminodeoxychorismate lyase

lipoate biosynthesis protein A

4. Molybdopterin

Rv3109 moaA molybdenum cofactor biosynthesis, protein A

Rv0869c moaA2 molybdenum cofactor biosynthesis, protein A

Rv0438c moaA3 molybdenum cofactor biosynthesis, protein A

Riv310 moaB molybdenum cofactor biosynthesis, protein B

Rv0984 moaB2 molybdenum cofactor biosynthesis, protein B

Rv3111 moaC molybdenum cofactor biosynthesis, protein $\mathrm{C}$

Rv0864 moaC2 molybdenum cofactor biosynthesis, protein $\mathrm{C}$

Rv3324c moaC3 molybdenum cofactor biosynthesis, protein $C$

Rv3112 moaD molybdopterin converting factor subunit 1

Rv0868c moaD2 molybdopterin converting factor

\begin{tabular}{|c|c|c|}
\hline & & \\
\hline Rv3119 & MOaE & $\begin{array}{l}\text { molybdopterin-converting factor } \\
\text { subunit } 2\end{array}$ \\
\hline Rv0866 & MoaE2 & $\begin{array}{l}\text { molybdopterin-converting factor } \\
\text { subunit } 2\end{array}$ \\
\hline Rv3322c & MOaE3 & $\begin{array}{l}\text { molybdopterin-converting factor } \\
\text { subunit } 2\end{array}$ \\
\hline Rv0994 & moeA & molybdopterin biosynthesis \\
\hline Rv3116 & moeB & molybdopterin biosynthesis \\
\hline Rv2338c & moeW & molybdopterin biosynthesis \\
\hline Rv1681 & moeX & weak similarity to $E$. coli MoaA \\
\hline Rv1355c & moeY & weak similarity to $E$. coli MoeB \\
\hline Rv3206c & moeZ & $\begin{array}{l}\text { probably involved in } \\
\text { molybdopterin biosynthesis }\end{array}$ \\
\hline v0865 & $\operatorname{mog}$ & molybdopterin biosynthesis \\
\hline
\end{tabular}

5. Pantothenate

Rv $1092 \mathrm{C}$ coaA

Rv2225 panB

Rv3602c panC

Rv3601c pand

6. Pyridoxine

Rv2607 pdxH pyridoxamine 5'-phosphate oxidase

7. Pyridine nucleotide

Rv1594 nadA quinolinate synthase

Rv1595 nadB L-aspartate oxidase

Rv1596 nadC nicotinate-nucleotide pyrophos

Rv0423c thic phatase

thiamine synthesis, pyrimidine

moiety

8. Thiamine

Rv0422c thiD

Rv0414c thie

phosphomethylpyrimidine kinase thiamine synthesis, thiazole moiety

Rv0417 thig thiamine synthesis, thiazole moiety

Rv2977c thil probable thiamine-monophosphate kinase

9. Riboflavin

Rv1940 ribA GTP cyclohydrolase II

Rv1415 ribA2 probable GTP cyclohydrolase I

Rv1412 ribC riboflavin synthase $\alpha$ chain

Rv2671 ribD probable riboflavin deaminase

Rv2786c ribF riboflavin kinase

Rv1409 ribG riboflavin biosynthesis

Rv1416 ribH riboflavin synthase $\beta$ chain

Rv3300c - probable deaminase, riboflavin synthesis

10. Thioredoxin, glutaredoxin and mycothio

Rv0773c ggtA putative $\gamma$-glutamyl transpeptidase

Rv2394 ggtB $\gamma$-glutamyltranspeptidase

precursor

Rv2855 gorA glutathione reductase homologue

Rv0816c thiX equivalent to $M$. leprae ThiX

Rv1470 trxA thioredoxin

Rv1471 trxB thioredoxin reductase

Rv3913 trxB2 thioredoxin reductase

Rv3914 trxC thioredoxin

11. Menaquinone, $P Q Q$, ubiquinone and othe terpenoids

Rv2682c dxs 1-deoxy-D-xylulose 5-phosphate

Rv0562 grcC1 $\begin{aligned} & \text { synthase } \\ & \text { heptaprenyl diphosphate }\end{aligned}$

Rvo562 grect heptaprenyl

Rv0989c grcC2 heptaprenyl diphosphate Rv3398c idsA $\begin{aligned} & \text { geranylgeranyl pyrophosphate } \\ & \text { synthase }\end{aligned}$

Rv2173 idsA2 $\begin{aligned} & \text { gynthase } \\ & \text { geranylgeranyl pyrophosphate }\end{aligned}$

synthase

Rv3383c idsB transfergeranyl, similar geranyl

Rv0534c menA pyrophosphate synthase

Rv0534c menA 4-dihydroxy-2-naphtho

Rv0548c menB naphthoate synthase

Rv0553 menC o-succinylbenzoate-CoA synthase

Rv0555 menD 2-succinyl-6-hydroxy-2,4-cyclo-

Rv0542c menE hexadiene-1-carboxylate synthase

Rv3853 menG S-adenosylmethionine:

2-demethylmenaquinon

Rv3397c phyA phytoene synthase

Rv0693 pqqE coenzyme PQQ synthesis

protein $\mathrm{E}$

Rv0558 ubiE ubiquinone/menaquinone biosynthesis methyltransferase

12. Heme and porphyrin

Rv0509 hemA glutamyl-tRNA reductase

Rv0512 hemB $\delta$-aminolevulinic acid dehydratase

Rv0510 hemC porphobilinogen deaminase

Rv2678c hemE uroporphyrinogen decarboxylase 


\begin{tabular}{|c|c|c|c|c|c|c|c|c|}
\hline Rv1300 & hemk & protoporphyrinogen oxidase & & & transferase & Rv2931 & $p p s A$ & phenolpthiocerol synthesis ( $p k s B$ ) \\
\hline Rv0524 & hemL & glutamate-1-semialdehyde amino- & & & & Rv2932 & $p p s B$ & phenolpthiocerol synthesis (pksC) \\
\hline & & & 3. Acyltran & sferases, & mycolyltransferases and & Rv2933 & $p p s C$ & phenolpthiocerol synthesis $(p k s D)$ \\
\hline Rv2388c & hemN & oxygen-independent copropor- & phospholip & id synthes & & Rv2934 & $p p s D$ & phenolpthiocerol synthesis (pksE) \\
\hline & & phyrinogen III oxidase & Rv2289 & $c a h$ & CDP-diacylglycerol phosphatidyl- & Rv2935 & ppsE & phenolpthiocerol synthesis (pksF) \\
\hline Rv2677c & hem $Y^{\prime}$ & protoporphyrinogen oxidase & & & hydrolase & Rv2928 & tes $A$ & thioesterase \\
\hline Rv1485 & hem $Z$ & ferrochelatase & $\begin{array}{l}\text { Rv2881c } \\
\text { Rv3804c }\end{array}$ & $\begin{array}{l}c d s A \\
f b p A\end{array}$ & $\begin{array}{l}\text { phosphatidate cytidylyltransferase } \\
\text { antigen } 85 \mathrm{~A} \text {, mycolyltransferase }\end{array}$ & Rv1544 & - & probable ketoacyl reductase \\
\hline 13. Cobala & $\operatorname{amin}$ & & Rv1886c & $f b p B$ & antigen $85 \mathrm{~B}$, mycolyltransferase & J. Broad & gulatory & functions \\
\hline Rv2849c & cobA & cob(I)alamin adenosyltransferase & Rv0129c & $f b p C$ & antigen $85 \mathrm{C}$, mycolytransferase & 1. Repres & sors/activa & tors \\
\hline Rv2848c & $\operatorname{cob} B$ & cobyrinic acid a,c-diamide synthase & Rv3803c & $f b p D$ & antigen MPT51, mycolyltrans- & Rv1657 & $\arg R$ & arginine repressor \\
\hline Rv2231c & $c o b c$ & aminotransferase & & & ferase & Rv1267c & $e m b R$ & regulator of $e m b A B$ genes \\
\hline Rv2236c & $\operatorname{cobD}$ & cobinamide synthase & Rv0564c & $g p d A 1$ & glycerol-3-phosphate dehydroge- & & & (AfsR/Dndl/RedD family) \\
\hline Rv2064 & $c o b G$ & percorrin reductase & & & nase & Rv1909c & furA & ferric uptake regulatory protein \\
\hline Rv2065 & $\mathrm{cobH}$ & precorrin isomerase & Rv2982c & gpdA2 & glycerol-3-phosphate dehydroge- & Rv2359 & furB & ferric uptake regulatory protein \\
\hline Rv2066 & cobl & Cobl-CobJ fusion protein & & & nase & Rv2919c & $\operatorname{gin} B$ & nitrogen regulatory protein \\
\hline Rv2070c & cobk & precorrin reductase & Rv2612c & $p g s A$ & CDP-diacylglycerol-glycerol-3- & Rv2711 & ideR & iron dependent repressor, IdeR \\
\hline Rv2072c & $c o b L$ & probable methyltransferase & & & phosphate phosphatidyltrans- & Rv2720 & $\operatorname{lex} A$ & LexA, SOS repressor protein \\
\hline Rv2071c & cobM & precorrin-3 methylase & & & ferase & Rv1479 & $\operatorname{mox} R$ & transcriptional regulator, MoxR \\
\hline Rv2062c & $\operatorname{cob} N$ & cobalt insertion & Rv1822 & pgsa2 & CDP-diacylglycerol-glycerol-3- & & & homologue \\
\hline Rv2208 & cobs & $\begin{array}{l}\text { cobalamin ( } 5^{\prime} \text {-phosphate) } \\
\text { synthase }\end{array}$ & & & $\begin{array}{l}\text { phosphate phosphatidyltrans- } \\
\text { ferase }\end{array}$ & Rv3692 & $\operatorname{mox} R 2$ & $\begin{array}{l}\text { transcriptional regulator, MoxR } \\
\text { homologue }\end{array}$ \\
\hline Rv2207 & $\operatorname{cobT}$ & $\begin{array}{l}\text { nicotinate-nucleotide-dimethyl- } \\
\text { benzimidazole transferase }\end{array}$ & Rv2746c & $p g s A 3$ & $\begin{array}{l}\text { CDP-diacylglycerol-glycerol-3- } \\
\text { phosphate phosphatidyltrans- }\end{array}$ & Rv3164c & $\operatorname{mox} R 3$ & $\begin{array}{l}\text { transcriptional regulator, MoxR } \\
\text { homologue }\end{array}$ \\
\hline Rv0254c & $\operatorname{cobU}$ & cobinamide kinase & & & ferase & Rv0212c & nadR & similar to E.coli NadR \\
\hline Rv0255c & $\operatorname{cobQ}$ & cobyric acid synthase & Rv1551 & plsB1 & glycerol-3-phosphate acyltrans- & Rv0117 & oxys & transcriptional regulator (LysR \\
\hline Rv3713 & cobQ2 & possible cobyric acid synthase & & & ferase & & & \\
\hline Rv0306 & & $\begin{array}{l}\text { similar to BluB cobalamin synthe- } \\
\text { sis protein R. capsulatus }\end{array}$ & Rv2482c & plsB2 & $\begin{array}{l}\text { glycerol-3-phosphate acyltrans- } \\
\text { ferase }\end{array}$ & Rv1379 & pyrR & $\begin{array}{l}\text { regulatory protein pyrimidine } \\
\text { biosynthesis }\end{array}$ \\
\hline 14. Iron ut & ilization & & Rv0437c & $p s d$ & $\begin{array}{l}\text { putative phosphatidylserine } \\
\text { decarboxylase }\end{array}$ & Rv2788 & $\operatorname{sir} R$ & $\begin{array}{l}\text { iron-dependent transcriptional } \\
\text { repressor }\end{array}$ \\
\hline Rv1876 & bfra & bacterioferritin & Rv0436c & DSSA & CDP-diacylglycerol-serine & Rv3082c & virs & putative virulence regulating \\
\hline Rv3841 & $b f r B$ & bacte & & & o-phosphatidyltransferase & & & protein (Aro clYuls tamilus \\
\hline $\begin{array}{l}\text { Rv3215 } \\
\text { Rv3214 }\end{array}$ & $\begin{array}{l}\text { entC } \\
\text { entD }\end{array}$ & $\begin{array}{l}\text { probable isochorismate synthase } \\
\text { weak similarity to many phospho- }\end{array}$ & Rv0045c & - & $\begin{array}{l}\text { possible dihydrolipoamide acetyl- } \\
\text { transferase }\end{array}$ & Rv3219 & whiB1 & $\begin{array}{l}\text { WhiB transcriptional activator } \\
\text { homologue }\end{array}$ \\
\hline & & glycerate mutases & Rvo914c & - & lipid transfer protein & Rv3260c & whiB2 & WhiB transcriptional activator \\
\hline Rv2895c & viuB & ins involved in & Rv1543 & - & probable fatty-acyl CoA reductase & & & homologue \\
\hline & & vibrio & Rv1627c & - & lipid c & Rv3416 & whiB3 & Iscriptional activator \\
\hline Rv3525c & - & similar to ferripyochelin binding & Rv1814 & - & possible C -5 sterol desaturase & & & homologue \\
\hline & & protein & Rv1867 & - & $\begin{array}{l}\text { similar to acetyl CoA } \\
\text { synthase/lipid carriers }\end{array}$ & Rv3681c & whiB4 & $\begin{array}{l}\text { WhiB transcriptional activator } \\
\text { homologue }\end{array}$ \\
\hline H. Lipid bi & osynthesis & & Rv2261c & - & oprotein N-acyltrans- & Rv0023 & - & putative transcriptional regulator \\
\hline 1. Synthes & is of fatty a & ycolic acids & & & & Rv0043c & - & lator (GntR \\
\hline Rv3285 & $\operatorname{accA3}$ & acetyl/propionyl CoA carboxylase & Rv2262c & & apolipoprotein $\mathrm{N}$-acyltrans- & & & family) \\
\hline Rv0904c & $\operatorname{accD} 3$ & $\begin{array}{l}\alpha \text { subunit } \\
\text { acetyl/propionyl CoA carboxylase }\end{array}$ & & & $\begin{array}{l}\text { ferase-b } \\
\text { lipid carrier protein }\end{array}$ & Rv0067c & - & $\begin{array}{l}\text { transcriptional regulator } \\
\text { (TetR/AcrR family) }\end{array}$ \\
\hline & & $\beta$ subunit & Rv3720 & - & C-term similar to cyclopropane & Rv0078 & - & transcriptional regulator \\
\hline Rv3799c & $\operatorname{accD} 4$ & acetyl/propionyl CoA carboxylase & & & fatty acid synthases & & & (TetR/AcrR family) \\
\hline Rv3280 & $\operatorname{accD5} 5$ & $\begin{array}{l}\beta \text { subunit } \\
\text { acetyl/propionyl CoA carboxylase }\end{array}$ & 1. Polyketic & de and $n$ & & Rv0081 & - & $\begin{array}{l}\text { transcriptional regulator (ArsR } \\
\text { family) }\end{array}$ \\
\hline & & $\beta$ subunit & Rv2940c & mas & mycocerosic acid synthase & Rv0135c & - & putative transcriptional regulator \\
\hline Rv2247 & $\operatorname{accD} 6$ & $\begin{array}{l}\text { acetyl/propionyl CoA carboxylase } \\
\beta \text { subunit }\end{array}$ & Rv2384 & $m b t A$ & $\begin{array}{l}\text { mycobactin/exochelin synthesis } \\
\text { (salicylate-AMP ligase) }\end{array}$ & $\begin{array}{l}\text { Rv0144 } \\
\text { Rv0158 }\end{array}$ & - & $\begin{array}{l}\text { putative transcriptional regulator } \\
\text { transcriptional regulator }\end{array}$ \\
\hline Rv2244 & acpM & acyl carrier protein (meromycolate & Rv2383c & $m b t B$ & mycobactin/exochelin synthesis & & & (TetR/AcrR family) \\
\hline & & exten & & & & Rv0165c & - & transcriptional regulator (GntR \\
\hline Rv2523c & $\operatorname{acps}$ & CoA:apo-[ACP] pantethienephos- & Rv2382c & mbtc & mycobactin/exochelin synthesis & & & family) \\
\hline & & & Rv2381c & $m b t D$ & ynthesis & Rv0195 & - & transcriptional regulator \\
\hline Rv2243 & $f a b D$ & malonyl CoA- $[\mathrm{ACP}]$ transacylase & & & (polyketid & & & \\
\hline Rv0649 & $f a b D 2$ & malonyl CoA-[ACP] transacylase & Rv2380c & mbtE & mycobactin/exochelin synthesis & Rv0196 & - & transcriptional regulator \\
\hline Rv1483 & fabG1 & 3-oxoacyl-[ACP] reductase (aka & & & (lysine & & & (TetR/AcrR \\
\hline & & MabA) & Rv2379c & mbtF & mycobactin/exochelin synthesis & Rv0232 & - & transcriptional regulator \\
\hline Rv1350 & fabG2 & 3-oxoacyl-[ACP] Reductase & & & & & & \\
\hline Rv2002 & fabG3 & 3-oxoacyl-[ACP] reductase & Rv2378c & mbtG & mycobactin/exochelin synthesis & Rv0238 & - & transcriptional regulator \\
\hline Rv0242c & fabG4 & 3-oxoacyl-[ACP] reductase & & & & & & \\
\hline Rv2766c & fabG5 & 3-oxoacyl-[ACP] reductase & Rv2377c & $\mathrm{mbtH}$ & mycobactin/exochelin synthesis & Rv0273c & - & putative transcriptional regulator \\
\hline Rv0533c & $f a b H$ & $\beta$-ketoacyl-ACP synthase III & Rv0101 & nrp & unknown non-ribosomal peptide & Rv0302 & - & egulator \\
\hline Rv2524c & fas & fatty ac & & & & & & \\
\hline Rv1484 & $\operatorname{inh} A$ & enoyl-[ACP] reductase & Rv1153c & omt & PKS o-methyltransferase & Rv0324 & - & transcriptional regulator \\
\hline Rv2245 & kasA & $\begin{array}{l}\beta \text {-ketoacyl-ACP synthase } \\
\text { (meromycolate extension) }\end{array}$ & Rv3824c & papA1 & $\begin{array}{l}\text { PKS-associated protein, unknown } \\
\text { function }\end{array}$ & Rv0328 & - & $\begin{array}{l}\text { anscriptional regulator } \\
\text { etR/AcrR family) }\end{array}$ \\
\hline Rv2246 & kas $B$ & $\begin{array}{l}\beta \text {-ketoacyl-ACP synthase } \\
\text { (meromycolate extension) }\end{array}$ & Rv3820c & рарА2 & $\begin{array}{l}\text { PKS-associated protein, unknown } \\
\text { function }\end{array}$ & $\begin{array}{l}\text { Rv0348 } \\
\text { Rv0377 }\end{array}$ & - & $\begin{array}{l}\text { putative transcriptional regulator } \\
\text { transcriptional regulator (LysR }\end{array}$ \\
\hline Rv1618 & $\operatorname{tes} B 1$ & thioes & Rv1182 & рарАЗ & PKS-associated protein, unknown & & & \\
\hline Rv2605c & tesB2 & thioes & & & function & Rv0386 & - & transcriptic \\
\hline Rv0033 & - & possit & Rv1528c & papA4 & PKS-associated protein, unknown & & & (LuxR/UhpA \\
\hline Rv1344 & - & possi & & & & Rv0452 & - & iptional regulator \\
\hline Rv1722 & - & possible biotin carboxylase & Rv2939 & papA5 & PKS-associated protein, unknown & Rv0465c & - & regulator \\
\hline Rv3221c & - & resembles biotin carboxyl carrier & & & & & & \\
\hline Rv3472 & - & possible acyl carrier protein & $\begin{array}{l}\text { Rv2946c } \\
\text { Rv3825c }\end{array}$ & $\begin{array}{l}p k s 1 \\
p k s 2\end{array}$ & $\begin{array}{l}\text { polyketide synthase } \\
\text { polyketide synthase }\end{array}$ & Rv0472c & - & $\begin{array}{l}\text { criptional regulator } \\
\text { (AcrR family) }\end{array}$ \\
\hline 2. Modifice & ation of fatty & ty an & & $p k s 3$ & se & Rv0474 & - & egulator \\
\hline Rv3391 & acrat & fatty a & Rv1181 & $p k s 4$ & & & & \\
\hline Rv3392c & cmaA1 & $\begin{array}{l}\text { cyclopropane mycolic acid } \\
\text { synthase } 1\end{array}$ & $\begin{array}{l}\text { Rv1527c } \\
\text { Rv0405 }\end{array}$ & $\begin{array}{l}p k s 5 \\
p k s 6\end{array}$ & $\begin{array}{l}\text { polyketide synthase } \\
\text { polyketide synthase }\end{array}$ & Rv0485 & - & $\begin{array}{l}\text { transcriptional regulator (ROK } \\
\text { family) }\end{array}$ \\
\hline Rv0503c & cmaA2 & $\begin{array}{l}\text { cyclopropane mycolic acid syn- } \\
\text { thase } 2\end{array}$ & $\begin{array}{l}\text { Rv1661 } \\
\text { Rv1662 }\end{array}$ & $\begin{array}{l}p k s 7 \\
p k s 8\end{array}$ & $\begin{array}{l}\text { polyketide synthase } \\
\text { polyketide synthase }\end{array}$ & Rv0494 & - & $\begin{array}{l}\text { transcriptional regulator (GntR } \\
\text { family) }\end{array}$ \\
\hline Rv0824c & $\operatorname{des} A 1$ & acyl-[ACP] desaturase & Rv1664 & $p k s 9$ & polyketide & Rv0552 & - & ive transcriptional regulator \\
\hline Rv1094 & desA2 & acyl-[ACP] d & Rv1660 & pks 10 & synthase (chalcone & Rv0576 & - & scriptional regulator \\
\hline Rv3229c & $\operatorname{des} A 3$ & acyl-[ACP] desaturase & & & & Rv0586 & - & transcriptional regulator (GntR \\
\hline Rv0645c & $m m a A 1$ & methoxymycolic acid synthase 1 & Rv1665 & pks11 & ide synthase (chalcone & & & \\
\hline Rv0644c & mmaA2 & methoxymycolic acid synthase 2 & & & synthase-like) & Rv0650 & - & transcriptional regulator ( $\mathrm{ROK}$ \\
\hline Rv0643c & $\operatorname{mmaA3}$ & methoxymycolic acid synthase 3 & Rv2048c & pks 12 & polyketide synthase (erythronolide & & & \\
\hline Rv0642c & $m m a A 4$ & methoxymycolic acid synthase 4 & & & synthase-like) & Rv0653c & - & putative transcriptional regulator \\
\hline Rv0447c & ufaAt & $\begin{array}{l}\text { unknown fatty acid methyltrans- } \\
\text { ferase }\end{array}$ & $\begin{array}{l}\text { Rv3800c } \\
\text { Rv1342c }\end{array}$ & $\begin{array}{l}\text { pks } 13 \\
\text { pks14 }\end{array}$ & $\begin{array}{l}\text { polyketide synthase } \\
\text { polyketide synthase (chalcone }\end{array}$ & Rv0681 & - & $\begin{array}{l}\text { transcriptional regulator } \\
\text { (TetR/AcrR family) }\end{array}$ \\
\hline Rv3538 & ufaA2 & unknown fatty acid methyltrans- & & & synthase-like) & Rv0691c & - & transcriptional regulator \\
\hline & & & Rv2947c & pks 15 & & & & \\
\hline Rv0469 & umaA1 & unknown mycolic acid methyl- & Rv1013 & pks 16 & polyketide synthase & Rv0737 & - & putative transcriptional regulator \\
\hline & & transferase & & pks 17 & polyketide synthase & Rv0744c & - & putative transcriptional regulator \\
\hline Rv0470c & umaA2 & unknown mycolic acid methyl- & Rv1372 & pks 18 & polyketide synthase & Rv0792c & - & transcriptional regulator (GntR \\
\hline
\end{tabular}




\begin{tabular}{|c|c|c|c|c|c|c|c|c|}
\hline \multirow{2}{*}{ Rv0823c } & & family) & \multirow{2}{*}{$\begin{array}{l}\text { Rv3160c } \\
\text { Rv3167c } \\
\text { Rv3173c }\end{array}$} & \multicolumn{2}{|r|}{ putative transcriptional regulator } & \multirow[b]{2}{*}{ Rv0018c } & & truncated \\
\hline & & $\begin{array}{l}\text { transcriptional regulator } \\
\text { (NifR3/Smm1 family) }\end{array}$ & & - & $\begin{array}{l}\text { putative transcriptional regulator } \\
\text { transcriptional regulator }\end{array}$ & & $p p p$ & $\begin{array}{l}\text { putative phosphoprotein phos- } \\
\text { phatase }\end{array}$ \\
\hline Rv0827c & - & $\begin{array}{l}\text { transcriptional regulator (ArsR } \\
\text { family) }\end{array}$ & & & $\begin{array}{l}\text { (TetR/AcrR family) } \\
\text { putative transcriptional regulator }\end{array}$ & Rv2234 & ptpA & $\begin{array}{l}\text { low molecular weight protein-tyro- } \\
\text { sine-phosphatase }\end{array}$ \\
\hline Rv0890c & - & $\begin{array}{l}\text { transcriptional regulator } \\
\text { (LuxR/UhpA family) }\end{array}$ & Rv3208 & - & $\begin{array}{l}\text { transcriptional regulator } \\
\text { (TetR/AcrR family) }\end{array}$ & Rv0153c & - & $\begin{array}{l}\text { putative protein-tyrosine-phos- } \\
\text { phatase }\end{array}$ \\
\hline Rv0891c & - & putative transcriptional regulator & Rv3249c & - & transcriptional regulator & & & \\
\hline Rv0894 & - & putative transcriptional regulator & & & (TetR/AcrR family) & II. Macron & nolecule & metabolism \\
\hline Rv1019 & - & $\begin{array}{l}\text { transcriptional regulator } \\
\text { (TetR/AcrR family) }\end{array}$ & Rv3291c & - & $\begin{array}{l}\text { transcriptional regulator } \\
\text { (Lrp/AsnC family) }\end{array}$ & $\begin{array}{l}\text { A. Synthes } \\
\text { 1. Riboson }\end{array}$ & $\begin{array}{l}\text { sis and } m \\
\text { mal protei }\end{array}$ & $\begin{array}{l}\text { odification of macromolecules } \\
\text { n synthesis and modification }\end{array}$ \\
\hline Rv1049 & - & $\begin{array}{l}\text { transcriptional regulator (MarR } \\
\text { family) }\end{array}$ & Rv3295 & - & $\begin{array}{l}\text { transcriptional regulator } \\
\text { (TetR/AcrR family) }\end{array}$ & $\operatorname{Rv} 3420 \mathrm{c}$ & riml & $\begin{array}{l}\text { ribosomal protein } \mathrm{S} 18 \text { acetyl } \\
\text { transferase }\end{array}$ \\
\hline Rv1129c & - & $\begin{array}{l}\text { transcriptional regulator } \\
\text { (PbsX/Xre family) }\end{array}$ & Rv3334 & - & $\begin{array}{l}\text { transcriptional regulator (MerR } \\
\text { family) }\end{array}$ & $\begin{array}{l}\text { Rv0995 } \\
\text { Rv0641 }\end{array}$ & $\begin{array}{l}\operatorname{rim} J \\
\operatorname{rplA}\end{array}$ & $\begin{array}{l}\text { acetylation of } 30 S \mathrm{~S} 5 \text { subunit } \\
50 S \text { ribosomal protein } \mathrm{L} 1\end{array}$ \\
\hline Rv1151c & - & putative transcriptional regulator & Rv3405c & - & putative transcriptional regulator & Rv0704 & rpIB & $50 S$ ribosomal protein L2 \\
\hline Rv1152 & - & $\begin{array}{l}\text { transcriptional regulator (GntR } \\
\text { family) }\end{array}$ & $\begin{array}{l}\text { Rv3522 } \\
\text { Rv3557c }\end{array}$ & - & $\begin{array}{l}\text { putative transcriptional regulator } \\
\text { transcriptional regulator }\end{array}$ & $\begin{array}{l}\text { Rv0701 } \\
\text { Rv0702 }\end{array}$ & $\begin{array}{l}r p / C \\
r p l D\end{array}$ & $\begin{array}{l}50 S \text { ribosomal protein L3 } \\
50 S \text { ribosomal protein } L 4\end{array}$ \\
\hline Rv1167c & - & putative transcriptional regulator & & & (TetR/AcrR family) & Rv0716 & rplE & $50 S$ ribosomal protein L5 \\
\hline Rv1219c & - & putative transcriptional regulator & Rv3574 & - & transcriptional regulator & Rv0719 & rplf & $50 S$ ribosomal protein $\mathrm{L} 6$ \\
\hline Rv1255c & - & $\begin{array}{l}\text { transcriptional regulator } \\
\text { TetR/AcrR family) }\end{array}$ & Ry3575c & - & $\begin{array}{l}\text { (TetR/AcrR family) } \\
\text { transcriptional requlator (Lacl }\end{array}$ & $\begin{array}{l}\text { Rv0056 } \\
\text { Rv0651 }\end{array}$ & roll & $\begin{array}{l}50 \text { S ribosomal protein L9 } \\
50 \text { S ribosomal protein } L 10\end{array}$ \\
\hline Rv1332 & - & putative transcriptional regulator & & & family) & Rv0640 & rolk & $50 S$ ribosomal protein L11 \\
\hline Rv1353c & - & $\begin{array}{l}\text { transcriptional regulator } \\
\text { (TetR/AcrR family) }\end{array}$ & $\begin{array}{l}\text { Rv3583c } \\
\text { Rv3676 }\end{array}$ & - & $\begin{array}{l}\text { putative transcriptional regulator } \\
\text { transcriptional regulator ( } \mathrm{Crp} / \mathrm{Fnr}\end{array}$ & $\begin{array}{l}\text { Rv0652 } \\
\text { Rv3443c }\end{array}$ & $\begin{array}{l}\text { roll } \\
\text { rolM }\end{array}$ & $\begin{array}{l}50 S \text { ribosomal protein } L 7 / L 12 \\
50 \text { s ribosomal protein } L 13\end{array}$ \\
\hline Rv1358 & - & transcriptional regulator & & & family) & Rv0714 & rp/N & $50 S$ ribosomal protein L14 \\
\hline & - & $\begin{array}{l}\text { (LuxR/UhpA family) } \\
\text { putative transcriptional regulator }\end{array}$ & Rv3678c & - & $\begin{array}{l}\text { transcriptional regulator (LysR } \\
\text { family) }\end{array}$ & $\begin{array}{l}\text { Rv0723 } \\
\text { Rv0708 }\end{array}$ & $\begin{array}{l}r p / O \\
r p I P\end{array}$ & $\begin{array}{l}50 S \text { ribosomal protein L15 } \\
50 \text { S ribosomal protein L16 }\end{array}$ \\
\hline Rv1395 & - & $\begin{array}{l}\text { transcriptional regulator } \\
\text { (AraC/XyIS family) }\end{array}$ & Rv3736 & - & $\begin{array}{l}\text { transcriptional regulator } \\
\text { (AraC/XylS family) }\end{array}$ & $\begin{array}{l}\text { Rv3456c } \\
\text { Rv0720 }\end{array}$ & $r p / Q$ & $\begin{array}{l}50 \text { ribosomal protein L17 } \\
50 \text { S ribosomal protein L18 }\end{array}$ \\
\hline Rv1404 & - & $\begin{array}{l}\text { transcriptional regulator (MarR } \\
\text { family) }\end{array}$ & Rv3744 & - & $\begin{array}{l}\text { transcriptional regulator (ArsR } \\
\text { family) }\end{array}$ & $\begin{array}{l}\text { Rv2904c } \\
\text { Rv1643 }\end{array}$ & $\begin{array}{l}\text { rplS } \\
\text { rplT }\end{array}$ & $\begin{array}{l}50 S \text { ribosomal protein } L 19 \\
50 S \text { ribosomal protein } L 20\end{array}$ \\
\hline Rv1423 & - & putative transcriptional regulator & $\operatorname{Rv} 3830 \mathrm{c}$ & - & transcriptional regulator & Rv2442c & rple & 50 S ribosomal protein $\mathrm{L} 21$ \\
\hline Rv1460 & - & putative transcriptional regulator & & & (TetR/AcrR family) & Rv0706 & $r p / V$ & 50 S ribosomal protein L22 \\
\hline Rv1474c & - & $\begin{array}{l}\text { transcriptional regulator } \\
\text { (TetR/AcrR family) }\end{array}$ & Rv3833 & - & $\begin{array}{l}\text { transcriptional regulator } \\
\text { (AraC/XylS family) }\end{array}$ & $\begin{array}{l}\text { Rv0703 } \\
\text { Rv0715 }\end{array}$ & $\begin{array}{l}r p / W \\
r p / X\end{array}$ & $\begin{array}{l}50 S \text { ribosomal protein } L 23 \\
50 \text { r ribosomal protein } L 24\end{array}$ \\
\hline Rv1534 & - & $\begin{array}{l}\text { transcriptional regulator } \\
\text { (TetR/AcrR family) }\end{array}$ & $\begin{array}{l}\text { Rv3840 } \\
\text { Rv3855 }\end{array}$ & - & $\begin{array}{l}\text { putative transcriptional regulator } \\
\text { putative transcriptional regulator }\end{array}$ & $\begin{array}{l}\text { Rv1015c } \\
\text { Rv2441c }\end{array}$ & $\begin{array}{l}\text { rp/Y } \\
\text { rpmA }\end{array}$ & $\begin{array}{l}50 \text { ribosomal protein } \mathrm{L} 25 \\
50 \text { S ribosomal protein } \mathrm{L} 27\end{array}$ \\
\hline Rv1556 & - & putative transcriptional regulator & & & & Rv0105c & rpmB & $50 S$ ribosomal protein L28 \\
\hline Rv1674c & - & putative transcriptional regulator & 2. Two cor & mponent s & ystems & Rv2058c & $r p m B 2$ & 50 S ribosomal protein L28 \\
\hline Rv1675c & - & putative transcriptional regulator & Rv $1028 \mathrm{c}$ & $k d p D$ & sensor histidine kinase & Rv0709 & rome & $50 S$ ribosomal protein L29 \\
\hline Rv1719 & - & $\begin{array}{l}\text { transcriptional regulator (IcIR } \\
\text { family) }\end{array}$ & Rv1027c & $k d p E$ & $\begin{array}{l}\text { two-component response } \\
\text { regulator }\end{array}$ & $\begin{array}{l}\text { Rv0722 } \\
\text { Rv1298 }\end{array}$ & $\begin{array}{l}\text { rpmD } \\
\text { rpmE }\end{array}$ & $\begin{array}{l}50 S \text { ribosomal protein L30 } \\
50 S \text { ribosomal protein L31 }\end{array}$ \\
\hline Rv1773c & - & $\begin{array}{l}\text { transcriptional regulator (IcIR } \\
\text { family) }\end{array}$ & Rv3246c & $m t r A$ & $\begin{array}{l}\text { two-component response } \\
\text { regulator }\end{array}$ & $\begin{array}{l}\text { Rv2057c } \\
\text { Rv3924c }\end{array}$ & $\begin{array}{l}\text { rpmG } \\
\text { rpmH }\end{array}$ & $\begin{array}{l}50 \text { S ribosomal protein L33 } \\
50 \text { S ribosomal protein L34 }\end{array}$ \\
\hline Rv1776c & - & putative transcriptional regulator & Rv3245c & $m t r B$ & sensor histidine kinase & Rv1642 & rpmi & 50 S ribosomal protein L35 \\
\hline Rv1816 & - & putative transcriptional regulator & Rv0844c & narl & two-component response & Rv3461c & rpms & 50 S ribosomal protein L36 \\
\hline Rv1846c & - & putative transcriptional regulator & & & regulator & Rv1630 & rpsa & $30 S$ ribosomal protein $S 1$ \\
\hline Rv1931c & - & $\begin{array}{l}\text { transcriptional regulator } \\
\text { (AraC/XylS family) }\end{array}$ & Rv0757 & phoP & $\begin{array}{l}\text { two-component response } \\
\text { regulator }\end{array}$ & $\begin{array}{l}\text { Rv2890c } \\
\text { Rv0707 }\end{array}$ & $\begin{array}{l}\operatorname{rps} B \\
\operatorname{rps} C\end{array}$ & $\begin{array}{l}30 S \text { ribosomal protein } \mathrm{S} 2 \\
30 \mathrm{~S} \text { ribosomal protein } \mathrm{S} 3\end{array}$ \\
\hline Rv1956 & - & putative transcriptional regulator & Rv0758 & phof & sensor histidine kinase & Rv3458c & $r p s D$ & $30 S$ ribosomal protein $\mathrm{S} 4$ \\
\hline Rv1963c & - & putative transcriptional regulator & Rv0491 & $\operatorname{reg} \times 3$ & two-component response & Rv0721 & rpse & $30 S$ ribosomal protein S5 \\
\hline Rv1985c & - & transcriptional regulator (LysR & & & regulator & Rv0053 & rpsF & $30 S$ ribosomal protein $\mathrm{S} 6$ \\
\hline & & family) & Rv0490 & $\operatorname{sen} \times 3$ & sensor histidine kinase & Rv0683 & rpsG & 30 S ribosomal protein S7 \\
\hline Rv1990c & - & putative transcriptional regulator & Rv0602c & tcra & two-component response & Rv0718 & rpsH & 30 S ribosomal protein $\mathrm{S} 8$ \\
\hline Rv1994c & - & transcriptional regulator (MerR & & & regulator & Rv3442c & rpsi & 30 S ribosomal protein $\$ 9$ \\
\hline & & family) & Rv0260c & - & two-component response & Rv0700 & rpss & $30 S$ ribosomal protein $\mathrm{S} 10$ \\
\hline Rv2017 & - & putative transcriptional regulator & & & regulator & Rv3459c & rpsk & $30 S$ ribosomal protein $\mathrm{S} 11$ \\
\hline & & (PbsX/Xre family) & Rv0600c & - & sensor histidine kinase & Rv0682 & rpsL & $30 S$ ribosomal protein $\mathrm{S} 12$ \\
\hline Rv2021c & - & putative transcriptional regulator & Rv0601c & - & sensor histidine kinase & Rv3460c & rpsM & $30 S$ ribosomal protein $\mathrm{S} 13$ \\
\hline Rv2034 & & $\begin{array}{l}\text { transcriptional regulator (ArsR } \\
\text { family) }\end{array}$ & Rv0818 & - & $\begin{array}{l}\text { two-component response } \\
\text { regulator }\end{array}$ & $\begin{array}{l}\text { Rv0717 } \\
\text { Rv2056c }\end{array}$ & $\begin{array}{l}\operatorname{rpsN} \\
\operatorname{rps} N 2\end{array}$ & $\begin{array}{l}30 S \text { ribosomal protein } S 14 \\
30 S \text { ribosomal protein S14 }\end{array}$ \\
\hline Rv2175c & & putative transcriptional regulator & Rv0845 & - & sensor histidine kinase & Rv2785c & rpso & 30 S ribosomal protein $\mathrm{S} 15$ \\
\hline Rv2250c & - & putative transcriptional regulator & Rv0902c & - & sensor histidine kinase & Rv2909c & rpsP & $30 S$ ribosomal protein $\mathrm{S} 16$ \\
\hline Rv2258c & - & putative transcriptional regulator & Rv0903c & - & two-component response & Rv0710 & $r p s Q$ & 30 S ribosomal protein $\$ 17$ \\
\hline Rv2282c & - & transcriptional regulator (LysR & & & regulator & Rv0055 & rpsR & 30 S ribosomal protein $\mathrm{S} 18$ \\
\hline & & family) & Rv0981 & - & two-component response & Rv2055c & rpsR2 & $30 S$ ribosomal protein $\mathrm{S} 18$ \\
\hline Rv2308 & - & putative transcriptional regulator & & & regulator & Rv0705 & rpss & $30 S$ ribosomal protein $\mathrm{S} 19$ \\
\hline Rv2324 & - & $\begin{array}{l}\text { transcriptional regulator } \\
\text { (Lrp/AsnC family) }\end{array}$ & $\begin{array}{l}\text { Rv0982 } \\
\text { Rv1032c }\end{array}$ & - & $\begin{array}{l}\text { sensor histidine kinase } \\
\text { sensor histidine kinase }\end{array}$ & $\begin{array}{l}\text { Rv2412 } \\
\text { Rv3241c }\end{array}$ & rpst & $\begin{array}{l}\text { 30S ribosomal protein } S 20 \\
\text { member of S3OAE ribosomal }\end{array}$ \\
\hline Rv2358 & - & $\begin{array}{l}\text { transcriptional regulator (ArsR } \\
\text { family) }\end{array}$ & Rv1033c & - & $\begin{array}{l}\text { two-component response } \\
\text { regulator }\end{array}$ & & & protein family \\
\hline Rv2488c & - & transcriptional regulator & Rv1626 & - & two-component response & 2. Riboson & ne modifi & ration \\
\hline & & (LuxR/UhpA family) & & & regulator & & $k s g A$ & 16S rRNA dimethyltransferase \\
\hline Rv2506 & - & transcriptional regulator & Rv2027c & - & sensor histidine kinase & Rv2838c & $r b f A$ & ribosome-binding factor $\mathrm{A}$ \\
\hline & - & $\begin{array}{l}\text { (TetR/AcrR family) } \\
\text { putative transcriptional regulator }\end{array}$ & Rv2884 & - & two-component response & Rv2907c & rimM & $16 \mathrm{~S}$ rRNA processing protein \\
\hline Rv2640c & - & transcriptional regulator (ArsR & Rv3132c & - & sensor histidine kinase & 3. Aminoa & cyl tRNA & synthases and their modification \\
\hline & & & Rv3133c & - & two-component response & Rv2555c & alas & alanyl-tRNA synthase \\
\hline Rv2642 & - & transcriptional regulator (ArsR & & & regulator & Rv1292 & args & arginyl-tRNA synthase \\
\hline & & family) & Rv3143 & - & putative sensory transduction & Rv2572c & asps & aspartyl-tRNA synthase \\
\hline Rv2669 & - & putative transcriptional regulator & & & protein & Rv $3580 \mathrm{c}$ & cyss & cysteinyl-tRNA synthase \\
\hline Rv2745c & - & tative transcriptional regulator & Rv3220c & - & sensor histidine kinase & Rv2130c & cysS2 & cysteinyl-tRNA synthase \\
\hline Rv2779c & - & transcriptional regulator & Rv3764c & - & sensor histidine kinase & Rv1406 & fmt & methionyl-tRNA formyltransferase \\
\hline Rv2887 & - & $\begin{array}{l}\text { (Lrp/AsnC family) } \\
\text { transcriptional regulator (MarR }\end{array}$ & Rv3765c & - & $\begin{array}{l}\text { two-component response } \\
\text { regulator }\end{array}$ & Rv3011c & gatA & $\begin{array}{l}\text { glu-tRNA-gln amidotransferase, } \\
\text { subunit B }\end{array}$ \\
\hline & & family) & & & & Rv3009c & gatB & glu-tRNA-gln amidotransferase, \\
\hline Rv2912c & - & transcriptional regulator & & hreonir & rotein kinases and phosphoprotein & & & subunit A \\
\hline & & & & & & Rv3012c & gatC & glu-tRNA-gln amidotransferase \\
\hline Rv2989 & - & transcriptional regulator (IcIR & Rv0015c & $p k n A$ & serine-threonine & & & subunit $C$ \\
\hline & & & Rv0014c & $p k n B$ & serine-threonine protein kinase & Rv2992c & gits & glutamyl-tRNA synthase \\
\hline Rv3050c & - & putative transcriptional regulator & Rv0931c & $p k n D$ & serine-threonine protein kinase & Rv2357c & glys & glycyl-tRNA synthase \\
\hline & - & putative transcriptional regulator & Rv 1743 & pknE & serine-threonine protein kinase & Rv2580c & hiss & histidyl-tRNA synthase \\
\hline Rv3058c & - & putative transcriptional regulator & Rv1746 & $p k n F$ & serine-threonine protein kinase & Rv1536 & iles & isoleucyl-tRNA synthase \\
\hline Rv3060c & - & transcriptional regulator (GntR & Rv0410c & $p k n G$ & serine-threonine protein kinase & Rvo041 & leus & leucyl-tRNA synthase \\
\hline & & family) & Rv1266c & $p k n H$ & serine-threonine protein kinase & Rv3598c & lyss & lysyl-tRNA synthase \\
\hline & - & putative transcriptional regulator & Rv2914c & $p k n l$ & serine-threonine protein kinase & Rv1640c & lysX & C-term lysyl-tRNA synthase \\
\hline & - & putative transcriptional regulator & Rv2088 & pkns & serine-threonine protein kinase & Rv1007c & mets & methionyl-tRNA synthase \\
\hline Rv3124 & - & $\begin{array}{l}\text { transcriptional regulator } \\
\text { (AfsR/Dndl/RedD family) }\end{array}$ & $\begin{array}{l}\text { Rv3080c } \\
\text { Rv2176 }\end{array}$ & $\begin{array}{l}p k n K \\
p k n L\end{array}$ & $\begin{array}{l}\text { serine-threonine protein kinase } \\
\text { serine-threonine protein kinase, }\end{array}$ & Rv1649 & phes & $\begin{array}{l}\text { phenylalanyl-tRNA synthase } \alpha \\
\text { subunit }\end{array}$ \\
\hline
\end{tabular}




\begin{tabular}{|c|c|c|c|c|c|c|c|c|}
\hline Rv1650 & phet & $\begin{array}{l}\text { phenylalanyl-tRNA synthase } \beta \\
\text { subunit }\end{array}$ & Rv2090 & - & $\begin{array}{l}\text { partially similar to DNA poly- } \\
\text { merase I }\end{array}$ & $\begin{array}{l}\text { 2. DNA } \\
\text { Rv0670 }\end{array}$ & end & endonuclease IV (apurinase) \\
\hline Rv2845c & pros & prolyl-tRNA synthase & Rv2191 & - & similar to both PolC and UvrC & Rv1108c & $x s \in A$ & exonuclease VII large subunit \\
\hline Rv3834c & sers & seryl-tRNA synthase & & & proteins & Rv1107c & $x s \in B$ & exonuclease VII small subunit \\
\hline Rv2614c & thrs & threonyl-tRNA synthase & Rv2464c & - & probable DNA glycosylase, & 3. Proteins & & and olyconentides \\
\hline Rv2906c & $\operatorname{trm} D$ & $\begin{array}{l}\text { tRNA (guanine-N1)-methyltrans- } \\
\text { ferase }\end{array}$ & Rv3201c & - & $\begin{array}{l}\text { endonuclease VIII } \\
\text { probable ATP-dependent DNA }\end{array}$ & Rv3305c & $\begin{array}{l}\text {, peptides } \\
\text { amiA }\end{array}$ & $\begin{array}{l}\text { and glycopeptides } \\
\text { probable aminohydrolase }\end{array}$ \\
\hline Rv3336c & trps & tryptophanyl tRNA synthase & & & helicase & Rv3306c & $a m i B$ & probable aminohydrolase \\
\hline Rv1689 & tyrs & tyrosyl-tRNA synthase & Rv3202c & - & similar to UvrD proteins & Rv3596c & $c / p C$ & ATP-dependent Clp protease \\
\hline Rv2448c & vals & valyl-tRNA synthase & $\begin{array}{l}\text { Rv3263 } \\
\text { Rv3644c }\end{array}$ & $\begin{array}{l}- \\
-\end{array}$ & $\begin{array}{l}\text { probable DNA methylase } \\
\text { similar in N-term to DNA poly- }\end{array}$ & Rv2461c & $c i p P$ & $\begin{array}{l}\text { ATP-dependent Clp protease pro- } \\
\text { teolytic subunit }\end{array}$ \\
\hline 4. Nucleop & roteins & & & & merase III & Rv2460c & clpP2 & ATP-dependent Clp protease pro- \\
\hline Rv1407 & fmu & similar to Fmu protein & & & & & & teolytic subunit \\
\hline Rv3852 & hns & HU-histone protein & 6. Protein & translatio & and modification & Rv2457c & $c / p X$ & ATP-dependent Clp protease \\
\hline $\begin{array}{l}\text { Rv2986c } \\
\text { Rv1388 }\end{array}$ & $\begin{array}{l}\text { hupB } \\
\text { miHF }\end{array}$ & $\begin{array}{l}\text { DNA-binding protein II } \\
\text { integration host factor }\end{array}$ & $\begin{array}{l}\text { Rv0429c } \\
\text { Rv2534c } \\
\text { Rv2882c }\end{array}$ & $\begin{array}{l}\text { def } \\
\text { efp }\end{array}$ & $\begin{array}{l}\text { polypeptide deformylase } \\
\text { elongation factor } P \\
\text { ribosome recycling factor }\end{array}$ & Rv2667 & $\operatorname{clp} X^{\prime}$ & $\begin{array}{l}\text { ATP-binding subunit ClpX } \\
\text { similar to ClpC from M. leprae but } \\
\text { shorter }\end{array}$ \\
\hline $\begin{array}{l}\text { 5. DNA rep } \\
\text { tion/modifi }\end{array}$ & $\begin{array}{l}\text { lication, } \\
\text { cation }\end{array}$ & pair, recombination and restric- & $\begin{array}{l}\text { Rv0684 } \\
\text { Rv0120c }\end{array}$ & $\begin{array}{l}\text { fusA } \\
\text { fusA2 }\end{array}$ & $\begin{array}{l}\text { elongation factor } G \\
\text { elongation factor } G\end{array}$ & $\begin{array}{l}\text { Rv3419c } \\
\text { Rv2725c }\end{array}$ & $\begin{array}{l}g c p \\
h f i X\end{array}$ & $\begin{array}{l}\text { glycoprotease } \\
\text { GTP-binding protein }\end{array}$ \\
\hline Rv1317c & alkA & $\begin{array}{l}\text { DNA-3-methyladenine glycosi- } \\
\text { dase II }\end{array}$ & $\begin{array}{l}\text { Rv1080c } \\
\text { Rv3462c }\end{array}$ & $\begin{array}{l}\text { greA } \\
\text { infA }\end{array}$ & $\begin{array}{l}\text { transcription elongation factor } \mathrm{G} \\
\text { initiation factor IF-1 }\end{array}$ & $\begin{array}{l}\text { Rv1223 } \\
\text { Rv2861c }\end{array}$ & $\begin{array}{l}\text { htrA } \\
\text { mapA1 }\end{array}$ & $\begin{array}{l}\text { serine protease } \\
\text { methionine aminopeptidase }\end{array}$ \\
\hline $\begin{array}{l}\text { Rv2836c } \\
\text { Rv1329c }\end{array}$ & $\begin{array}{l}\operatorname{din} F \\
\operatorname{din} G\end{array}$ & $\begin{array}{l}\text { DNA-damage-inducible protein } \mathrm{F} \\
\text { probable ATP-dependent helicase }\end{array}$ & $\begin{array}{l}\text { Rv2839c } \\
\text { Rv1641 }\end{array}$ & $\begin{array}{l}\operatorname{infB} \\
\text { infC }\end{array}$ & $\begin{array}{l}\text { initiation factor IF-2 } \\
\text { initiation factor IF-3 }\end{array}$ & Rv0734 & mapA2 & $\begin{array}{l}\text { probable methionine aminopepti- } \\
\text { dase }\end{array}$ \\
\hline Rv3056 & $\operatorname{din} P$ & DNA-damage-inducible protein & Rv0009 & ppiA & peptidyl-prolyl cis-trans isomerase & Rv0319 & $p c p$ & pyrrolidone-carboxylate peptidase \\
\hline Rv1537 & $\operatorname{din} x$ & $\begin{array}{l}\text { probable DNA-damage-inducible } \\
\text { protein }\end{array}$ & $\begin{array}{l}\text { Rv2582 } \\
\text { Rv1299 }\end{array}$ & ppiB & $\begin{array}{l}\text { peptidyl-prolyl cis-trans isomerase } \\
\text { peptide chain release factor } 1\end{array}$ & $\begin{array}{l}\text { Rv0125 } \\
\text { Rv2213 }\end{array}$ & pepA & $\begin{array}{l}\text { probable serine protease } \\
\text { aminopeptidase } A / l\end{array}$ \\
\hline Rv0001 & $d n a A$ & $\begin{array}{l}\text { chromosomal replication initiator } \\
\text { protein }\end{array}$ & $\begin{array}{l}\text { Rv3105c } \\
\text { Rv2889c }\end{array}$ & $\begin{array}{l}\text { prfB } \\
\text { tsf }\end{array}$ & $\begin{array}{l}\text { peptide chain release factor } 2 \\
\text { elongation factor EF-Ts }\end{array}$ & $\begin{array}{l}\text { Rv0800 } \\
\text { Rv2467 }\end{array}$ & $\begin{array}{l}\text { pepC } \\
\text { pepD }\end{array}$ & $\begin{array}{l}\text { aminopeptidase I } \\
\text { probable aminopeptidase }\end{array}$ \\
\hline Rv0058 & dnaB & DNA helicase (contains intein) & Rv0685 & tuf & elongation factor EF-Tu & Rv2089c & pepE & cytoplasmic peptidase \\
\hline Rv1547 & dnaEt & DNA polymerase III, $\alpha$ subunit & & & & Rv2535c & $p e p Q$ & cytoplasmic peptidase \\
\hline Rv3370c & dnaE2 & DNA polymerase III $\alpha$ chain & $\begin{array}{l}\text { 7. RNA syr } \\
\text { transcriptic }\end{array}$ & $\begin{array}{l}\text { nthesis, } F \\
\text { on }\end{array}$ & NA modification and DNA & Rv2782c & $p e p R$ & $\begin{array}{l}\text { protease/peptidase, M16 family } \\
\text { (insulinase) }\end{array}$ \\
\hline Rv0002 & $\begin{array}{l}\text { dnaG } \\
\text { dnaN }\end{array}$ & $\begin{array}{l}\text { DNA primase } \\
\text { DNA polymerase III, } \beta \text { subunit }\end{array}$ & Rv1253 & deaD & ATP-dependent DNA/RNA & Rv2109c & prcA & proteasome $\alpha$-type subunit 1 \\
\hline Rv3711c & dnaQ & DNA polymerase $I I I \epsilon$ chain & & & helicase & Rv2110c & $\operatorname{prcB}$ & proteasome $\beta$-type subunit 2 \\
\hline Rv3721c & $d n a Z X$ & $\begin{array}{l}\text { DNA polymerase III, } \gamma \text { (dnaZ) and } \\
\tau(\text { dnaX) }\end{array}$ & Rv2783c & $g p s l$ & $\begin{array}{l}\text { pppGpp synthase and polyribo- } \\
\text { nucleotide phosphorylase }\end{array}$ & $\begin{array}{l}\text { Rv0782 } \\
\text { Rv0781 }\end{array}$ & $\begin{array}{l}\text { ptrBa } \\
\text { ptrBb }\end{array}$ & $\begin{array}{l}\text { protease II, } \alpha \text { subunit } \\
\text { protease II, } \beta \text { subunit }\end{array}$ \\
\hline Rv2924c & $f p g$ & $\begin{array}{l}\text { formamidopyrimidine-DNA glyco- } \\
\text { sylase }\end{array}$ & $\begin{array}{l}\text { Rv2841c } \\
\text { Rv2533c }\end{array}$ & $\begin{array}{l}\text { nusA } \\
\text { nusB }\end{array}$ & $\begin{array}{l}\text { transcription termination factor } \\
\mathrm{N} \text {-utilization substance protein B }\end{array}$ & Rv0724 & sppA & $\begin{array}{l}\text { protease IV, signal peptide pepti- } \\
\text { dase }\end{array}$ \\
\hline Rv0006 & gyrA & DNA gyrase subunit A & Rv0639 & nUSG & transcription antitermination & Rv0198c & - & probable zinc metalloprotease \\
\hline Rv0005 & gyrB & DNA gyrase subunit B & & & $n$ & Rv0457c & - & probable peptida \\
\hline Rv2092c & helY & probable helicase, Ski2 subfamily & Rv3907c & PCnA & polynucleotide polymerase & Rv0840c & - & probable proline iminopeptidase \\
\hline Rv2101 & helz & $\begin{array}{l}\text { probable helicase, Snf } 2 / \text { Rad } 54 \\
\text { family }\end{array}$ & Rv3232c & $p v d S$ & $\begin{array}{l}\text { Ima factor for } \\
\text { roduction }\end{array}$ & $\begin{array}{l}\text { Rv0983 } \\
\text { Rv1977 }\end{array}$ & - & $\begin{array}{l}\text { probable serine protease } \\
\text { probable zinc metallopeptidase }\end{array}$ \\
\hline Rv2756c & $h s d M$ & $\begin{array}{l}\text { type I restriction/modification sys- } \\
\text { tem DNA methylase }\end{array}$ & Rv3211 & rhIE & $\begin{array}{l}\text { probable ATP-dependent } \\
\text { RNA helicase }\end{array}$ & $\begin{array}{l}\text { Rv3668c } \\
\text { Rv3671c }\end{array}$ & - & $\begin{array}{l}\text { probable alkaline serine protease } \\
\text { probable serine protease }\end{array}$ \\
\hline Rv2755c & $h s d S^{\prime}$ & $\begin{array}{l}\text { type I restriction/modification sys- } \\
\text { tem specificity determinant }\end{array}$ & Rv1297 & rho & $\begin{array}{l}\text { transcription termination } \\
\text { factor rho }\end{array}$ & $\begin{array}{l}\text { Rv3883c } \\
\text { Rv3886c }\end{array}$ & - & $\begin{array}{l}\text { probable secreted protease } \\
\text { protease }\end{array}$ \\
\hline Rv3296 & Ihr & ATP-dependent helicase & Rv3457c & rpoA & $\alpha$ subunit of RNA polymerase & & & \\
\hline Rv3014c & $\operatorname{lig} A$ & DNA ligase & Rv0667 & rpoB & $\beta$ st & \\
\hline Rv3062 & $\operatorname{lig} B$ & DNA ligase & Rv0668 & rpoc & $\beta^{\prime}$ subunit of RNA polymerase & \multicolumn{3}{|c|}{ 4. Polysaccharides, lipopolysaccharides and phospho- } \\
\hline Rv3731 & $\operatorname{lig} C$ & probable DNA ligase & Rv1364c & $r s b u$ & SigB regulation protein & Rv0062 & celA & cellulase/endoglucanase \\
\hline Rv 1020 & mfo & transcription-repair coupling factor & Rv3287c & rsbW & anti-sig & Rv3915 & cwiM & \\
\hline Rv2528c & mrr & restriction system protein & Rv2703 & $\operatorname{sig} A$ & ymerase sigma factor & Rv0315 & - & e $\beta$-1,3-glucanase \\
\hline Rv2985 & mutTf & MutT homologue & & & (aka MysA, RpoV) & Rv1090 & - & probable \\
\hline Rv1160 & mutT2 & MutT homologue & Rv2710 & $\operatorname{sig} B$ & RNA polymerase sigma factor & & & endoglucanase \\
\hline Rv0413 & mutT3 & MutT homologue & & & (aka MysB) & Rv1327c & - & probable glycosyl hydrolase, $\alpha$ - \\
\hline Rv3589 & mutY & probable DNA glycosylase & Rv2069 & $\operatorname{sig} C$ & ECF subfamily sigma subunit & & & ily \\
\hline Rv3297 & $n e i$ & probable endonuclease VIII & Rv3414c & $\operatorname{sig} D$ & ubfamily sigma subunit & Rv1333 & - & probabl \\
\hline Rv3674c & nth & donuclease III & Rv1221 & sige & ECF subfamily sigma subunit & Rv3463 & - & probable neuraminidase \\
\hline Rv1316c & ogt & $\begin{array}{l}\text { methylated-DNA-protein-cysteine } \\
\text { methyltransferase }\end{array}$ & $\begin{array}{l}\text { Rv3286c } \\
\text { Rv0182c }\end{array}$ & $\begin{array}{l}\text { sigF } \\
\text { sigG }\end{array}$ & $\begin{array}{l}\text { ECF subfamily sigma subunit } \\
\text { sigma-70 factors ECF subfamily }\end{array}$ & Rv3717 & - & $\begin{array}{l}\text { possible } \mathrm{N} \text {-acetylmuramoyl-L-ala- } \\
\text { nine amidase }\end{array}$ \\
\hline Rv1629 & polA & lymerase I & Rv3223c & $\mathrm{sigH}$ & ECF subfamily sigma subunit & & & \\
\hline Rv1402 & priA & losomal protein $n^{\prime}$ & Rv1189 & sigl & nily sigma factor & \multicolumn{3}{|c|}{ 5. Esterases and lipases } \\
\hline & & (replic & Rv3328c & sigu & & Rv0220 & $\operatorname{lipC}$ & proba \\
\hline Rv3585 & $\operatorname{rad} A$ & probable DNA repair RadA homo- & Rv0445c & sigk & ECF-type sigma factor & Rv1923 & $\operatorname{lipD}$ & probable esterase \\
\hline & & logue & Rv0735 & $\operatorname{sigh}$ & sigma-70 factors ECF subfamily & Rv3775 & $\operatorname{lipE}$ & \\
\hline $\begin{array}{l}\text { Rv2737c } \\
\text { Rv0630c }\end{array}$ & $\begin{array}{l}\text { recA } \\
\operatorname{rec} B\end{array}$ & recombinase (contains intein) & Rv3911 & $\operatorname{sig} M$ & probable sigma factor, similar to & $\begin{array}{l}\text { Rv3487c } \\
\text { Rv0646c }\end{array}$ & $\begin{array}{l}\operatorname{lipF} \\
\operatorname{lipG}\end{array}$ & $\begin{array}{l}\text { probable esterase } \\
\text { probable hydrolase }\end{array}$ \\
\hline Rv0631c & recc & $\begin{array}{l}\text { exodeoxyribonuclease V } \\
\text { exodeoxyribonuclease V }\end{array}$ & Rv3366 & spou & A methylase & Rv1399c & $\mathrm{lipH}$ & $\begin{array}{l}\text { probak } \\
\text { probak }\end{array}$ \\
\hline Rv0629c & recD & exodeoxyribonuclease V & Rv3455c & truA & probable pseudouridylate syn- & Rv1400c & lipl & prob \\
\hline Rv0003 & recF & $\begin{array}{l}\text { DNA replication and SOS induc- } \\
\text { tion }\end{array}$ & Rv2793c & $\operatorname{truB}$ & lase & $\begin{array}{l}\text { Rv1900c } \\
\text { Rv2385 }\end{array}$ & $\begin{array}{l}\text { lipJ } \\
\text { lipk }\end{array}$ & $\begin{array}{l}\text { probable esterase } \\
\text { probable acetyl-hydrola }\end{array}$ \\
\hline Rv2973c & $r e c G$ & ATP-dependent DNA helicase & Rv1644 & $\operatorname{tsn} A$ & putative 23 S rRNA methyltrans- & Rv1497 & lipL & probable \\
\hline Rv1696 & $\operatorname{recN}$ & & & & ferase & Rv2284 & lipM & prok \\
\hline $\operatorname{Rv} 3715 c$ & rech & $\begin{array}{l}\text { RecBC-Independent process of } \\
\text { DNA repair }\end{array}$ & Rv3649 & - & $\begin{array}{l}\text { ATP-dependent DNA/RNA heli- } \\
\text { case }\end{array}$ & $\begin{array}{l}\text { Rv2970c } \\
\text { Rv1426c }\end{array}$ & $\begin{array}{l}\operatorname{lipN} \\
\operatorname{lipO}\end{array}$ & $\begin{array}{l}\text { probable lipase/esterase } \\
\text { probable esterase }\end{array}$ \\
\hline Rv2736c & recX & protein for RecA & \multirow{2}{*}{\multicolumn{3}{|c|}{ 8. Polysaccharides (cytoplasmic) }} & Rv2463 & $\operatorname{lip} P$ & probable esterase \\
\hline Rv2593c & rUvA & Holliday junction binding protein, & & & & Rv2485c & $\operatorname{lip} Q$ & boxlyesterase \\
\hline & & & $\operatorname{Rv} 1326 \mathrm{c}$ & gigB & & & $\operatorname{liph}$ & \\
\hline Rv2592c & $r u v B$ & Holliday junction binding protein & Rv1328 & glgP & probable glycogen phosphory- & Rv3176c & lips & probable esterase/lipase \\
\hline Rv2594c & ruve & Holliday junction resolvase, endo- & & & & Rv2045c & $\operatorname{lip} T$ & ylesterase \\
\hline & $s s b$ & $\begin{array}{l}\text { deoxyribonucle } \\
\text { single strand } b\end{array}$ & Rv1564c & $\operatorname{glg} X$ & & & $\begin{array}{l}\operatorname{lipU} \\
\operatorname{lipV} V\end{array}$ & \\
\hline Rv1210 & $\operatorname{tag} A$ & ladenine glycosi- & v1563c & $g i g Y$ & & Rv0217c & lipW & probable \\
\hline & & & v1562c & $g i g Z$ & lalose trehalohy- & Rv2351c & pica & \\
\hline Rv3646c & topA & & & & & $\operatorname{Rv} 2350 c$ & $p l c B$ & phospholipase $\mathrm{C}$ precursor \\
\hline Rv2976c & ung & ycosylase & iv0126 & - & prob & $\operatorname{Rv} 2349 c$ & $\mathrm{plcC}$ & \\
\hline Rv1638 & UVrA & $A B C$ subunit $A$ & Rv1781c & - & probable 4 - $\alpha$-glucanotransferase & Rv1755c & $p / c D$ & partial CDS for phospholipase $C$ \\
\hline Rv1633 & uvrB & excinuclease $A B C$ subunit $B$ & Rv2471 & - & probable maltase $\alpha$-glucosidase & & & probable esterase pseudogene \\
\hline Rv1420 & uvrC & & & & & Rv1105 & - & probable esterase pseudogene \\
\hline & uvrD & $\begin{array}{l}\text { DNA-dependent ATPase I and } \\
\text { helicase II }\end{array}$ & $\begin{array}{l}\text { B. Degrad } \\
\text { 1. RNA }\end{array}$ & ation of & cromolecules & & & \\
\hline Rv3198c & uvrD2 & & Rv1014c & pth & peptidyl-tRNA hydrolase & Rv3469c & mhpE & probable 4-hydroxy-2-oxovalerate \\
\hline Rv0427c & $x$ thA & & & rnc & & & & \\
\hline Rv0071 & - & group II intron maturase & Rv2444c & rne & similar at $\mathrm{C}$-term to ribo- & Rv0316 & - & probable muconolactone iso- \\
\hline & - & & & & & & & \\
\hline Rv0944 & - & $\begin{array}{l}\text { possible formamidopyrimidine- } \\
\text { DNA glycosylase }\end{array}$ & $\begin{array}{l}\text { Rv2902c } \\
\text { Rv3923c }\end{array}$ & $\begin{array}{l}r n h B \\
r n p A\end{array}$ & $\begin{array}{l}\text { ribonuclease HII } \\
\text { ribonuclease } \mathrm{P} \text { protein compo- }\end{array}$ & Rv0771 & - & $\begin{array}{l}\text { probable 4-carboxymuconolac- } \\
\text { tone decarboxylase }\end{array}$ \\
\hline & - & probable 3-methylpurine DNA & & & $\begin{array}{l}\text { nent } \\
\text { ribonuclease } \mathrm{PH}\end{array}$ & $\begin{array}{l}\text { Rv0939 } \\
\text { Rv1723 }\end{array}$ & - & probable dehydrase \\
\hline & & glycosylase & Rv1340 & rphA & ribonuclease $\mathrm{PH}$ & Rv1723 & & 6-aminohexanoate-dimer hydro- \\
\hline
\end{tabular}




\begin{tabular}{|c|c|c|c|c|c|c|c|c|}
\hline \multirow[b]{2}{*}{ Rv2715 } & \multirow[b]{2}{*}{ - } & lase & Rv1367c & - & probable penicillin binding protein & Rv1030 & $k d p B$ & \multirow{2}{*}{$\begin{array}{l}\text { potassium-transporting ATPase B } \\
\text { chain }\end{array}$} \\
\hline & & 2-hydroxymuconic semialdehyde & Rv1730c & - & probable penicillin binding protein & & & \\
\hline v3530c & - & hydrolase & Rv1922 & - & probable penicillin binding protein & Rv1031 & $k d p C$ & potassium-transporting ATPase C \\
\hline & $\begin{array}{l}- \\
-\end{array}$ & probable cis-diol dehydrogenase & Rv2864c & & nicillin binding protein & & & chain \\
\hline Rv3534c & - & 4-hydroxy-2-oxovalerate aldolase & Rv3330 & - & probable penicillin binding protein & Rv3236c & kefB & probable glutathione-regulated \\
\hline Rv3536c & - & $\begin{array}{l}\text { aromatic hydrocarbon degrada- } \\
\text { tion }\end{array}$ & $\begin{array}{l}\text { Rv3627c } \\
\text { 4. Conserve }\end{array}$ & ed membr & probable penicillin binding protein & Rv2877c & merT & $\begin{array}{l}\text { potassium-efflux protein } \\
\text { possible mercury resistance } \\
\text { transport system }\end{array}$ \\
\hline $\begin{array}{l}\text { C. Cell en } \\
\text { 1. Lipopro }\end{array}$ & $\begin{array}{l}\text { velope } \\
\text { teins (lpph }\end{array}$ & -Ipro) 65 & Rv0402c & $m m p L 1$ & $\begin{array}{l}\text { conserved large membrane } \\
\text { protein }\end{array}$ & Rv1811 & mgtC & $\begin{array}{l}\text { probable magnesium transport } \\
\text { ATPase protein C }\end{array}$ \\
\hline & polysacc & arides, lipopolysaccharides, pro- & Rv0507 & $m m p L 2$ & $\begin{array}{l}\text { conserved large membrane } \\
\text { protein }\end{array}$ & Rv0362 & $m g t E$ & $\begin{array}{l}\text { putative magnesium ion } \\
\text { transporter }\end{array}$ \\
\hline teins and & antigens & & Rv0206c & $m m p L 3$ & conserved large membrane & Rv2856 & nict & probable nickel transport protein \\
\hline Rv0806c & $c p s Y$ & $\begin{array}{l}\text { probable UDP-glucose-4- } \\
\text { epimerase }\end{array}$ & & & $\begin{array}{l}\text { protein } \\
\text { conserved large membrane }\end{array}$ & Rv0924c & nramp & $\begin{array}{l}\text { transmembrane protein belonging } \\
\text { to Nramp family }\end{array}$ \\
\hline $\begin{array}{l}\text { Rv3811 } \\
\text { Rv1677 }\end{array}$ & $\begin{array}{l}c s p \\
d s b F\end{array}$ & $\begin{array}{l}\text { secreted protein } \\
\text { highly similar to C-term Mpt53 }\end{array}$ & Rv0676c & $m m p L 5$ & $\begin{array}{l}\text { protein } \\
\text { conserved large membrane }\end{array}$ & Rv2691 & $\operatorname{trk} A$ & $\begin{array}{l}\text { probable potassium uptake pro- } \\
\text { tein }\end{array}$ \\
\hline Rv3794 & $e m b A$ & $\begin{array}{l}\text { involved in arabinogalactan syn- } \\
\text { thesis }\end{array}$ & Rv1557 & $m m p L 6$ & $\begin{array}{l}\text { protein } \\
\text { conserved large membrane }\end{array}$ & Rv2692 & $\operatorname{trkB}$ & $\begin{array}{l}\text { probable potassium uptake pro- } \\
\text { tein }\end{array}$ \\
\hline Rv3795 & $e m b B$ & $\begin{array}{l}\text { involved in arabinogalactan syn- } \\
\text { thesis }\end{array}$ & Rv2942 & $\mathrm{mmpL} 7$ & $\begin{array}{l}\text { protein } \\
\text { conserved large membrane }\end{array}$ & $\begin{array}{l}\text { Rv2287 } \\
\text { Rv2723 }\end{array}$ & yjcE & $\begin{array}{l}\text { probable } \mathrm{Na}+/ \mathrm{H}+\text { exchanger } \\
\text { probable membrane protein, }\end{array}$ \\
\hline Rv3793 & $e m b c$ & $\begin{array}{l}\text { involved in arabinogalactan syn- } \\
\text { thesis }\end{array}$ & Rv3823c & $m m p L 8$ & $\begin{array}{l}\text { protein } \\
\text { conserved large membrane }\end{array}$ & Rv3162c & - & $\begin{array}{l}\text { tellurium resistance } \\
\text { probable membrane protein }\end{array}$ \\
\hline Rv3875 & esat6 & early secretory antigen target & & & protein & Rv3237c & & possible potassium channel \\
\hline Rv0112 & gca & $\begin{array}{l}\text { probable GDP-mannose dehy- } \\
\text { dratase }\end{array}$ & Rv2339 & $m m p L 9$ & $\begin{array}{l}\text { conserved large membrane } \\
\text { protein }\end{array}$ & & & $\begin{array}{l}\text { protein } \\
\text { probable cation-transporting }\end{array}$ \\
\hline $\begin{array}{l}\text { Rv0113 } \\
\text { Rv2965c }\end{array}$ & $\underset{k d t B}{\operatorname{gmh} A}$ & $\begin{array}{l}\text { phosphoheptose isomerase } \\
\text { lipopolysaccharide core biosyn- }\end{array}$ & Rv1183 & $m m p L 10$ & $\begin{array}{l}\text { conserved large membrane } \\
\text { protein }\end{array}$ & & & ATPase \\
\hline & & thesis $\mathrm{F}$ & Rv0202c & $m m p L 11$ & conserved large membrane & 3. Carboh & drates, & ganic acids and alcohols \\
\hline Rv2878c & mpt53 & secreted & & & protein & Rv2443 & $d c t A$ & -dicarboxylate transport protein \\
\hline Rv1980c & mpt64 & $\begin{array}{l}\text { secreted immunogenic protein } \\
\text { Mpb64/Mpt64 }\end{array}$ & Rv1522c & $m m p L 12$ & $\begin{array}{l}\text { conserved large membrane } \\
\text { protein }\end{array}$ & $\begin{array}{l}\text { Rv3476c } \\
\text { Rv1902c }\end{array}$ & $\begin{array}{l}\mathrm{kgtP} P \\
\text { nant }\end{array}$ & $\begin{array}{l}\text { sugar transport protein } \\
\text { probable sialic acid transporter }\end{array}$ \\
\hline Rv2875 & mpt70 & $\begin{array}{l}\text { major secreted immunogenic pro- } \\
\text { tein Mpt } 70 \text { precursor }\end{array}$ & Rv0403c & mmpS1 & $\begin{array}{l}\text { conserved small membrane } \\
\text { protein }\end{array}$ & Rv1236 & $\operatorname{sug} A$ & $\begin{array}{l}\text { membrane protein probably } \\
\text { involved in sugar transport }\end{array}$ \\
\hline Rv2873 & mpt83 & tein Mpt83 & Rv0506 & $m m p S 2$ & conserved small membrane & Rv1237 & $\operatorname{sug} B$ & protein \\
\hline Rv0899 & ompA & member of OmpA & & & protein & Rv1238 & sugC & omponent of \\
\hline Rv3810 & pirG & $\begin{array}{l}\text { cell surface protein precursor (Erp } \\
\text { protein) }\end{array}$ & Rv2198c & $m m p S 3$ & $\begin{array}{l}\text { conserved small membrane } \\
\text { protein }\end{array}$ & Rv3331 & sugl & $\begin{array}{l}\text { system } \\
\text { ar transport protein }\end{array}$ \\
\hline $\begin{array}{l}\text { Rv3782 } \\
\text { Rv1302 }\end{array}$ & $\begin{array}{l}r b E \\
r e\end{array}$ & $\begin{array}{l}\text { similar to rhamnosyl transferase } \\
\text { undecaprenyl-phosphate } \alpha-N \text { - }\end{array}$ & Rv0451c & $m m p S 4$ & $\begin{array}{l}\text { conserved small membrane } \\
\text { protein }\end{array}$ & Rv2835c & ugpA & rol-3-phosphate \\
\hline Rv2145c & wag31 & $\begin{array}{l}\text { acetylglucosaminyltransferase } \\
\text { antigen } 84 \text { (aka wag31) }\end{array}$ & Rv0677c & mmpS5 & $\begin{array}{l}\text { conserved small membrane } \\
\text { protein }\end{array}$ & Rv2833c & $\operatorname{ugp} B$ & $\begin{array}{l}\text { sn-glycerol-3-phosphate-binding } \\
\text { periplasmic lipoprotein }\end{array}$ \\
\hline Rv0431 & & ide (AT103) & & & & Rv2832c & ugpc & sn-glycerol-3-phosphate transport \\
\hline Rv0954 & - & cell envelope ant & 5. Other me & embrane $p$ & protein & & & ATP-bindir \\
\hline Rv1514c & - & $\begin{array}{l}\text { involved in polysaccharide syn- } \\
\text { thesis }\end{array}$ & & ocesses & & Rv2834c & ugpE & $\begin{array}{l}\text { sn-glycerol-3-phosphate transport } \\
\text { system protein }\end{array}$ \\
\hline Rv1518 & - & involved in exopolysaccharide & A. Transpor & rt/binding & proteins & $\begin{array}{l}\text { Rv2316 } \\
\text { Rv2318 }\end{array}$ & uspA & ort protein \\
\hline Rv1758 & - & $\begin{array}{l}\text { synt } \\
\text { part }\end{array}$ & $\begin{array}{l}\text { 1. Amino ac } \\
\text { Rv2127 }\end{array}$ & $\begin{array}{l}\text { cids } \\
\text { ansP }\end{array}$ & & & $\begin{array}{l}\text { uspC } \\
\text { uspe }\end{array}$ & $\begin{array}{l}\text { brotein } \\
\text { rotein }\end{array}$ \\
\hline Rv1910c & - & ted protein & Rv0346c & arop2 & o acid & Rv1 & & ansporter \\
\hline Rv1919c & - & pollen antigens & & & pe & Rv2038c & - & ugar transporter \\
\hline Rv1984c & - & otein & Rv0917 & betP & gly & Rv2039c & - & er \\
\hline Rv1987 & - & ecreted protein & Rv1704c & $c y c A$ & -alanine, D-serine & Rv2040c & - & ar transporter \\
\hline Rv2223c & - & ported protease & & & and $\mathrm{g}$ & Rv2041c & - & probable sugar transporter \\
\hline Rv2224c & - & prob & Rv3666c & $d p p A$ & eptide transport system & & & \\
\hline Rv2301 & - & proba & & & perm & 4. Anions & & \\
\hline Rv2345 & - & $\begin{array}{l}\text { precursor of probable membrane } \\
\text { protein }\end{array}$ & Rv3665c & $d p p B$ & $\begin{array}{l}\text { probable peptide transport system } \\
\text { permease }\end{array}$ & $\begin{array}{l}\text { Rv2684 } \\
\text { Rv2685 }\end{array}$ & $\begin{array}{l}\operatorname{ars} A \\
\operatorname{ars} B\end{array}$ & $\begin{array}{l}\text { arsenical pump } \\
\text { arsenical pump }\end{array}$ \\
\hline Rv2672 & - & exported protease & Rv3664c & $d p p C$ & oeptide transport system & Rv3578 & $\operatorname{arsB2}$ & pump \\
\hline Rv3019c & - & & & & & Rv2643 & $\operatorname{arsC}$ & prob \\
\hline $\begin{array}{l}\text { Rv3036c } \\
\text { Rv3449 }\end{array}$ & & $\begin{array}{l}\text { probable secreted protein } \\
\text { probable precursor of serine pro- }\end{array}$ & $\begin{array}{l}\text { Rv3663c } \\
\text { Rv0522 }\end{array}$ & $\begin{array}{l}d p p D \\
g a b P\end{array}$ & $\begin{array}{l}\text { probable ABC-transporter } \\
\text { probable } 4 \text {-amino butyrate trans- }\end{array}$ & Rv2397c & cysA & $\begin{array}{l}\text { sulphate transport ATP-binding } \\
\text { protein }\end{array}$ \\
\hline & & $\begin{array}{l}\text { tease } \\
\text { probable cutinase }\end{array}$ & & $g \operatorname{lnH}$ & mine binding protein & Rv2399c & cyst & $\begin{array}{l}\text { sulphate transport system perme- } \\
\text { ase protein }\end{array}$ \\
\hline $\begin{array}{l}\text { Rv3452 } \\
\text { Rv3724 }\end{array}$ & $\begin{array}{l}- \\
-\end{array}$ & $\begin{array}{l}\text { probable cutinase precursor } \\
\text { probable cutinase precursor }\end{array}$ & Rv2564 & $g \ln Q$ & $\begin{array}{l}\text { probable ATP-binding transport } \\
\text { protein }\end{array}$ & Rv2398c & cysW & $\begin{array}{l}\text { sulphate transport system perme- } \\
\text { ase protein }\end{array}$ \\
\hline 3. Mur & & 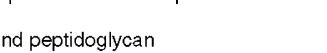 & Rv1280c & oppA & $\begin{array}{l}\text { probable oligopeptide transport } \\
\text { protein }\end{array}$ & $\begin{array}{l}\text { Rv1857 } \\
\text { Rv1858 }\end{array}$ & $\begin{array}{l}\bmod A \\
\bmod B\end{array}$ & $\begin{array}{l}\text { molybdate binding protein } \\
\text { transport system permease, }\end{array}$ \\
\hline Rv2911 & $d a c B$ & & Rv1283c & $o p p B$ & & & & \\
\hline $\begin{array}{l}\text { Rv2981c } \\
\text { Rv3809c }\end{array}$ & dallA & D-alanine ligase A & Rv1282c & oppC & oligopeptide transport system per- & Rv1859 & $\bmod C$ & molybdate uptake ABC- \\
\hline Rv1018c & gimU & $\begin{array}{l}\text { UDP-N-acetylglucosamine } \\
\text { pyrophosphorylase }\end{array}$ & $\begin{array}{l}\text { Rv1281c } \\
\text { Rv2320c }\end{array}$ & $\begin{array}{l}\text { oppD } \\
\text { rocE }\end{array}$ & $\begin{array}{l}\text { probable peptide transport protein } \\
\text { arginine/ornithine transporter }\end{array}$ & Rv1860 & $\bmod D$ & $\begin{array}{l}\text { precursor of Apa ( } 45 / 47 \\
\text { kD secreted protein) }\end{array}$ \\
\hline Rv3382c & $\mid y+B 1$ & ologue & Rv3253c & - & ionic amino acid & iv2329c & nark1 & xtrusion protein \\
\hline Rv1110 & lytB2 & & & & & iv1737c & nark2 & \\
\hline & murA & $\begin{array}{l}\text { UDP-N-acetylglucosamine-1-car- } \\
\text { boxyvinyltransferase }\end{array}$ & Rv3454 & - & possible proline permease & $\begin{array}{l}\text { Rv0261c } \\
\text { Rv0267 }\end{array}$ & $\begin{array}{l}\text { nark3 } \\
\text { narU }\end{array}$ & $\begin{array}{l}\text { nitrite extrusion protein } \\
\text { similar to nitrite extrusion }\end{array}$ \\
\hline Rv0482 & murB & yruvoylglu- & 2. Cations & & & & & \\
\hline & & & & $a m t$ & $r$ & Rv0934 & phost & hosphate \\
\hline Rv2152c & murC & UDP-N-acetyl-muramate-alanine & Rv1607 & chaA & & & & \\
\hline & & & Rv1239c & corA & & Rv0928 & phos2 & tS component of phosphate \\
\hline Rv2155c & murD & UDP-N-a & & & & & & \\
\hline & & & & & & & & \\
\hline $158 \mathrm{c}$ & MUrE & & Rv0103c & $\operatorname{ctpB}$ & & & & \\
\hline & & & & $\operatorname{ctpc}$ & & Rv3301c & phoYt & \\
\hline iv2157c & murF & $\begin{array}{l}\text { D-alanine:D-alanine-adding } \\
\text { enzyme }\end{array}$ & & $c t p D$ & le cadmium-transporting & Rv0821c & phoY2 & $\begin{array}{l}\text { or } \\
\text { hate transport system }\end{array}$ \\
\hline v2153c & murG & trar & & $\operatorname{ctp}$ & $\mathrm{pr}$ & & & \\
\hline & & & & & & Rv0545c & pitA & \\
\hline & murl & & Rv1992c & $\operatorname{ctp} G$ & & & & \\
\hline & murX & $\begin{array}{l}\text { phospho-N-acetylmuramoyl- } \\
\text { petapeptide transferase }\end{array}$ & Rv0425c & $\mathrm{ctpH}$ & $\begin{array}{l}\text { C-terminal region putative cation- } \\
\text { transporting ATPase }\end{array}$ & $\begin{array}{l}\text { Rv2281 } \\
\text { Rv0930 }\end{array}$ & $\begin{array}{l}\text { pitB } \\
\text { pstA1 }\end{array}$ & $\begin{array}{l}\text { phate permease } \\
\text { component of phosphate }\end{array}$ \\
\hline Rv3332 & $\operatorname{nag} A$ & $\mathrm{~N}$-acetylglucosamine-6-P- & Rv0107c & $c t p l$ & probable magnesium transport & & & uptake \\
\hline & & & & & & 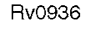 & pstA2 & \\
\hline Rv0016c & $p b p A$ & penicillin-binding protein & Rv0969 & $\operatorname{ctp} V$ & 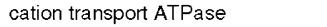 & & & uptake \\
\hline $\begin{array}{l}\text { Rv2 } 163 c \\
\text { Rv0050 }\end{array}$ & pbpB & penicillin-binding protein 2 & $\begin{array}{l}\text { Rv3044 } \\
\text { Rv0265c }\end{array}$ & fecB & $\begin{array}{l}\text { putative FellI-dicitrate transporter } \\
\text { iron transport protein Felll dici- }\end{array}$ & Rv0933 & pstB & ABC transport component of \\
\hline $\begin{array}{l}\text { Rv0050 } \\
\text { Rv3682 }\end{array}$ & $\begin{array}{l}\text { PONAT } \\
\text { ponA2 }\end{array}$ & $\begin{array}{l}\text { penicillin-bonding protein } \\
\text { class A penicillin binding protein }\end{array}$ & $\begin{array}{l}\text { Rv0265c } \\
\text { trate }\end{array}$ & & $\begin{array}{l}\text { iron transport protein Felll dici- } \\
\text { transporter }\end{array}$ & Rv0935 & pstC & PstC component of phosphate \\
\hline Rv0017c & $\operatorname{rod} A$ & FtsW/RodA/SpovE family & Rv1029 & kdpA & potassium-transporting ATPase A & & & uptake \\
\hline Rv0907 & & probable penicillin binding protein & & & chain & Rv0929 & pstC2 & membrane-bound component of \\
\hline
\end{tabular}




\begin{tabular}{|c|c|c|c|c|c|}
\hline & & phosphate transport system & & & unit \\
\hline Rv0932c & psts & $\begin{array}{l}\text { PstS component of phosphate } \\
\text { uptake }\end{array}$ & Rv1821 & $\sec A 2$ & $\begin{array}{l}\text { SecA, preprotein translocase sub- } \\
\text { unit }\end{array}$ \\
\hline Rv2400c & subl & sulphate binding precursor & Rv2587c & $\sec D$ & protein-export membrane protein \\
\hline Rv0143c & - & probable chloride channel & Rv0638 & $\sec E$ & SecE preprotein translocase \\
\hline Rv1707 & - & probable sulphate permease & Rv2586c & $\sec F$ & protein-export membrane protein \\
\hline Rv1739c & - & possible sulphate transporter & Rv1440 & $\sec G$ & protein-export membrane protein \\
\hline Rv3679 & - & possible anion transporter & & & SecG \\
\hline Rv3680 & - & probable anion transporter & Rv0732 & $\sec Y$ & $\begin{array}{l}\text { SecY subunit of preprotein translo- } \\
\text { case }\end{array}$ \\
\hline 5. Fatty aci & cid transpor & & Rv2462c & tig & chaperone protein, similar to \\
\hline Rv2790c & Itpl & non-specific lipid transport protein & & & trigger factor \\
\hline Rv3540c & ltp2 & non-specific lipid transport protein & Rv2813 & - & $\begin{array}{l}\text { probable general secretion path- } \\
\text { way protein }\end{array}$ \\
\hline 6. Efflux pr & roteins & & & & \\
\hline Rv2936 & drra & similar daunorubicin resistance & E. Adaptat & jons and & typical conditions \\
\hline & & ABC-transporter & Rv1901 & $\operatorname{cin} A$ & competence damage protein \\
\hline Rv2937 & $d r r B$ & $\begin{array}{l}\text { similar daunorubicin resistance } \\
\text { transmembrane protein }\end{array}$ & Rv3648c & $\operatorname{csp} A$ & $\begin{array}{l}\text { cold shock protein, transcriptional } \\
\text { regulator }\end{array}$ \\
\hline Rv2938 & $d r r C$ & similar daunorubicin resistance & Rv0871 & $\operatorname{csp} B$ & probable cold shock protein \\
\hline & & transmembrane protein & Rv3063 & $\operatorname{cst} A$ & starvation-induced stress \\
\hline Rv2846c & efpA & putative efflux protein & & & response protein \\
\hline Rv3065 & emrE & resistance to ethidium bromide & Rv3490 & otsA & probable $\alpha, \alpha$-trehalose-phosphate \\
\hline Rv0783c & - & multidrug resistance protein & & & synthase \\
\hline Rv0849 & - & possible quinolone efflux pump & Rv2006 & $o t s B$ & trehalose-6-phosphate phos- \\
\hline Rv1145 & - & probable drug transporter & & & phatase \\
\hline Rv1146 & - & probable drug transporter & Rv3372 & otsB2 & trehalose-6-phosphate phos- \\
\hline Rv1250 & - & probable drug efflux protein & & & phatase \\
\hline Rv1258c & - & $\begin{array}{l}\text { probable multidrug resistance } \\
\text { pump }\end{array}$ & $\begin{array}{l}\text { Rv3758c } \\
\text { Rv3757c }\end{array}$ & $\begin{array}{l}\text { prov } \\
\text { prow }\end{array}$ & $\begin{array}{l}\text { osmoprotection ABC transporter } \\
\text { transport system permease }\end{array}$ \\
\hline Rv1410c & - & probable drug efflux protein & Rv3759c & proX & similar to osmoprotection proteins \\
\hline Rv1634 & - & probable drug efflux protein & Rv3756c & proz & transport system permease \\
\hline Rv1819c & - & $\begin{array}{l}\text { probable multidrug resistance } \\
\text { pump }\end{array}$ & Rv1026 & - & $\begin{array}{l}\text { probable pppGpp-5'phosphohydro- } \\
\text { lase }\end{array}$ \\
\hline Rv2136c & - & $\begin{array}{l}\text { putative bacitracin resistance pro- } \\
\text { tein }\end{array}$ & F. Detoxific & iation & \\
\hline Rv2209 & - & probable drug efflux protein & Rv2428 & $a h p C$ & alkyl hydroperoxide reductase \\
\hline Rv2333c & - & $\begin{array}{l}\text { probable tetracenomycin } \mathrm{C} \text { resis- } \\
\text { tance protein }\end{array}$ & $\begin{array}{l}\text { Rv2429 } \\
\text { Rv2238c }\end{array}$ & $\begin{array}{l}\text { ahpD } \\
\text { ahpE }\end{array}$ & $\begin{array}{l}\text { member of AhpC/TSA family } \\
\text { member of AhpC/TSA family }\end{array}$ \\
\hline Rv2994 & - & probable fluoroquinolone efflux & Rv2521 & $b c p$ & bacterioferritin comigratory protein \\
\hline Rv1877 & - & $\begin{array}{l}\text { protein } \\
\text { probable drug efflux protein }\end{array}$ & Rv1608c & $b c p B$ & $\begin{array}{l}\text { probable bacterioferritin comigra- } \\
\text { tory protein }\end{array}$ \\
\hline Rv2459 & - & probable drug efflux protein & Rv3473c & bpoA & $\begin{array}{l}\text { probable non-heme bromoperoxi- } \\
\text { dase }\end{array}$ \\
\hline B. Chaperc & ones/Heat & shock & Rv1123c & bpoB & probable non-heme bromoperoxi- \\
\hline Rv0384c & $c / p B$ & heat shock protein & & & dase \\
\hline Rv0352 & dnas & $\begin{array}{l}\text { acts with GrpE to stimulate DnaK } \\
\text { ATPase }\end{array}$ & Rv0554 & bpoc & $\begin{array}{l}\text { probable non-heme bromoperoxi- } \\
\text { dase }\end{array}$ \\
\hline Rv2373c & $d n a J 2$ & DnaJ homologue & Rv3617 & ephA & probable epoxide hydrolase \\
\hline Rv0350 & dnak & $70 \mathrm{kD}$ heat shock protein, chromo- & Rv1938 & $e p h B$ & probable epoxide hydrolase \\
\hline & & some replication & Rv1124 & ephc & probable epoxide hydrolase \\
\hline Rv3417c & groEL1 & $60 \mathrm{kD}$ chaperonin 1 & Rv2214c & ephD & probable epoxide hydrolase \\
\hline Rv0440 & groEL2 & $60 \mathrm{kD}$ chaperonin 2 & Rv3670 & ephE & probable epoxide hydrolase \\
\hline Rv3418c & groEs & $10 \mathrm{kD}$ chaperone & Rv0134 & ephF & probable epoxide hydrolase \\
\hline Rv0351 & $g r p E$ & stimulates DnaK ATPase activity & Rv3171c & $h p x$ & probable non-heme haloperoxi- \\
\hline Rv2374c & hrcA & heat-inducible transcription & & & dase \\
\hline & & repressor & Rv1908c & katG & catalase-peroxidase \\
\hline Rv0251c & $h s p$ & possible heat shock protein & Rv3846 & sodA & superoxide dismutase \\
\hline Rv0353 & $h s p A$ & heat shock regulator & Rv0432 & sodC & superoxide dismutase precursor - \\
\hline Rv2031c & $h s p X$ & $14 \mathrm{kD}$ antigen, heat shock protein & & & $(\mathrm{Cu}-\mathrm{Zn})$ \\
\hline & & Hsp20 family & Rv1932 & $\operatorname{tpx}$ & thiol peroxidase \\
\hline Rv2299c & $h t p G$ & heat shock protein Hsp9o family & Rv0634c & - & putative glyoxylase II \\
\hline Rv0563 & htpX & probable (transmembrane) heat & Rv2581c & - & putative glyoxylase II \\
\hline & & shock protein & Rv3177 & - & probable non-heme haloperoxi- \\
\hline Rv2701c & $\operatorname{suh} B$ & $\begin{array}{l}\text { putative extragenic suppressor } \\
\text { protein }\end{array}$ & & & dase \\
\hline Rv3269 & & probable heat shock protein & IV. Other & & \\
\hline & & & A. Virulenc & & \\
\hline C. Cell divi & ision & & Rv0169 & mce 1 & cell invasion protein \\
\hline Rv3641c & fic & possible cell division protein & Rv0589 & mce2 & cell invasion protein \\
\hline Rv3102c & $f t s E$ & membrane protein & Rv1966 & mce3 & cell invasion protein \\
\hline Rv3610c & $f t s H$ & inner membrane protein, & Rv3499c & mce 4 & cell invasion protein \\
\hline v2748c & & chaperone & Rv3100c & $s m p B$ & probable small protein $b$ \\
\hline Rv2748c & ttsk & chromosome partitioning & Rv1694 & thya & cytotoxin/hemolysin homologue \\
\hline Rv2151c & $f t s Q$ & ingrowth of wall at septum & Rv0024 & - & putative $\mathrm{p} 60$ homologue \\
\hline Rv2154c & $f t s W$ & membrane protein (shape determi- & Rv0167 & - & part of mce 1 operon \\
\hline & & nation) & Rv0168 & - & part of mce 1 operon \\
\hline Rv3101c & $f t s X$ & membrane protein & Rv0170 & - & part of mce 1 operon \\
\hline Rv2921c & fts $Y$ & cell division protein FtsY & Rv0171 & - & part of mce 1 operon \\
\hline Rv2150c & $f t s Z$ & circumferential ring, GTPase & Rv0172 & - & part of mce 1 operon \\
\hline Rv3919c & gid & glucose inhibited division protein $B$ & Rv0174 & - & part of mce 1 operon \\
\hline Rv3625c & mess & probable cell cycle protein & Rv0587 & - & part of mce2 operon \\
\hline Rv3917c & parA & chromosome partitioning; DNA - & Rv0588 & - & part of mce 2 operon \\
\hline & & binding & Rv0590 & - & part of mce 2 operon \\
\hline Rv3918c & parB & possibly involved in chromosome & Rv0591 & - & part of mce 2 operon \\
\hline & & partitioning & Rv0592 & - & part of mce2 operon \\
\hline Rv2922c & $s m c$ & member of Smc1/Cut3/Cut 14 & Rv0594 & - & part of mce 2 operon \\
\hline & & family & Rv1085c & - & possible hemolysin \\
\hline Rv0012 & - & possible cell division protein & Rv1477 & - & putative exported p 60 protein \\
\hline Rv0435c & - & ATPase of AAA-family & & & homologue \\
\hline Rv2115c & - & ATPase of AAA-family & Rv1478 & - & putative exported p60 protein \\
\hline Rv3213c & - & possible role in chromosome seg- & & & homologue \\
\hline & & regation & Rv1566c & - & putative exported p 60 protein \\
\hline Rv1708 & - & possible role in chromosome parti- & & & homologue \\
\hline & & tioning & Rv1964 & - & part of mce 3 operon \\
\hline & & & Rv1965 & - & part of mce 3 operon \\
\hline D. Protein & and peptid & de secretion & Rv1967 & - & part of mce 3 operon \\
\hline Rv2916c & ffh & signal recognition particle protein & Rv1968 & - & part of mce 3 operon \\
\hline Rv2903c & lepB & signal peptidase I & Rv1969 & - & part of mce 3 operon \\
\hline Rv1614 & lgt & prolipoprotein diacylglyceryl trans- & Rv1971 & - & part of mce 3 operon \\
\hline & & ferase & Rv2190c & - & putative p60 homologue \\
\hline Rv1539 & Ispa & lipoprotein signal peptidase & Rv3494c & - & part of mce 4 operon \\
\hline Rv0379 & $\sec$ & probable transport protein & Rv3496c & - & part of mce 4 operon \\
\hline & & & Rv3497c & - & part of mce 4 operon \\
\hline & & & В & & \\
\hline
\end{tabular}

\section{E. Adaptations and atypical conditions}

Rv1901 cinA competence damage protein reld shock

obable cold shock protein response protein synthase

osmoprotection ABC transporte ransport system permease similar to osmoprotection protein robable pppGpp-5'phosphohydro-

(n) bacterioferritin comigratory protein tory protein

probable non-heme bromoperoxi-

Rv1123c bpoB

probable epoxide hydrolase probable epoxide hydrolase robable epoxide hydrolase probable epoxide hydrolase

uperoxide dismutase precursor -

robable non-heme haloperoxi-

cell invasion protein

cell invasion protein

ell invasion prote

cytotoxin/hemolysin homologue

putative $\mathrm{p} 60$ homologue

part of mce 1 operon

mce 1 opero

1 operon

utative exported 060 protein

omologue

part of mce 4 operon member of AhpC/TSA family

\begin{tabular}{|c|c|c|}
\hline Rv3500c & - & part of mce 4 operon \\
\hline Rv3501c & - & part of mce 4 operon \\
\hline Rv3896c & - & putative $\mathrm{p} 60$ homologue \\
\hline Rv3922c & - & possible hemolysin \\
\hline \multicolumn{3}{|c|}{$\begin{array}{l}\text { B. IS elements, Repeated sequences, and Phage } \\
\text { 1. IS elements }\end{array}$} \\
\hline \multirow{3}{*}{\multicolumn{2}{|c|}{$\begin{array}{l}\text { IS6110 } \\
\text { IS } 1081 \\
\text { Others }\end{array}$}} & 16 copies \\
\hline & & 6 copies \\
\hline & & 34 copies \\
\hline \multicolumn{2}{|c|}{ 2. REP $13 E 12$ family } & 7 copies \\
\hline \multicolumn{3}{|c|}{ 3. Phage-related functions } \\
\hline Rv2894c & xerc & integrase/recombinase \\
\hline Rv1701 & xerD & integrase/recombinase \\
\hline Rv1054 & - & integrase-a \\
\hline Rv1055 & - & integrase-b \\
\hline Rv1573 & - & phiRV1 phage related protein \\
\hline Rv1574 & - & phiRV1 phage related protein \\
\hline Rv1575 & - & phiRV1 phage related protein \\
\hline Rv1576c & - & phiRV1 phage related protein \\
\hline Rv1577c & - & phiRV1 possible prohead protease \\
\hline Rv1578c & - & phiRV1 phage related protein \\
\hline Rv1579c & - & phiRV1 phage related protein \\
\hline Rv1580c & - & phiRV1 phage related protein \\
\hline Rv1581c & - & phiRV1 phage related protein \\
\hline Rv1582c & & phiRV1 phage related protein \\
\hline Rv1583c & - & phiRV1 phage related protein \\
\hline Rv1584c & - & phiRV1 phage related protein \\
\hline Rv1585c & - & phiRV1 phage related protein \\
\hline Rv1586c & - & phiRV1 integrase \\
\hline Rv2309c & - & integrase \\
\hline Rv2310 & - & excisionase \\
\hline Rv2646 & - & phiRV2 integrase \\
\hline Rv2647 & - & phiRV2 phage related protein \\
\hline Rv2650c & - & phiRV2 phage related protein \\
\hline Rv2651c & - & phiRV2 prohead protease \\
\hline Rv2652c & - & phiRV2 phage related protein \\
\hline Rv2653c & - & phiRV2 phage related protein \\
\hline Rv2654c & - & phiRV2 phage related protein \\
\hline Rv2655c & - & phiRV2 phage related protein \\
\hline Rv2656c & - & phiRV2 phage related protein \\
\hline Rv2657c & - & $\begin{array}{l}\text { similar to gp36 of mycobacterio- } \\
\text { phage L5 }\end{array}$ \\
\hline Rv2658c & - & phiRV2 phage related protein \\
\hline Rv2659c & - & phiRV2 integrase \\
\hline Rv2830c & - & similar to phage $\mathrm{P} 1$ phd gene \\
\hline Rv3750c & - & excisionase \\
\hline Rv3751 & - & putative integrase \\
\hline
\end{tabular}

C. PE and PPE families

1. $P E$ family

PE subfamily 38 members

PE_PGRS subfamily 61 members

2. PPE family 68 members

$D$. Antibiotic production and resistance

Rv2068c blac class A $\beta$-lactamase

Rv3290c lat lysine- $\epsilon$ aminotransferase

Rv2043c pncA pyrazinamide resistance/sensitivity

Rv0133 - possible puromycin $\mathrm{N}$-acetyltrans-

ferase

- aminoglycoside 2'-N-acetyltrans-

Rv0802c - acetyltransferase

Rv1082 - similar to S lincolnensis ImbE

Rv1170 - similar to S. lincoinensis ImbE

Rv1347c - possible aminoglycoside 6'-N-

Rv2036 - $\quad \begin{aligned} & \text { acetyltransferase } \\ & \text { similar to lincomycin production }\end{aligned}$

Rv2303c - $\quad$ gimilar to S. griseus macrotetrolide

Rv3225c - $\quad$ resistance protein

photransferases

$\begin{array}{lll}\text { Rv3700c - } & \text { probable acetyltransferase } \\ \text { Rv3817 } & \text { probable aminoglycoside } 3^{\prime} \text {-phos- }\end{array}$ photransferase

E. Bacteriocin-like proteins

F. Cytochrome P450 enzymes 22

G. Coenzyme F420-dependent enzymes

H. Miscellaneous transferases $\quad 61$

1. Miscellaneous phosphatases, lyases, and hydrolases 18

J. Cyclases 6

K. Chelatases

V. Conserved hypotheticals 912

VI. Unknowns 606

TOTAL 3924 


\title{
Deciphering the biology of
} Mycobacterium tuberculosis from the complete genome sequence

\author{
S. T. Cole ${ }^{\star}$, R. Brosch ${ }^{\star}$ J. Parkhill, T. Garnier ${ }^{\star}$, C. Churcher, D. Harris, S. V. Gordon ${ }^{\star}$ K. Eiglmeier ${ }^{\star}$, S. Gas*, \\ C. E. Barry III $\dagger$, F. Tekaia $\ddagger$, K. Badcock, D. Basham, D. Brown, T. Chillingworth, R. Connor, R. Davies, \\ K. Devlin, T. Feltwell, S. Gentles, N. Hamlin, S. Holroyd, T. Hornsby, K. Jagels, A. Krogh\$, J. McLean, \\ S. Moule, L. Murphy, K. Oliver, J. Osborne, M. A. Quail, M.-A. Rajandream, J. Rogers, S. Rutter, \\ K. Seeger, J. Skelton, R. Squares, S. Squares, J. E. Sulston, K. Taylor, S. Whitehead \& B. G. Barrell \\ Sanger Centre, Wellcome Trust Genome Campus, Hinxton CB10 1SA, UK \\ * Unité de Génétique Moléculaire Bactérienne, and $\ddagger$ Unité de Génétique Moléculaire des Levures, Institut Pasteur, 28 rue du Docteur Roux, 75724 Paris Cedex 15, France \\ $\dagger$ Tuberculosis Research Unit, Laboratory of Intracellular Parasites, Rocky Mountain Laboratories, National Institute of Allergy and Infectious Diseases, National \\ Institutes of Health, Hamilton, Montana 59840, USA \\ $\$$ Center for Biological Sequence Analysis, Technical University of Denmark, Lyngby, Denmark
}

Countless millions of people have died from tuberculosis, a chronic infectious disease caused by the tubercle bacillus. The complete genome sequence of the best-characterized strain of Mycobacterium tuberculosis, H37Rv, has been determined and analysed in order to improve our understanding of the biology of this slow-growing pathogen and to help the conception of new prophylactic and therapeutic interventions. The genome comprises $4,411,529$ base pairs, contains around 4,000 genes, and has a very high guanine + cytosine content that is reflected in the biased amino-acid content of the proteins. M. tuberculosis differs radically from other bacteria in that a very large portion of its coding capacity is devoted to the production of enzymes involved in lipogenesis and lipolysis, and to two new families of glycine-rich proteins with a repetitive structure that may represent a source of antigenic variation.

Despite the availability of effective short-course chemotherapy (DOTS) and the Bacille Calmette-Guerin (BCG) vaccine, the tubercle bacillus continues to claim more lives than any other single infectious agent ${ }^{1}$. Recent years have seen increased incidence of tuberculosis in both developing and industrialized countries, the widespread emergence of drug-resistant strains and a deadly synergy with the human immunodeficiency virus (HIV). In 1993, the gravity of the situation led the World Health Organisation (WHO) to declare tuberculosis a global emergency in an attempt to heighten public and political awareness. Radical measures are needed now to prevent the grim predictions of the WHO becoming reality. The combination of genomics and bioinformatics has the potential to generate the information and knowledge that will enable the conception and development of new therapies and interventions needed to treat this airborne disease and to elucidate the unusual biology of its aetiological agent, Mycobacterium tuberculosis.

The characteristic features of the tubercle bacillus include its slow growth, dormancy, complex cell envelope, intracellular pathogenesis and genetic homogeneity ${ }^{2}$. The generation time of $M$. tuberculosis, in synthetic medium or infected animals, is typically $\sim 24$ hours. This contributes to the chronic nature of the disease, imposes lengthy treatment regimens and represents a formidable obstacle for researchers. The state of dormancy in which the bacillus remains quiescent within infected tissue may reflect metabolic shutdown resulting from the action of a cell-mediated immune response that can contain but not eradicate the infection. As immunity wanes, through ageing or immune suppression, the dormant bacteria reactivate, causing an outbreak of disease often many decades after the initial infection ${ }^{3}$. The molecular basis of dormancy and reactivation remains obscure but is expected to be genetically programmed and to involve intracellular signalling pathways.

The cell envelope of M. tuberculosis, a Gram-positive bacterium with a $\mathrm{G}+\mathrm{C}$-rich genome, contains an additional layer beyond the peptidoglycan that is exceptionally rich in unusual lipids, glycoli- pids and polysaccharides ${ }^{4,5}$. Novel biosynthetic pathways generate cell-wall components such as mycolic acids, mycocerosic acid, phenolthiocerol, lipoarabinomannan and arabinogalactan, and several of these may contribute to mycobacterial longevity, trigger inflammatory host reactions and act in pathogenesis. Little is known about the mechanisms involved in life within the macrophage, or the extent and nature of the virulence factors produced by the bacillus and their contribution to disease.

It is thought that the progenitor of the M. tuberculosis complex, comprising M. tuberculosis, M. bovis, M. bovis BCG, M. africanum and $M$. microti, arose from a soil bacterium and that the human bacillus may have been derived from the bovine form following the domestication of cattle. The complex lacks interstrain genetic diversity, and nucleotide changes are very rare ${ }^{6}$. This is important in terms of immunity and vaccine development as most of the proteins will be identical in all strains and therefore antigenic drift will be restricted. On the basis of the systematic sequence analysis of 26 loci in a large number of independent isolates ${ }^{6}$, it was concluded that the genome of $M$. tuberculosis is either unusually inert or that the organism is relatively young in evolutionary terms.

Since its isolation in 1905, the H37Rv strain of M. tuberculosis has found extensive, worldwide application in biomedical research because it has retained full virulence in animal models of tuberculosis, unlike some clinical isolates; it is also susceptible to drugs and amenable to genetic manipulation. An integrated map of the 4.4 megabase $(\mathrm{Mb})$ circular chromosome of this slow-growing pathogen had been established previously and ordered libraries of cosmids and bacterial artificial chromosomes (BACs) were available ${ }^{7,8}$.

\section{Organization and sequence of the genome}

Sequence analysis. To obtain the contiguous genome sequence, a combined approach was used that involved the systematic sequence analysis of selected large-insert clones (cosmids and BACs) as well as 
random small-insert clones from a whole-genome shotgun library. This culminated in a composite sequence of $4,411,529$ base pairs (bp) (Figs 1,2), with a G $+\mathrm{C}$ content of $65.6 \%$. This represents the second-largest bacterial genome sequence currently available (after that of Escherichia coli $)^{9}$. The initiation codon for the $d n a A$ gene, a hallmark for the origin of replication, oriC, was chosen as the start point for numbering. The genome is rich in repetitive DNA, particularly insertion sequences, and in new multigene families and duplicated housekeeping genes. The $\mathrm{G}+\mathrm{C}$ content is relatively constant throughout the genome (Fig. 1) indicating that horizontally transferred pathogenicity islands of atypical base composition are probably absent. Several regions showing higher than average $G$ $+\mathrm{C}$ content (Fig. 1) were detected; these correspond to sequences belonging to a large gene family that includes the polymorphic $\mathrm{G}+$ C-rich sequences (PGRSs).

Genes for stable RNA. Fifty genes coding for functional RNA molecules were found. These molecules were the three species produced by the unique ribosomal RNA operon, the 10Sa RNA involved in degradation of proteins encoded by abnormal messenger RNA, the RNA component of RNase P, and 45 transfer RNAs. No 4.5S RNA could be detected. The rrn operon is situated unusually as it occurs about 1,500 kilobases $(\mathrm{kb})$ from the putative oriC; most eubacteria have one or more $\mathrm{rrn}$ operons near to oriC to exploit the gene-dosage effect obtained during replication ${ }^{10}$. This arrangement may be related to the slow growth of $M$. tuberculosis. The genes encoding tRNAs that recognize 43 of the 61 possible sense codons were distributed throughout the genome and, with one

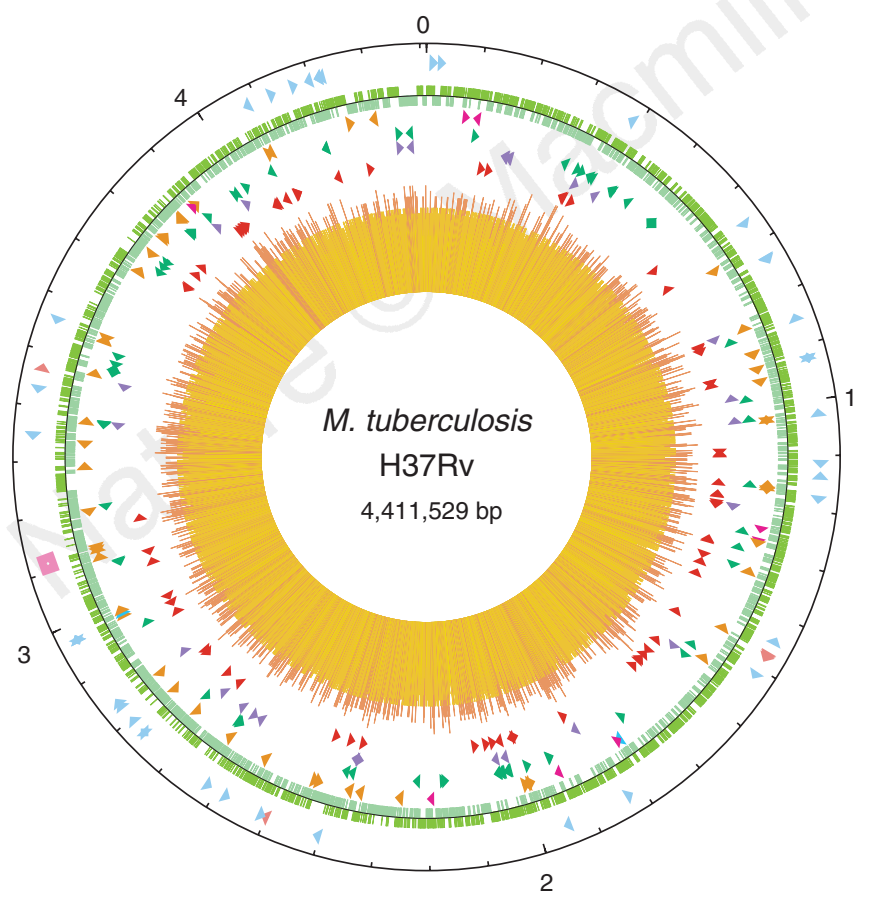

Figure 1 Circular map of the chromosome of M. tuberculosis H37Rv. The outer circle shows the scale in $\mathrm{Mb}$, with 0 representing the origin of replication. The first ring from the exterior denotes the positions of stable RNA genes (tRNAs are blue, others are pink) and the direct repeat region (pink cube); the second ring inwards shows the coding sequence by strand (clockwise, dark green; anticlockwise, light green); the third ring depicts repetitive DNA (insertion sequences, orange; $13 \mathrm{E} 12$ REP family, dark pink; prophage, blue); the fourth ring shows the positions of the PPE family members (green); the fifth ring shows the PE family members (purple, excluding PGRS); and the sixth ring shows the positions of the PGRS sequences (dark red). The histogram (centre) represents $\mathrm{G}+\mathrm{C}$ content, with $<65 \% \mathrm{G}+\mathrm{C}$ in yellow, and $>65 \% \mathrm{G}+\mathrm{C}$ in red. The figure was generated with software from DNASTAR. exception, none of these uses $\mathrm{A}$ in the first position of the anticodon, indicating that extensive wobble occurs during translation. This is consistent with the high $\mathrm{G}+\mathrm{C}$ content of the genome and the consequent bias in codon usage. Three genes encoding tRNAs for methionine were found; one of these genes $(\operatorname{met} V)$ is situated in a region that may correspond to the terminus of replication (Figs 1, 2 ). As $m e t V$ is linked to defective genes for integrase and excisionase, perhaps it was once part of a phage or similar mobile genetic element.

Insertion sequences and prophages. Sixteen copies of the promiscuous insertion sequence IS6110 and six copies of the more stable element IS1081 reside within the genome of $\mathrm{H} 37 \mathrm{Rv}^{8}$. One copy of IS1081 is truncated. Scrutiny of the genomic sequence led to the identification of a further 32 different insertion sequence elements, most of which have not been described previously, and of the 13E12 family of repetitive sequences which exhibit some of the characteristics of mobile genetic elements (Fig. 1). The newly discovered insertion sequences belong mainly to the IS 3 and IS256 families, although six of them define a new group. There is extensive similarity between IS1561 and IS1552 with insertion sequence elements found in Nocardia and Rhodococcus spp., suggesting that they may be widely disseminated among the actinomycetes.

Most of the insertion sequences in M. tuberculosis H37Rv appear to have inserted in intergenic or non-coding regions, often near tRNA genes (Fig. 1). Many are clustered, suggesting the existence of insertional hot-spots that prevent genes from being inactivated, as has been described for Rhizobium ${ }^{11}$. The chromosomal distribution of the insertion sequences is informative as there appears to have been a selection against insertions in the quadrant encompassing oriC and an overrepresentation in the direct repeat region that contains the prototype IS6110. This bias was also observed experimentally in a transposon mutagenesis study ${ }^{12}$.

At least two prophages have been detected in the genome sequence and their presence may explain why $M$. tuberculosis shows persistent low-level lysis in culture. Prophages phiRv1 and phiRv2 are both $\sim 10 \mathrm{~kb}$ in length and are similarly organized, and some of their gene products show marked similarity to those encoded by certain bacteriophages from Streptomyces and saprophytic mycobacteria. The site of insertion of phiRv1 is intriguing as it corresponds to part of a repetitive sequence of the 13E12 family that itself appears to have integrated into the biotin operon. Some strains of M. tuberculosis have been described as requiring biotin as a growth supplement, indicating either that phiRv1 has a polar effect on expression of the distal bio genes or that aberrant excision, leading to mutation, may occur. During the serial attenuation of $M$. bovis that led to the vaccine strain $M$. bovis BCG, the phiRv1 prophage was lost ${ }^{13}$. In a systematic study of the genomic diversity of prophages and insertion sequences (S.V.G. et al., manuscript in preparation), only IS1532 exhibited significant variability, indicating that most of the prophages and insertion sequences are currently stable. However, from these combined observations, one can conclude that horizontal transfer of genetic material into the free-living ancestor of the M. tuberculosis complex probably occurred in nature before the tubercle bacillus adopted its specialized intracellular niche.

Figure 2 Linear map of the chromosome of M. tuberculosis H37Rv showing the position and orientation of known genes and coding sequences (CDS). We used the following functional categories (adapted from ref. 20): lipid metabolism (black); intermediary metabolism and respiration (yellow); information pathways (pink); regulatory proteins (sky blue); conserved hypothetical proteins (orange); proteins of unknown function (light green); insertion sequences and phagerelated functions (blue); stable RNAs (purple); cell wall and cell processes (dark green); PE and PPE protein families (magenta); virulence, detoxification and adaptation (white). For additional information about gene functions, refer to http://www.sanger.ac.uk. 
Genes encoding proteins. 3,924 open reading frames were identified in the genome (see Methods), accounting for $\sim 91 \%$ of the potential coding capacity (Figs 1,2). A few of these genes appear to have in-frame stop codons or frameshift mutations (irrespective of the source of the DNA sequenced) and may either use frameshifting during translation or correspond to pseudogenes. Consistent with the high $\mathrm{G}+\mathrm{C}$ content of the genome, GTG initiation codons $(35 \%)$ are used more frequently than in Bacillus subtilis (9\%) and E. coli (14\%), although ATG (61\%) is the most common translational start. There are a few examples of atypical initiation codons, the most notable being the ATC used by infC, which begins with ATT in both B. subtilis and E. coli $i^{9,14}$. There is a slight bias in the orientation of the genes (Fig. 1) with respect to the direction of replication as $\sim 59 \%$ are transcribed with the same polarity as replication, compared with $75 \%$ in B. subtilis. In other bacteria, genes transcribed in the same direction as the replication forks are believed to be expressed more efficiently ${ }^{9,14}$. Again, the more even distribution in gene polarity seen in $M$. tuberculosis may reflect the slow growth and infrequent replication cycles. Three genes $(\operatorname{dnaB}, \operatorname{rec} A$ and Rv1461) have been invaded by sequences encoding inteins (protein introns) and in all three cases their counterparts in M. leprae also contain inteins, but at different $\operatorname{sites}^{15}$ (S.T.C. et al., unpublished observations).

Protein function, composition and duplication. By using various database comparisons, we attributed precise functions to $\sim 40 \%$ of the predicted proteins and found some information or similarity for another $44 \%$. The remaining $16 \%$ resembled no known proteins and may account for specific mycobacterial functions. Examination of the amino-acid composition of the M. tuberculosis proteome by correspondence analysis ${ }^{16}$, and comparison with that of other microorganisms whose genome sequences are available, revealed a statistically significant preference for the amino acids Ala, Gly, Pro, Arg and Trp, which are all encoded by $\mathrm{G}+\mathrm{C}$-rich codons, and a comparative reduction in the use of amino acids encoded by $\mathrm{A}+\mathrm{T}$ rich codons such as Asn, Ile, Lys, Phe and Tyr (Fig. 3). This approach also identified two groups of proteins rich in Asn or Gly that belong to new families, PE and PPE (see below). The fraction of the proteome that has arisen through gene duplication is similar to that seen in E. coli or B. subtilis ( $\sim 51 \%$; refs 9,14$)$, except that the level of sequence conservation is considerably higher, indicating that there may be extensive redundancy or differential production of the corresponding polypeptides. The apparent lack of divergence following gene duplication is consistent with the hypothesis that M. tuberculosis is of recent descent ${ }^{6}$.

\section{General metabolism, regulation and drug resistance}

Metabolic pathways. From the genome sequence, it is clear that the tubercle bacillus has the potential to synthesize all the essential amino acids, vitamins and enzyme co-factors, although some of the pathways involved may differ from those found in other bacteria. $M$. tuberculosis can metabolize a variety of carbohydrates, hydrocarbons, alcohols, ketones and carboxylic acids ${ }^{2,17}$. It is apparent from genome inspection that, in addition to many functions involved in lipid metabolism, the enzymes necessary for glycolysis, the pentose phosphate pathway, and the tricarboxylic acid and glyoxylate cycles are all present. A large number ( $\sim 200)$ of oxidoreductases, oxygenases and dehydrogenases is predicted, as well as many oxygenases containing cytochrome $\mathrm{P} 450$, that are similar to fungal proteins involved in sterol degradation. Under aerobic growth conditions, ATP will be generated by oxidative phosphorylation from electron transport chains involving a ubiquinone cytochrome $b$ reductase complex and cytochrome $c$ oxidase. Components of several anaerobic phosphorylative electron transport chains are also present, including genes for nitrate reductase (nar $G H J I)$, fumarate reductase ( $f r d A B C D)$ and possibly nitrite reductase (nirBD), as well as a new reductase $($ nar $X)$ that results from a rearrangement of a homologue of the narGHJI operon. Two genes encoding haemoglobin-like proteins, which may protect against oxidative stress or be involved in oxygen capture, were found. The ability of the bacillus to adapt its metabolism to environmental change is significant as it not only has to compete with the lung for oxygen but must also adapt to the microaerophilic/anaerobic environment at the heart of the burgeoning granuloma.

Regulation and signal transduction. Given the complexity of the environmental and metabolic choices facing M. tuberculosis, an extensive regulatory repertoire was expected. Thirteen putative sigma factors govern gene expression at the level of transcription initiation, and more than 100 regulatory proteins are predicted (Table 1). Unlike B. subtilis and E. coli, in which there are $>30$ copies of different two-component regulatory systems ${ }^{14}, M$. tuberculosis has only 11 complete pairs of sensor histidine kinases and response regulators, and a few isolated kinase and regulatory genes. This relative paucity in environmental signal transduction pathways is probably offset by the presence of a family of eukaryotic-like serine/ threonine protein kinases (STPKs), which function as part of a phosphorelay system ${ }^{18}$. The STPKs probably have two domains: the well-conserved kinase domain at the amino terminus is predicted to be connected by a transmembrane segment to the carboxy-terminal region that may respond to specific stimuli. Several of the predicted envelope lipoproteins, such as that encoded by $l_{p p} R$ (Rv2403), show extensive similarity to this putative receptor domain of STPKs, suggesting possible interplay. The STPKs probably function in signal transduction pathways and may govern important cellular decisions such as dormancy and cell division, and although their partners are unknown, candidate genes for phosphoprotein phosphatases have been identified.

Drug resistance. $M$. tuberculosis is naturally resistant to many antibiotics, making treatment difficult ${ }^{19}$. This resistance is due mainly to the highly hydrophobic cell envelope acting as a permeability barrier ${ }^{4}$, but many potential resistance determinants are also encoded in the genome. These include hydrolytic or drug-modifying enzymes such as $\beta$-lactamases and aminoglycoside acetyl transferases, and many potential drug-efflux systems, such as 14 members of the major facilitator family and numerous $\mathrm{ABC}$ transporters. Knowledge of these putative resistance mechanisms will promote better use of existing drugs and facilitate the conception of new therapies.

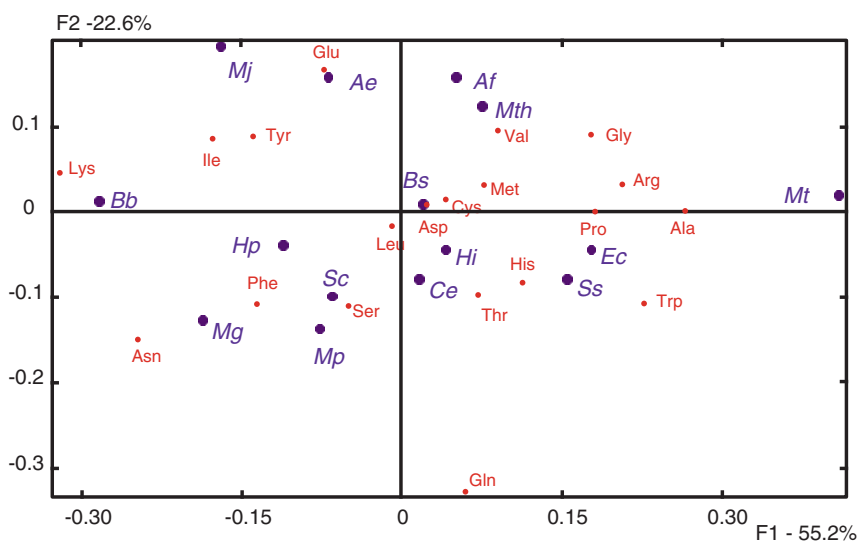

Figure 3 Correspondence analysis of the proteomes from extensively sequenced organisms as a function of amino-acid composition. Note the extreme position of $M$. tuberculosis and the shift in amino-acid preference reflecting increasing $\mathrm{G}+\mathrm{C}$ content from left to right. Abbreviations used: $A e$, Aquifex aeolicus; Af, Archaeoglobus fulgidis; Bb, Borrelia burgdorfei; Bs, $B$. subtilis; Ce, Caenorhabditis elegans; Ec, E. coli; Hi, Haemophilus influenzae; Hp, Helicobacter pylori; Mg, Mycoplasma genitalium; Mj, Methanococcus jannaschi; Mp, Mycoplasma pneumoniae; Mt, M. tuberculosis; Mth, Methanobacterium thermoautotrophicum; Sc, Saccharomyces cerevisiae; Ss, Synechocystis sp. strain PCC6803. F1 and F2, first and second factorial axes ${ }^{16}$. 
a

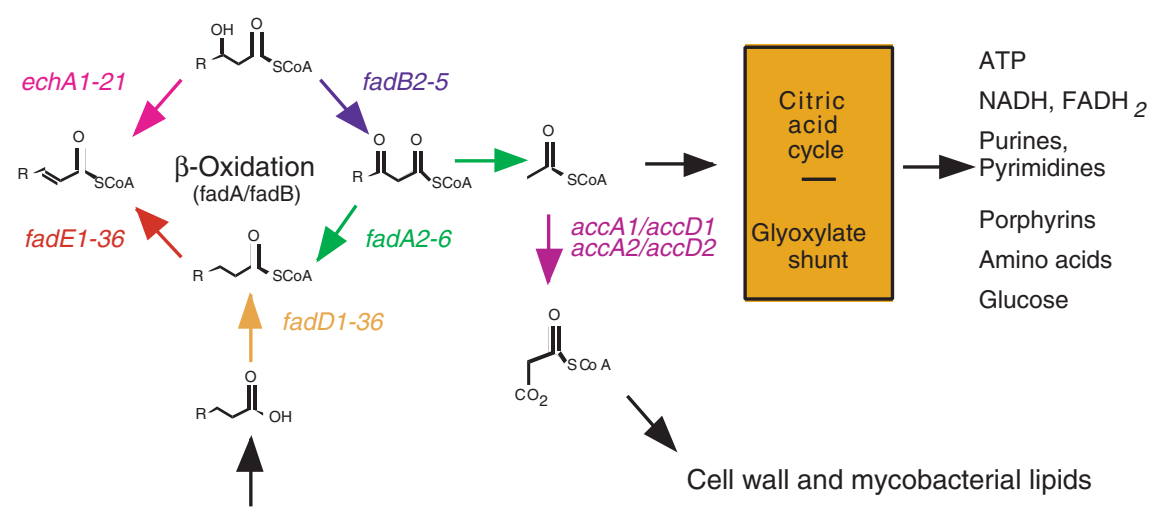

Host membranes

b
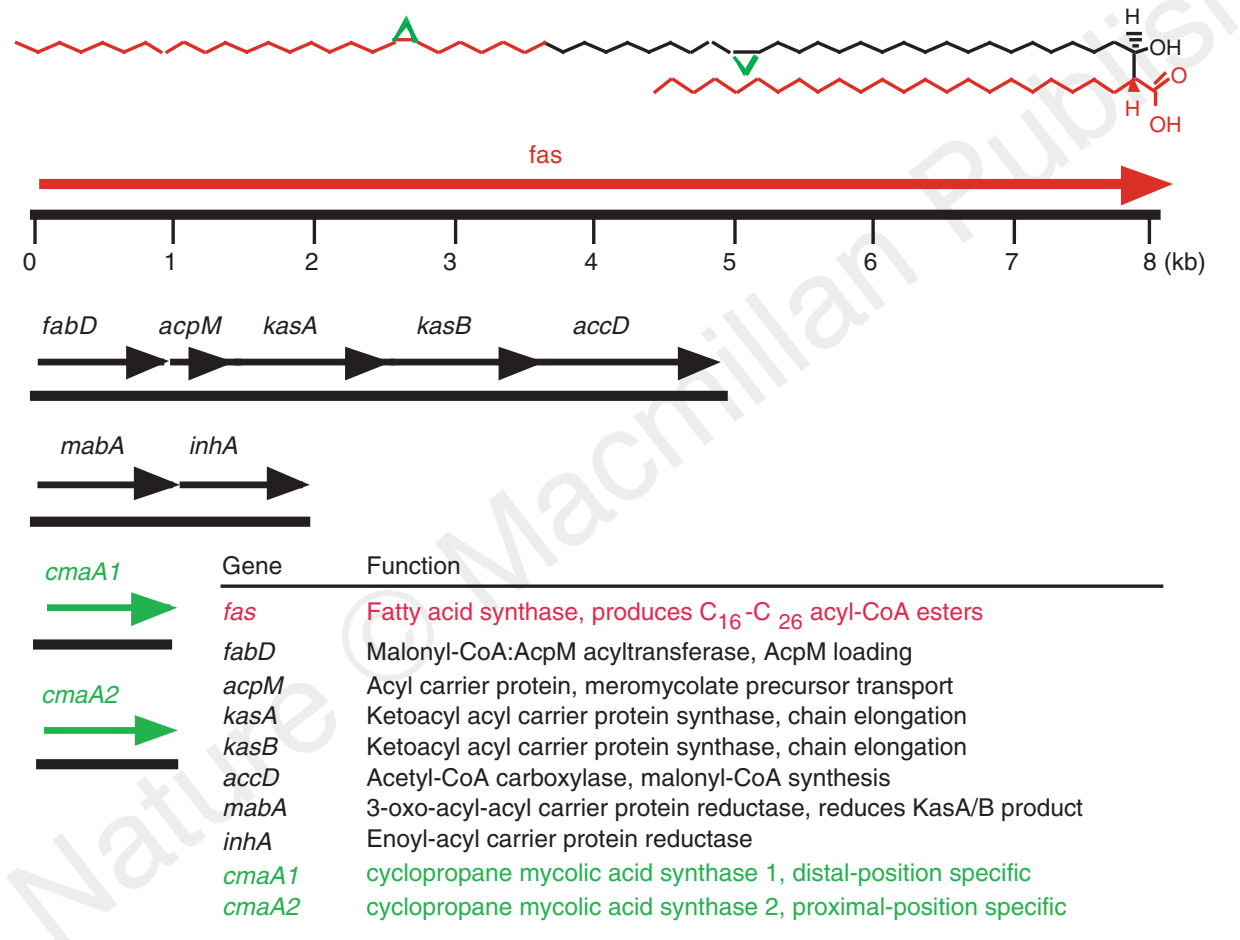

c

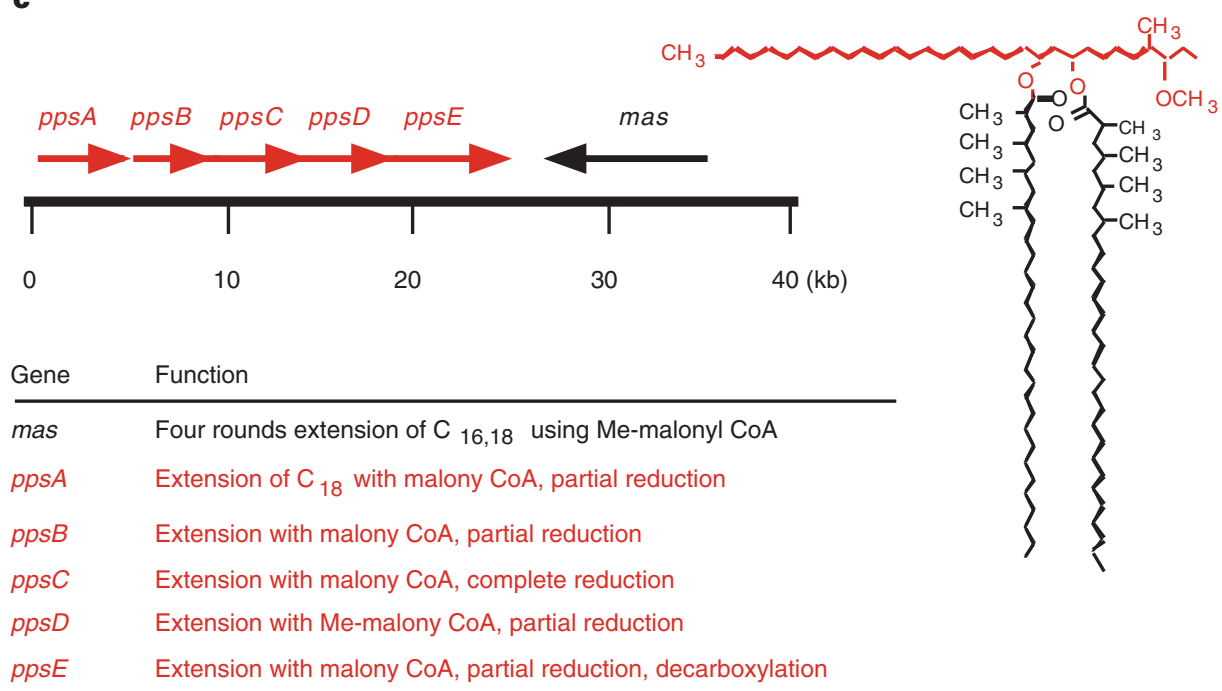

Figure $\mathbf{4}$ Lipid metabolism. a, Degradation of host-cell lipids is vital in the intracellular life of M. tuberculosis. Host-cell membranes provide precursors for many metabolic processes, as well as potential precursors of mycobacterial cell-wall constituents, through the actions of a broad family of $\beta$-oxidative enzymes encoded by multiple copies in the genome. These enzymes produce acetyl CoA, which can be converted into many different metabolites and fuel for the bacteria through the actions of the enzymes of the citric acid cycle and the glyoxylate shunt of this cycle. b. The genes that synthesize mycolic acids, the dominant lipid component of the mycobacterial cell wall, include the type I fatty acid synthase (fas) and a unique type II system which relies on extension of a precursor bound to an acyl carrier protein to form full-length ( $\sim 80$-carbon) mycolic acids. The cma genes are responsible for cyclopropanation. c, The genes that produce phthiocerol dimycocerosate form a large operon and represent type I (mas) and type II (the pps operon) polyketide synthase systems. Functions are colour coordinated. 


\section{Lipid metabolism}

Very few organisms produce such a diverse array of lipophilic molecules as $M$. tuberculosis. These molecules range from simple fatty acids such as palmitate and tuberculostearate, through isoprenoids, to very-long-chain, highly complex molecules such as mycolic acids and the phenolphthiocerol alcohols that esterify with mycocerosic acid to form the scaffold for attachment of the mycosides. Mycobacteria contain examples of every known lipid and polyketide biosynthetic system, including enzymes usually found in mammals and plants as well as the common bacterial systems. The biosynthetic capacity is overshadowed by the even more remarkable radiation of degradative, fatty acid oxidation systems and, in total, there are $\sim 250$ distinct enzymes involved in fatty acid metabolism in M. tuberculosis compared with only 50 in E. coli ${ }^{20}$.

Fatty acid degradation. In vivo-grown mycobacteria have been suggested to be largely lipolytic, rather than lipogenic, because of the variety and quantity of lipids available within mammalian cells and the tubercle ${ }^{2}$ (Fig. 4a). The abundance of genes encoding components of fatty acid oxidation systems found by our genomic approach supports this proposition, as there are 36 acyl-CoA synthases and a family of 36 related enzymes that could catalyse the first step in fatty acid degradation. There are 21 homologous enzymes belonging to the enoyl-CoA hydratase/isomerase superfamily of enzymes, which rehydrate the nascent product of the acylCoA dehydrogenase. The four enzymes that convert the 3-hydroxy fatty acid into a 3-keto fatty acid appear less numerous, mainly
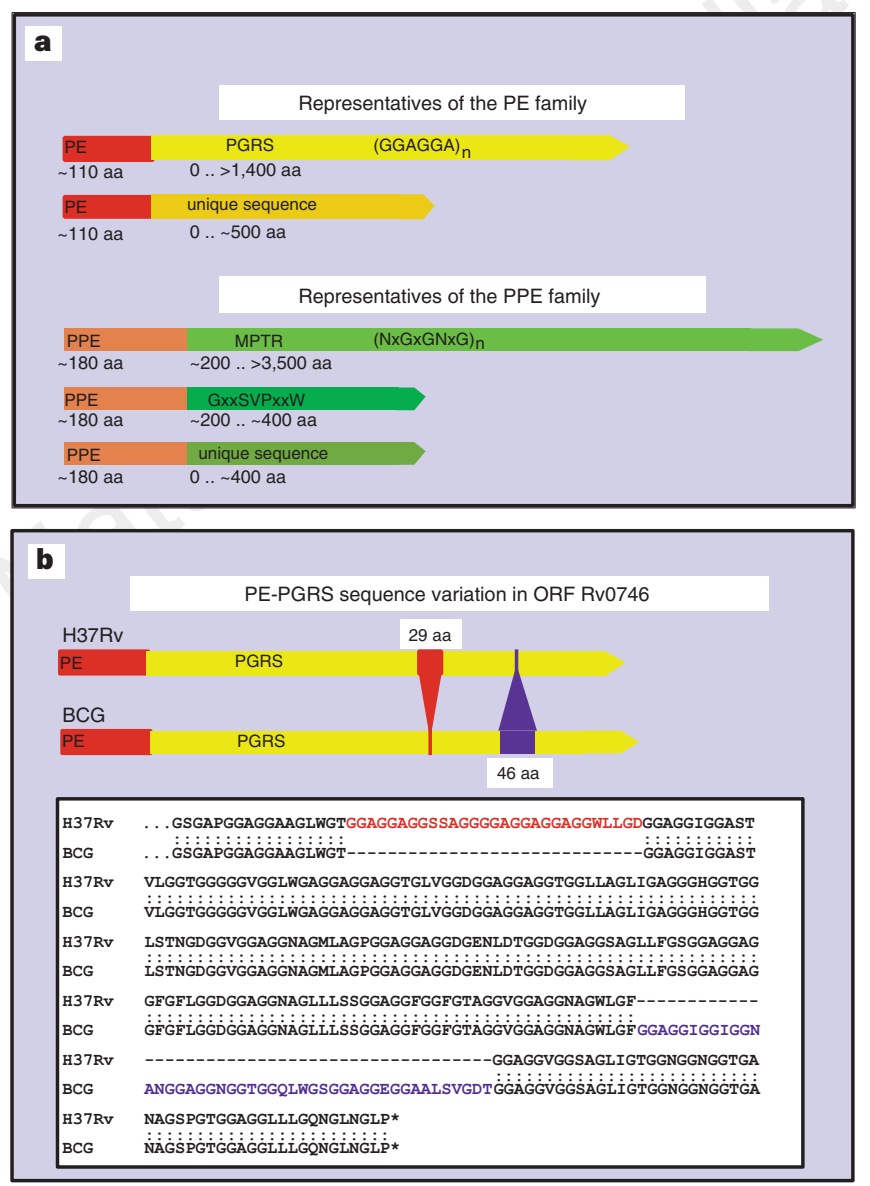

Figure $\mathbf{5}$ The PE and PPE protein families. a, Classification of the PE and PPE protein families. b. Sequence variation between $M$. tuberculosis H37Rv and $M$. bovis BCG-Pasteur in the PE-PGRS encoded by open reading frame (ORF) Rv0746. because they are difficult to distinguish from other members of the short-chain alcohol dehydrogenase family on the basis of primary sequence. The five enzymes that complete the cycle by thiolysis of the $\beta$-ketoester, the acetyl-CoA C-acetyltransferases, do indeed appear to be a more limited family. In addition to this extensive set of dissociated degradative enzymes, the genome also encodes the canonical FadA/FadB $\beta$-oxidation complex (Rv0859 and Rv0860). Accessory activities are present for the metabolism of odd-chain and multiply unsaturated fatty acids.

Fatty acid biosynthesis. At least two discrete types of enzyme system, fatty acid synthase (FAS) I and FAS II, are involved in fatty acid biosynthesis in mycobacteria (Fig. 4b). FAS I (Rv2524, fas) is a single polypeptide with multiple catalytic activities that generates several shorter CoA esters from acetyl-CoA primers ${ }^{5}$ and probably creates precursors for elongation by all of the other fatty acid and polyketide systems. FAS II consists of dissociable enzyme components which act on a substrate bound to an acyl-carrier protein (ACP). FAS II is incapable of de novo fatty acid synthesis but instead elongates palmitoyl-ACP to fatty acids ranging from 24 to 56 carbons in length ${ }^{17,21}$. Several different components of FAS II may be targets for the important tuberculosis drug isoniazid, including the enoyl-ACP reductase InhA ${ }^{22}$, the ketoacyl-ACP synthase KasA and the ACP AcpM ${ }^{21}$. Analysis of the genome shows that there are only three potential ketoacyl synthases: KasA and KasB are highly related, and their genes cluster with acpM, whereas $\mathrm{KasC}$ is a more distant homologue of a ketoacyl synthase III system. The number of ketoacyl synthase and ACP genes indicates that there is a single FAS II system. Its genetic organization, with two clustered ketoacyl synthases, resembles that of type II aromatic polyketide biosynthetic gene clusters, such as those for actinorhodin, tetracycline and tetracenomycin in Streptomyces species ${ }^{23}$. InhA seems to be the sole enoyl-ACP reductase and its gene is co-transcribed with a $f a b G$ homologue, which encodes 3-oxoacyl-ACP reductase. Both of these proteins are probably important in the biosynthesis of mycolic acids.

Fatty acids are synthesized from malonyl-CoA and precursors are generated by the enzymatic carboxylation of acetyl (or propionyl)CoA by a biotin-dependent carboxylase (Fig. 4b). From study of the genome we predict that there are three complete carboxylase systems, each consisting of an $\alpha$ - and a $\beta$-subunit, as well as three $\beta$-subunits without an $\alpha$-counterpart. As a group, all of the carboxylases seem to be more related to the mammalian homologues than to the corresponding bacterial enzymes. Two of these carboxylase systems ( $a c c A 1, a c c D 1$ and $a c c A 2, a c c D 2)$ are probably involved in degradation of odd-numbered fatty acids, as they are adjacent to genes for other known degradative enzymes. They may convert propionyl-CoA to succinyl-CoA, which can then be incorporated into the tricarboxylic acid cycle. The synthetic carboxylases ( $a c c A 3, a c c D 3, a c c D 4, a c c D 5$ and $a c c D 6)$ are more difficult to understand. The three extra $\beta$-subunits might direct carboxylation to the appropriate precursor or may simply increase the total amount of carboxylated precursor available if this step were ratelimiting.

Synthesis of the paraffinic backbone of fatty and mycolic acids in the cell is followed by extensive postsynthetic modifications and unsaturations, particularly in the case of the mycolic acids ${ }^{24,25}$. Unsaturation is catalysed either by a FabA-like $\beta$-hydroxyacylACP dehydrase, acting with a specific ketoacyl synthase, or by an aerobic terminal mixed function desaturase that uses both molecular oxygen and NADPH. Inspection of the genome revealed no obvious candidates for the FabA-like activity. However, three potential aerobic desaturases (encoded by $\operatorname{des} A 1, \operatorname{des} A 2$ and $\operatorname{des} A 3$ ) were evident that show little similarity to related vertebrate or yeast enzymes (which act on CoA esters) but instead resemble plant desaturases (which use ACP esters). Consequently, the genomic data indicate that unsaturation of the meromycolate chain may occur while the acyl group is bound to AcpM.

Much of the subsequent structural diversity in mycolic acids is 
generated by a family of $S$-adenosyl-L-methionine-dependent enzymes, which use the unsaturated meromycolic acid as a substrate to generate cis and trans cyclopropanes and other mycolates. Six members of this family have been identified and characterized ${ }^{25}$ and two clustered, convergently transcribed new genes are evident in the genome (umaA1 and umaA2). From the functions of the known family members and the structures of mycolic acids in $M$. tuberculosis, it is tempting to speculate that these new enzymes may introduce the trans cyclopropanes into the meromycolate precursor. In addition to these two methyltransferases, there are two other unrelated lipid methyltransferases (Ufa1 and Ufa2) that share homology with cyclopropane fatty acid synthase of $E$. coli ${ }^{25}$. Although cyclopropanation seems to be a relatively common modification of mycolic acids, cyclopropanation of plasma-membrane constituents has not been described in mycobacteria. Tuberculostearic acid is produced by methylation of oleic acid, and may be synthesized by one of these two enzymes.

Condensation of the fully functionalized and preformed meromycolate chain with a 26-carbon $\alpha$-branch generates full-length mycolic acids that must be transported to their final location for attachment to the cell-wall arabinogalactan. The transfer and subsequent transesterification is mediated by three well-known immunogenic proteins of the antigen 85 complex $^{26}$. The genome encodes a fourth member of this complex, antigen $85 \mathrm{C}^{\prime}(\mathrm{fbpC2}$, Rv0129), which is highly related to antigen $85 \mathrm{C}$. Further studies are needed to show whether the protein possesses mycolytransferase activity and to clarify the reason behind the apparent redundancy. Polyketide synthesis. Mycobacteria synthesize polyketides by several different mechanisms. A modular type I system, similar to that involved in erythromycin biosynthesis ${ }^{23}$, is encoded by a very large operon, $p p s A B C D E$, and functions in the production of phenolphthiocerol ${ }^{5}$. The absence of a second type I polyketide synthase suggests that the related lipids phthiocerol A and B, phthiodiolone A and phthiotriol may all be synthesized by the same system, either from alternative primers or by differential postsynthetic modification. It is physiologically significant that the $p p s$ gene cluster occurs immediately upstream of mas, which encodes the multifunctional enzyme mycocerosic acid synthase (MAS), as their products phthiocerol and mycocerosic acid esterify to form the very abundant cell-wall-associated molecule phthiocerol dimycocerosate (Fig. 4c).

Members of another large group of polyketide synthase enzymes are similar to MAS, which also generates the multiply methylbranched fatty acid components of mycosides and phthiocerol dimycocerosate, abundant cell-wall-associated molecules ${ }^{5}$. Although some of these polyketide synthases may extend type I FAS CoA primers to produce other long-chain methyl-branched fatty acids such as mycolipenic, mycolipodienic and mycolipanolic acids or the phthioceranic and hydroxyphthioceranic acids, or may even show functional overlap ${ }^{5}$, there are many more of these enzymes than there are known metabolites. Thus there may be new lipid and polyketide metabolites that are expressed only under certain conditions, such as during infection and disease.

A fourth class of polyketide synthases is related to the plant enzyme superfamily that includes chalcone and stilbene synthase ${ }^{23}$. These polyketide synthases are phylogenetically divergent from all other polyketide and fatty acid synthases and generate unreduced polyketides that are typically associated with anthocyanin pigments and flavonoids. The function of these systems, which are often linked to apparent type I modules, is unknown. An example is the gene cluster spanning $p k s 10, p k s 7, p k s 8$ and $p k s 9$, which includes two of the chalcone-synthase-like enzymes and two modules of an apparent type I system. The unknown metabolites produced by these enzymes are interesting because of the potent biological activities of some polyketides such as the immunosuppressor rapamycin.

Siderophores. Peptides that are not ribosomally synthesized are made by a process that is mechanistically analogous to polyketide synthesis $^{23,27}$. These peptides include the structurally related ironscavenging siderophores, the mycobactins and the exochelins ${ }^{2,28}$, which are derived from salicylate by the addition of serine (or threonine), two lysines and various fatty acids and possible polyketide segments. The mbt operon, encoding one apparent salicylateactivating protein, three amino-acid ligases, and a single module of a type I polyketide synthase, may be responsible for the biosynthesis of the mycobacterial siderophores. The presence of only one nonribosomal peptide-synthesis system indicates that this pathway may generate both siderophores and that subsequent modification of a single $\epsilon$-amino group of one lysine residue may account for the different physical properties and function of the siderophores ${ }^{28}$.

\section{Immunological aspects and pathogenicity}

Given the scale of the global tuberculosis burden, vaccination is not only a priority but remains the only realistic public health intervention that is likely to affect both the incidence and the prevalence of the disease ${ }^{29}$. Several areas of vaccine development are promising, including DNA vaccination, use of secreted or surface-exposed proteins as immunogens, recombinant forms of BCG and rational attenuation of $M$. tuberculosis ${ }^{29}$. All of these avenues of research will benefit from the genome sequence as its availability will stimulate more focused approaches. Genes encoding 90 lipoproteins were identified, some of which are enzymes or components of transport systems, and a similar number of genes encoding preproteins (with type I signal peptides) that are probably exported by the Secdependent pathway. M. tuberculosis seems to have two copies of secA. The potent T-cell antigen Esat-6 (ref. 30), which is probably secreted in a Sec-independent manner, is encoded by a member of a multigene family. Examination of the genetic context reveals several similarly organized operons that include genes encoding large ATPhydrolysing membrane proteins that might act as transporters. One of the surprises of the genome project was the discovery of two extensive families of novel glycine-rich proteins, which may be of immunological significance as they are predicted to be abundant and potentially polymorphic antigens.

The PE and PPE multigene families. About $10 \%$ of the coding capacity of the genome is devoted to two large unrelated families of acidic, glycine-rich proteins, the PE and PPE families, whose genes are clustered (Figs 1,2) and are often based on multiple copies of the polymorphic repetitive sequences referred to as PGRSs, and major polymorphic tandem repeats (MPTRs), respectively ${ }^{31,32}$. The names PE and PPE derive from the motifs Pro-Glu (PE) and Pro-ProGlu (PPE) found near the $\mathrm{N}$ terminus in most cases ${ }^{33}$. The 99 members of the PE protein family all have a highly conserved Nterminal domain of $\sim 110$ amino-acid residues that is predicted to have a globular structure, followed by a C-terminal segment that varies in size, sequence and repeat copy number (Fig. 5). Phylogenetic analysis separated the PE family into several subfamilies. The largest of these is the highly repetitive PGRS class, which contains 61 members; members of the other subfamilies, share very limited sequence similarity in their C-terminal domains (Fig. 5). The predicted molecular weights of the PE proteins vary considerably as a few members contain only the $\mathrm{N}$-terminal domain, whereas most have C-terminal extensions ranging in size from 100 to 1,400 residues. The PGRS proteins have a high glycine content (up to $50 \%$ ), which is the result of multiple tandem repetitions of GlyGly-Ala or Gly-Gly-Asn motifs, or variations thereof.

The 68 members of the PPE protein family (Fig. 5) also have a conserved N-terminal domain that comprises $\sim 180$ amino-acid residues, followed by $\mathrm{C}$-terminal segments that vary markedly in sequence and length. These proteins fall into at least three groups, one of which constitutes the MPTR class characterized by the presence of multiple, tandem copies of the motif Asn-X-Gly-XGly-Asn-X-Gly. The second subgroup contains a characteristic, well-conserved motif around position 350, whereas the third contains 
proteins that are unrelated except for the presence of the common 180-residue PPE domain.

The subcellular location of the PE and PPE proteins is unknown and in only one case, that of a lipase (Rv3097), has a function been demonstrated. On examination of the protein database from the extensively sequenced $M$. leprae ${ }^{15}$, no PGRS- or MPTR-related polypeptides were detected but a few proteins belonging to the non-MPTR subgroup of the PPE family were found. These proteins include one of the major antigens recognized by leprosy patients, the serine-rich antigen ${ }^{34}$. Although it is too early to attribute biological functions to the PE and PPE families, it is tempting to speculate that they could be of immunological importance. Two interesting possibilities spring to mind. First, they could represent the principal source of antigenic variation in what is otherwise a genetically and antigenically homogeneous bacterium. Second, these glycine-rich proteins might interfere with immune responses by inhibiting antigen processing.

Several observations and results support the possibility of antigenic variation associated with both the PE and the PPE family proteins. The PGRS member Rv1759 is a fibronectin-binding protein of relative molecular mass 55,000 (ref. 35) that elicits a variable antibody response, indicating either that individuals mount different immune responses or that this PGRS protein may vary between strains of $M$. tuberculosis. The latter possibility is supported by restriction fragment length polymorphisms for various PGRS and MPTR sequences in clinical isolates ${ }^{33}$. Direct support for genetic variation within both the PE and the PPE families was obtained by comparative DNA sequence analysis (Fig. 5). The gene for the PE-PGRS protein Rv0746 of BCG differs from that in H37Rv by the deletion of 29 codons and the insertion of 46 codons. Similar variation was seen in the gene for the PPE protein Rv0442 (data not shown). As these differences were all associated with repetitive sequences they could have resulted from intergenic or intragenic recombinational events or, more probably, from strand slippage during replication ${ }^{32}$. These mechanisms are known to generate antigenic variability in other bacterial pathogens ${ }^{36}$.

There are several parallels between the PGRS proteins and the Epstein-Barr virus nuclear antigens (EBNAs). Members of both polypeptide families are glycine-rich, contain extensive Gly-Ala repeats, and exhibit variation in the length of the repeat region between different isolates. The Gly-Ala repeat region of EBNA1 functions as a cis-acting inhibitor of the ubiquitin/proteasome antigen-processing pathway that generates peptides presented in the context of major histocompatibility complex (MHC) class I molecules ${ }^{37,38}$. MHC class I knockout mice are very susceptible to $M$. tuberculosis, underlining the importance of a cytotoxic T-cell response in protection against disease $\mathrm{s}^{3,39}$. Given the many potential effects of the PPE and PE proteins, it is important that further studies are performed to understand their activity. If extensive antigenic variability or reduced antigen presentation were indeed found, this would be significant for vaccine design and for understanding protective immunity in tuberculosis, and might even explain the varied responses seen in different BCG vaccination programmes $^{40}$.

Pathogenicity. Despite intensive research efforts, there is little information about the molecular basis of mycobacterial virulence ${ }^{41}$. However, this situation should now change as the genome sequence will accelerate the study of pathogenesis as never before, because other bacterial factors that may contribute to virulence are becoming apparent. Before the completion of the genome sequence, only three virulence factors had been described ${ }^{41}$ : catalase-peroxidase, which protects against reactive oxygen species produced by the phagocyte; mce, which encodes macrophage-colonizing factor ${ }^{42}$; and a sigma factor gene, sigA (aka $r p o V$ ), mutations in which can lead to attenuation ${ }^{41}$. In addition to these single-gene virulence factors, the mycobacterial cell wall ${ }^{4}$ is also important in pathology, but the complex nature of its biosynthesis makes it difficult to identify critical genes whose inactivation would lead to attenuation.

On inspection of the genome sequence, it was apparent that four copies of mce were present and that these were all situated in operons, comprising eight genes, organized in exactly the same manner. In each case, the genes preceding mce code for integral membrane proteins, whereas mce and the following five genes are all predicted to encode proteins with signal sequences or hydrophobic stretches at the $\mathrm{N}$ terminus. These sets of proteins, about which little is known, may well be secreted or surface-exposed; this is consistent with the proposed role of Mce in invasion of host cells ${ }^{42}$. Furthermore, a homologue of $\operatorname{smp} B$, which has been implicated in intracellular survival of Salmonella typhimurium, has also been identified $^{43}$. Among the other secreted proteins identified from the genome sequence that could act as virulence factors are a series of phospholipases C, lipases and esterases, which might attack cellular or vacuolar membranes, as well as several proteases. One of these phospholipases acts as a contact-dependent haemoly$\sin (\mathrm{N}$. Stoker, personal communication). The presence of storage proteins in the bacillus, such as the haemoglobin-like oxygen captors described above, points to its ability to stockpile essential growth factors, allowing it to persist in the nutrient-limited environment of the phagosome. In this regard, the ferritin-like proteins, encoded by $b f r A$ and $b f r B$, may be important in intracellular survival as the capacity to acquire enough iron in the vacuole is very limited.

\section{Methods}

Sequence analysis. Initially, $\sim 3.2 \mathrm{Mb}$ of sequence was generated from $\operatorname{cosmids}^{8}$ and the remainder was obtained from selected BAC clones ${ }^{7}$ and 45,000 whole-genome shotgun clones. Sheared fragments $(1.4-2.0 \mathrm{~kb})$ from cosmids and BACs were cloned into M13 vectors, whereas genomic DNA was cloned in pUC18 to obtain both forward and reverse reads. The PGRS genes were grossly underrepresented in pUC18 but better covered in the BAC and cosmid M13 libraries. We used small-insert libraries ${ }^{44}$ to sequence regions prone to compression or deletion and, in some cases, obtained sequences from products of the polymerase chain reaction or directly from BACs ${ }^{7}$. All shotgun sequencing was performed with standard dye terminators to minimize compression problems, whereas finishing reactions used dRhodamine or BigDye terminators (http://www.sanger.ac.uk). Problem areas were verified by using dye primers. Thirty differences were found between the genomic shotgun sequences and the cosmids; twenty of which were due to sequencing errors and ten to mutations in cosmids ( 1 error per $320 \mathrm{~kb}$ ). Less than $0.1 \%$ of the sequence was from areas of single-clone coverage, and $<0.2 \%$ was from one strand with only one sequencing chemistry.

Informatics. Sequence assembly involved PHRAP, GAP4 (ref. 45) and a customized perl script that merges sequences from different libraries and generates segments that can be processed by several finishers simultaneously. Sequence analysis and annotation was managed by DIANA (B.G.B. et al., unpublished). Genes encoding proteins were identified by TB-parse ${ }^{46}$ using a hidden Markov model trained on known M. tuberculosis coding and noncoding regions and translation-initiation signals, with corroboration by positional base preference. Interrogation of the EMBL, TREMBL, SwissProt, PROSITE $^{47}$ and in-house databases involved BLASTN, BLASTX ${ }^{48}$, DOTTER (http://www.sanger.ac.uk) and FASTA ${ }^{49}$. tRNA genes were located and identified using tRNAscan and tRNAscan-SE ${ }^{50}$. The complete sequence, a list of annotated cosmids and linking regions can be found on our website (http:// www. sanger.ac.uk) and in MycDB (http://www.pasteur.fr/mycdb/).

Received 15 April; accepted 8 May 1998.

\footnotetext{
1. Snider, D. E. Jr, Raviglione, M. \& Kochi, A. in Tuberculosis: Pathogenesis, Protection, and Control (ed. Bloom, B. R.) 2-11 (Am. Soc. Microbiol., Washington DC, 1994).

. Wheeler, P. R. \& Ratledge, C. in Tuberculosis: Pathogenesis, Protection, and Control (ed. Bloom, B. R.) 353-385 (Am. Soc. Microbiol., Washington DC, 1994).

3. Chan, J. \& Kaufmann, S. H. E. in Tuberculosis: Pathogenesis, Protection, and Control (ed. Bloom, B. R.) 271-284 (Am. Soc. Microbiol., Washington DC, 1994).

4. Brennan, P. J. \& Draper, P. in Tuberculosis: Pathogenesis, Protection, and Control (ed. Bloom, B. R.) 271-284 (Am. Soc. Microbiol., Washington DC, 1994).
}

5. Kolattukudy, P. E., Fernandes, N. D., Azad, A. K., Fitzmaurice, A. M. \& Sirakova, T. D. Biochemistry 
and molecular genetics of cell-wall lipid biosynthesis in mycobacteria. Mol. Microbiol. 24, 263-270 (1997).

6. Sreevatsan, S. et al. Restricted structural gene polymorphism in the Mycobacterium tuberculosi complex indicates evolutionarily recent global dissemination. Proc. Natl Acad. Sci. USA 94, 98699874 (1997).

7. Brosch, R. et al. Use of a Mycobacterium tuberculosis $\mathrm{H} 37 \mathrm{Rv}$ bacterial artificial chromosome library for genome mapping, sequencing and comparative genomics. Infect. Immun. 66, 2221-2229 (1998).

8. Philipp, W. J. et al. An integrated map of the genome of the tubercle bacillus, Mycobacterium tuberculosis $\mathrm{H} 37 \mathrm{Rv}$, and comparison with Mycobacterium leprae. Proc. Natl Acad. Sci. USA 93, 3132 3137 (1996).

9. Blattner, F. R. et al. The complete genome sequence of Escherichia coli K-12. Science 277, 1453-1462 (1997).

10. Cole, S. T. \& Saint-Girons, I. Bacterial genomics. FEMS Microbiol. Rev. 14, 139-160 (1994).

11. Freiberg, C. et al. Molecular basis of symbiosis between Rhizobium and legumes. Nature 387, 394-401 (1997).

12. Bardarov, S. et al. Conditionally replicating mycobacteriophages: a system for transposon delivery to Mycobacterium tuberculosis. Proc. Natl Acad. Sci. USA 94, 10961-10966 (1997).

13. Mahairas, G. G., Sabo, P. J., Hickey, M. J., Singh, D. C. \& Stover, C. K. Molecular analysis of genetic differences between Mycobacterium bovis BCG and virulent M. bovis. J. Bacteriol. 178, 1274-1282 (1996).

14. Kunst, F. et al. The complete genome sequence of the gram-positive bacterium Bacillus subtilis. Nature 390, 249-256 (1997).

15. Smith, D. R. et al. Multiplex sequencing of $1.5 \mathrm{Mb}$ of the Mycobacterium leprae genome. Genome Res 7, 802-819 (1997).

16. Greenacre, M. Theory and Application of Correspondence Analysis (Academic, London, 1984).

17. Ratledge, C. R. in The Biology of the Mycobacteria (eds Ratledge, C. \& Stanford, J.) 53-94 (Academic San Diego, 1982).

18. Av-Gay, Y. \& Davies, J. Components of eukaryotic-like protein signaling pathways in Mycobacterium tuberculosis. Microb. Comp. Genomics 2, 63-73 (1997).

19. Cole, S. T. \& Telenti, A. Drug resistance in Mycobacterium tuberculosis. Eur. Resp. Rev. 8, 701S-713S (1995).

20. Riley, M. \& Labedan, B. in Escherichia coli and Salmonella (ed. Neidhardt, F. C.) 2118-2202 (ASM Washington, 1996)

21. Mdluli, K. et al. Inhibition of a Mycobacterium tuberculosis $\beta$-ketoacyl ACP synthase by isoniazid. Science 280, 1607-1610 (1998).

22. Banerjee, A. et al. inh A, a gene encoding a target for isoniazid and ethionamide in Mycobacterium tuberculosis. Science 263, 227-230 (1994).

23. Hopwood, D. A. Genetic contributions to understanding polyketide synthases. Chem. Rev. 97, 2465 2497 (1997).

24. Minnikin, D. E. in The Biology of the Mycobacteria (eds Ratledge, C. \& Stanford, J.) 95-184 (Academic, London, 1982).

25. Barry, C. E. III et al. Mycolic acids: structure, biosynthesis, and phsyiological functions. Prog. Lipid Res. (in the press).

26. Belisle, J. T. et al. Role of the major antigen of Mycobacterium tuberculosis in cell wall biogenesis. Science 276, 1420-1422 (1997).

27. Marahiel, M. A., Stachelhaus, T. \& Mootz, H. D. Modular peptide synthetases involved in nonribosomal peptide synthesis. Chem. Rev. 97, 2651-2673 (1997).

28. Gobin, J. et al. Iron acquisition by Mycobacterium tuberculosis: isolation and characterization of a family of iron-binding exochelins. Proc. Natl Acad. Sci. USA 92, 5189-5193 (1995).

29. Young, D. B. \& Fruth, U. in New Generation Vaccines (eds Levine, M., Woodrow, G., Kaper, J. \& Cobon, G. S.) 631-645 (Marcel Dekker, New York, 1997).

30. Sorensen, A. L., Nagai, S., Houen, G., Andersen, P. \& Anderson, A. B. Purification and characterization of a low-molecular-mass T-cell antigen secreted by Mycobacterium tuberculosis. Infect. Immun. 63,
$1710-1717$ (1995).

31. Hermans, P. W. M., van Soolingen, D. \& van Embden, J. D. A. Characterization of a major polymorphic tandem repeat in Mycobacterium tuberculosis and its potential use in the epidemiology of Mycobacterium kansasii and Mycobacterium gordonae. J. Bacteriol. 174, 4157-4165 (1992).

32. Poulet, S. \& Cole, S. T. Characterisation of the polymorphic GC-rich repetitive sequence (PGRS) present in Mycobacterium tuberculosis. Arch. Microbiol. 163, 87-95 (1995).

33. Cole, S. T. \& Barrell, B. G. in Genetics and Tuberculosis (eds Chadwick, D. J. \& Cardew, G., Novartis Foundation Symp. 217) 160-172 (Wiley, Chichester, 1998).

34. Vega-Lopez, F. et al. Sequence and immunological characterization of a serine-rich antigen from Mycobacterium leprae. Infect. Immun. 61, 2145-2153 (1993).

35. Abou-Zeid, C. et al. Genetic and immunological analysis of Mycobacterium tuberculosis fibronectinbinding proteins. Infect. Immun. 59, 2712-2718 (1991).

36. Robertson, B. D. \& Meyer, T. F. Genetic variation in pathogenic bacteria. Trends Genet. 8, 422-427 (1992).

37. Levitskaya, J. et al. Inhibition of antigen processing by the internal repeat region of the Epstein-Barr virus nuclear antigen-1. Nature 375, 685-688 (1995).

38. Levitskaya, J., Sharipo, A., Leonchiks, A., Ciechanover, A. \& Masucci, M. G. Inhibition of ubiquitin/ proteasome-dependent protein degradation by the Gly-Ala repeat domain of the Epstein-Barr virus nuclear antigen 1. Proc. Natl Acad. Sci. USA 94, 12616-12621 (1997).

39. Flynn, J. L., Goldstein, M. A., Treibold, K. J., Koller, B. \& Bloom, B. R. Major histocompatability complex class-I restricted $\mathrm{T}$ cells are required for resistance to Mycobacterium tuberculosis infection. Proc. Natl Acad. Sci. USA 89, 12013-12017 (1992).

40. Bloom, B. R. \& Fine, P. E. M. in Tuberculosis: Pathogenesis, Protection, and Control (ed. Bloom, B. R.) 531-557 (Am. Soc. Microbiol., Washington DC, 1994).

41. Collins, D. M. In search of tuberculosis virulence genes. Trends Microbiol. 4, 426-430 (1996).

42. Arruda, S., Bomfim, G., Knights, R., Huima-Byron, T. \& Riley, L. W. Cloning of an M. tuberculosis DNA fragment associated with entry and survival inside cells. Science 261, 1454-1457 (1993).

43. Baumler, A. J., Kusters, J. G., Stojikovic, I. \& Heffron, F. Salmonella typhimurium loci involved in survival within macrophages. Infect. Immun. 62, 1623-1630 (1994).

44. McMurray, A. A., Sulston, J. E. \& Quail, M. A. Short-insert libraries as a method of problem solving in genome sequencing. Genome Res. 8, 562-566 (1998).

45. Bonfield, J. K., Smith, K. F. \& Staden, R. A new DNA sequence assembly program. Nucleic Acids Res. 24, 4992-4999 (1995)

46. Krogh, A., Mian, I. S. \& Haussler, D. A hidden Markov model that finds genes in E. coli DNA. Nucleic Acids Res. 22, 4768-4778 (1994).

47. Bairoch, A., Bucher, P. \& Hofmann, K. The PROSITE database, its status in 1997. Nucleic Acids Res. 25 217-221 (1997).

48. Altschul, S., Gish, W., Miller, W., Myers, E. \& Lipman, D. A basic local alignment search tool. J. Mol. Biol. 215, 403-410 (1990).

49. Pearson, W. \& Lipman, D. Improved tools for biological sequence comparisons. Proc. Natl Acad. USA 85, 2444-2448 (1988)

50. Lowe, T. M. \& Eddy, S. R. tRNAscan-SE: a program for improved detection of transfer RNA genes in genomic DNA. Nucleic Acids Res. 25, 955-964 (1997).

Acknowledgements. We thank Y. Av-Gay, F.-C. Bange, A. Danchin, B. Dujon, W. R. Jacobs Jr, L. Jones, M. McNeil, I. Moszer, P. Rice and J. Stephenson for advice, reagents and support. This work was supported by the Wellcome Trust. Additional funding was provided by the Association Francaise Raoul Follereau the World Health Organisation and the Institut Pasteur. S.V.G. received a Wellcome Trust travelling research fellowship.

Correspondence and requests for materials should be addressed to B.G.B. (barrell@sanger.ac.uk) or S.T.C. (stcole@pasteur.fr). The complete sequence has been deposited in EMBL/GenBank/DDBJ as MTBH37RV, accession number AL123456.

\section{YOURS TO HAVE AND TO $\mathrm{BU} \mathrm{T}$ $\mathrm{NOT}$ $\mathrm{TO}$ \\ $T$ he publication you are reading is protected by copyright law. \\ Photocopying copyright material without permission is no different from stealing a magazine from a newsagent, only it doesn't seem like theft. \\ If you take photocopies from books, magazines and periodicals at work your employer should be licensed with CLA. \\ Make sure you are protected by a photocopying licence.

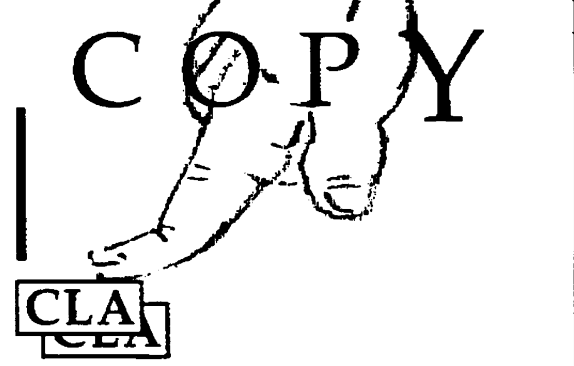 \\ The Copyright Licensing Agency Limited 90 Tottenhani Court Raad, London W1P OLP Telephone: 01714365931 Fax: 01714363986}


Table 1. Functional classification of Mycobacterium tuberculosis protein-coding genes

\begin{tabular}{|c|c|c|c|c|c|}
\hline $\begin{array}{l}\text { I. Small-m } \\
\text { A. Degrad } \\
\text { 1. Carbon }\end{array}$ & $\begin{array}{l}\text { lolecule } \mathrm{m} \\
\text { ation } \\
\text { compound }\end{array}$ & netabolism & Rv2831 & echA16 & $\begin{array}{l}\text { superfamily } \\
\text { enoyl-CoA hydratase/isomerase } \\
\text { superfamily }\end{array}$ \\
\hline Rv0186 & bglS & $\beta$-glucosidase & Rv3039c & echA17 & enoyl-CoA hydratase/isomerase \\
\hline $\begin{array}{l}\text { Rv2202c } \\
\text { Rv0727c }\end{array}$ & cbhhK & $\begin{array}{l}\text { carbohydrate kinase } \\
\text { L-fuculose phosphate aldolase }\end{array}$ & & & superfamily \\
\hline $\begin{array}{l}\text { Rv0727c } \\
\text { Rv1731 }\end{array}$ & $\begin{array}{l}\text { fucA } \\
\text { gabD1 }\end{array}$ & & Rv3373 & echA18 & $\begin{array}{l}\text { enoyl-CoA hydratase/isomerase } \\
\text { superfamily, N-term }\end{array}$ \\
\hline Rv0234c & gabD2 & $\begin{array}{l}\text { genase } \\
\text { succinate-semialdehyde dehydro- }\end{array}$ & Rv3374 & echA18' & $\begin{array}{l}\text { enoyl-CoA hydratase/isomerase } \\
\text { superfamily, C-term }\end{array}$ \\
\hline Rv0501 & galE1 & $\begin{array}{l}\text { genase } \\
\text { UDP-glucose 4-epimerase }\end{array}$ & Rv3516 & echA19 & $\begin{array}{l}\text { enoyl-CoA hydratase/isomerase } \\
\text { superfamily }\end{array}$ \\
\hline $\begin{array}{l}\text { Rv0536 } \\
\text { Rv0620 }\end{array}$ & $\begin{array}{l}\text { galE2 } \\
\text { galK }\end{array}$ & $\begin{array}{l}\text { UDP-glucose 4-epimerase } \\
\text { galactokinase }\end{array}$ & Rv3550 & echA20 & $\begin{array}{l}\text { enoyl-CoA hydratase/isomerase } \\
\text { superfamily }\end{array}$ \\
\hline Rv0619 & galt & $\begin{array}{l}\text { galactose-1-phosphate uridylyl- } \\
\text { transferase C-term }\end{array}$ & Rv3774 & echA21 & $\begin{array}{l}\text { enoyl-CoA hydratase/isomerase } \\
\text { superfamily }\end{array}$ \\
\hline Rv0618 & galt' & $\begin{array}{l}\text { galactose-1-phosphate uridylyl- } \\
\text { transferase N-term }\end{array}$ & Rv0859 & $\operatorname{fad} A$ & $\begin{array}{l}\beta \text { oxidation complex, } \beta \text { subunit } \\
\text { (acetyl-CoA C-acetyltransferase) }\end{array}$ \\
\hline Rv0993 & galU & $\begin{array}{l}\text { UTP-glucose-1-phosphate uridylyl- } \\
\text { transferase }\end{array}$ & $\begin{array}{l}\text { Rv0243 } \\
\text { Rv1074c }\end{array}$ & $\begin{array}{l}\text { fadA2 } \\
\text { fadA3 }\end{array}$ & $\begin{array}{l}\text { acetyl-CoA C-acetyltransferase } \\
\text { acetyl-CoA C-acetyltransferase }\end{array}$ \\
\hline Rv3696c & glpK & $\begin{array}{l}\text { ATP:glycerol 3-phosphotrans- } \\
\text { ferase }\end{array}$ & Rv1323 & $\mathrm{fad} A 4$ & $\begin{array}{l}\text { acetyl-CoA C-acetyltransferase } \\
\text { (aka thiL) }\end{array}$ \\
\hline Rv3255c & $\operatorname{man} A$ & mannose-6-phosphate isomerase & Rv3546 & fadA5 & acetyl-CoA C-acetyltransferase \\
\hline Rv3441c & $m r s A$ & $\begin{array}{l}\text { phosphoglucomutase or phospho- } \\
\text { mannomutase }\end{array}$ & $\begin{array}{l}\text { Rv3556c } \\
\text { Rv0860 }\end{array}$ & $\begin{array}{l}\operatorname{fad} A 6 \\
\mathrm{fadB}\end{array}$ & $\begin{array}{l}\text { acetyl-CoA C-acetyltransferase } \\
\beta \text { oxidation complex, } \alpha \text { subunit }\end{array}$ \\
\hline Rv0118c & $O x C A$ & oxalyl-CoA decarboxylase & & & (multiple activities) \\
\hline Rv3068c & pgmA & phosphoglucomutase & Rv0468 & $\mathrm{fadB2}$ & 3-hydroxyacyl-CoA dehydroge- \\
\hline Rv3257c & pmmA & phosphomannomutase & & & nase \\
\hline $\begin{array}{l}\text { Rv3308 } \\
\text { Rv2702 }\end{array}$ & pmmB & phosphomannomutase & Rv1715 & $\mathrm{fadB3}$ & 3-hydroxyacyl-CoA dehydroge- \\
\hline $\begin{array}{l}\text { Rv2702 } \\
\text { Rv0408 }\end{array}$ & $\begin{array}{l}\text { ppgk } \\
\text { pta }\end{array}$ & phosphate acetyltransferase & Rv3141 & $\mathrm{fadB4}$ & $\begin{array}{l}\text { nase } \\
\text { 3-hydroxyacyl-CoA dehydroge- }\end{array}$ \\
\hline Rv0729 & $x y / B$ & xylulose kinase & & & nase \\
\hline Rv1096 & - & carbohydrate degrading enzyme & Rv1912c & $\mathrm{fadB5}$ & $\begin{array}{l}\text { 3-hydroxyacyl-CoA dehydroge- } \\
\text { nase }\end{array}$ \\
\hline 2. Amino a & acids and & amines & Rv1750c & fadD1 & acyl-CoA synthase \\
\hline Rv1905c & aao & D-amino acid oxidase & Rv0270 & $\mathrm{fadD} 2$ & acyl-CoA synthase \\
\hline Rv2531c & adi & ornithine/arginine decarboxylase & Rv3561 & $\mathrm{fadD} 3$ & acyl-CoA synthase \\
\hline Rv2780 & ald & L-alanine dehydrogenase & Rv0214 & fadD4 & acyl-CoA synthase \\
\hline Rv1538c & ans $A$ & L-asparaginase & Rv0166 & $\mathrm{fadD5}$ & acyl-CoA synthase \\
\hline Rv1001 & $\operatorname{arcA}$ & arginine deiminase & Rv1206 & fadD6 & acyl-CoA synthase \\
\hline Rv0753c & $m m s A$ & $\begin{array}{l}\text { methylmalmonate semialdehyde } \\
\text { dehydrogenase }\end{array}$ & $\begin{array}{l}\text { Rv0119 } \\
\text { Rv0551c }\end{array}$ & $\begin{array}{l}\text { fadD7 } \\
\text { fadD8 }\end{array}$ & $\begin{array}{l}\text { acyl-CoA synthase } \\
\text { acyl-CoA synthase }\end{array}$ \\
\hline Rv0751c & $m m s B$ & $\begin{array}{l}\text { methylmalmonate semialdehyde } \\
\text { oxidoreductase }\end{array}$ & $\begin{array}{l}\text { Rv2590 } \\
\text { Rv0099 }\end{array}$ & $\begin{array}{l}\text { fadD9 } \\
\text { fadD10 }\end{array}$ & $\begin{array}{l}\text { acyl-CoA synthase } \\
\text { acyl-CoA synthase }\end{array}$ \\
\hline Rv1187 & rocA & $\begin{array}{l}\text { pyrroline-5-carboxylate dehydro- } \\
\text { genase }\end{array}$ & $\begin{array}{l}\text { Rv1550 } \\
\text { Rv1549 }\end{array}$ & $\begin{array}{l}\text { fadD11 } \\
\text { fadD11 }\end{array}$ & $\begin{array}{l}\text { acyl-CoA synthase, } \mathrm{N} \text {-term } \\
\text { acyl-CoA synthase, } \mathrm{C} \text {-term }\end{array}$ \\
\hline Rv2322c & rocD1 & ornithine aminotransferase & Rv1427c & fadD12 & acyl-CoA synthase \\
\hline Rv2321c & rocD2 & ornithine aminotransferase & Rv3089 & fadD13 & acyl-CoA synthase \\
\hline Rv1848 & ureA & urease $\gamma$ subunit & Rv1058 & $\mathrm{fadD14}$ & acyl-CoA synthase \\
\hline Rv1849 & ure $B$ & urease $\beta$ subunit & Rv2187 & $\mathrm{fad} D 15$ & acyl-CoA synthase \\
\hline Rv1850 & ureC & urease $\alpha$ subunit & Rv0852 & $f a d D 16$ & acyl-CoA synthase \\
\hline Rv1853 & ureD & urease accessory protein & Rv3506 & $f a d D 17$ & acyl-CoA synthase \\
\hline Rv1851 & ureF & urease accessory protein & Rv3513c & fadD18 & acyl-CoA synthase \\
\hline Rv1852 & ureG & urease accessory protein & Rv3515c & fadD19 & acyl-CoA synthase \\
\hline Rv2913c & - & probable D-amino acid & Rv1185c & fadD21 & acyl-CoA synthase \\
\hline & & aminohydrolase & Rv2948c & fadD22 & acyl-CoA synthase \\
\hline Rv3551 & - & $\begin{array}{l}\text { possible glutaconate CoA- } \\
\text { transferase }\end{array}$ & $\begin{array}{l}\text { Rv3826 } \\
\text { Rv1529 }\end{array}$ & $\begin{array}{l}\mathrm{fadD23} \\
\mathrm{fadD24}\end{array}$ & $\begin{array}{l}\text { acyl-CoA synthase } \\
\text { acyl-CoA synthase }\end{array}$ \\
\hline & & & Rv1521 & fadD25 & acyl-CoA synthase \\
\hline 3. Fatty ac & & & Rv2930 & $\mathrm{fad} 26$ & acyl-CoA synthase \\
\hline Rv2501c & $\operatorname{acc} A 1$ & acetyl/propionyl-CoA carboxylase, & Rv0275c & $\mathrm{fad} D 27$ & acyl-CoA synthase \\
\hline Rv0973c & accA2 & acetyl/propionyl-CoA carboxylase, & Rv2950c & fadD29 & acyl-CoA synthase \\
\hline Rv2502c & accD1 & $\begin{array}{l}\alpha \text { subunit } \\
\text { acetyl/propionyl-CoA carboxylase, }\end{array}$ & $\begin{array}{l}\text { Rv0404 } \\
\text { Rv1925 }\end{array}$ & $\begin{array}{l}\operatorname{fad} D 30 \\
\operatorname{fad} D 31\end{array}$ & $\begin{array}{l}\text { acyl-CoA synthase } \\
\text { acyl-CoA synthase }\end{array}$ \\
\hline & & $\beta$ subunit & Rv3801c & $\mathrm{fadD} 32$ & acyl-CoA synthase \\
\hline Rv0974c & accD2 & acetyl/propionyl-CoA carboxylase, & Rv1345 & $\mathrm{fadD} 33$ & acyl-CoA synthase \\
\hline & & $\beta$ subunit & Rv0035 & $\operatorname{fad} D 34$ & acyl-CoA synthase \\
\hline Rv3667 & acs & acetyl-CoA synthase & Rv2505c & $\mathrm{fad} D 35$ & acyl-CoA synthase \\
\hline Rv3409c & choD & cholesterol oxidase & Rv1193 & $\mathrm{fadD} 36$ & acyl-CoA synthase \\
\hline Rv0222 & echA1 & enoyl-CoA hydratase/isomerase & Rv0131c & fadE1 & acyl-CoA dehydrogenase \\
\hline Rv0456c & echA2 & $\begin{array}{l}\text { supertamily } \\
\text { enoyl-CoA hydratase/isomerase }\end{array}$ & Rv0215c & fadE3 & $\begin{array}{l}\text { acyl-CoA dehydrogenase } \\
\text { acyl-CoA dehydrogenase }\end{array}$ \\
\hline & & superfamily & Rv0231 & fadE4 & acyl-CoA dehydrogenase \\
\hline Rv0632c & echA3 & enoyl-CoA hydratase/isomerase & Rv0244c & fadE5 & acyl-CoA dehydrogenase \\
\hline & & superfamily & Rv0271c & fadE6 & acyl-CoA dehydrogenase \\
\hline Rv0673 & echA4 & enoyl-CoA hydratase/isomerase & Rv0400c & fadE7 & acyl-CoA dehydrogenase \\
\hline Rv0675 & echA5 & $\begin{array}{l}\text { superfamily } \\
\text { enoyl-CoA hydratase/isomerase }\end{array}$ & & & $\begin{array}{l}\text { acyl-CoA dehydrogenase } \\
\text { (aka aidB) }\end{array}$ \\
\hline & & superfamily & Rv0752c & fadE9 & acyl-CoA dehydrogenase \\
\hline Rv0905 & echA6 & enoyl-CoA hydratase/isomerase & Rv0873 & fadE10 & acyl-CoA dehydrogenase \\
\hline & & superfamily (aka ecch) & Rv0972c & fadE12 & acyl-CoA dehydrogenase \\
\hline Rv0971c & echA7 & enoyl-CoA hydratase/isomerase & Rv0975c & fadE13 & acyl-CoA dehydrogenase \\
\hline & & & Rv1346 & fadE14 & acyl-CoA dehydrogenase \\
\hline Rv1070c & echA8 & enoyl-CoA hydratase/isomerase & Rv1467c & fadE15 & acyl-CoA dehydrogenase \\
\hline & & & & fadE16 & acyl-CoA dehydrogenase \\
\hline Rv1071c & echA9 & enoyl-CoA hydratase/isomerase & Rv1934c & $\mathrm{fadE} 17$ & acyl-CoA dehydrogenase \\
\hline & & superfamily & & fadE18 & acyl-CoA dehydrogenase \\
\hline Rv1142c & echA10 & $\begin{array}{l}\text { enoyl-CoA hydratase/isomerase } \\
\text { superfamily }\end{array}$ & Rv2500c & fadE19 & $\begin{array}{l}\text { acyl-CoA dehydrogenase } \\
\text { (aka } m m g C \text { ) }\end{array}$ \\
\hline Rv1141c & echA11 & enoyl-CoA hydratase/isomerase & Rv2724c & fadE20 & acyl-CoA dehydrogenase \\
\hline & & superfamily & Rv2789c & fadE21 & acyl-CoA dehydrogenase \\
\hline Rv1472 & echA12 & enoyl-CoA hydratase/isomerase & Rv3061c & fadE22 & acyl-CoA dehydrogenase \\
\hline & & & & fadE23 & acyl-CoA dehydrogenase \\
\hline Rv1935c & echA13 & enoyl-CoA hydratase/isomerase & Rv3139 & $\mathrm{fadE24}$ & acyl-CoA dehydrogenase \\
\hline & & $\begin{array}{l}\text { superfamily } \\
\text { enovl-CoA hydratase/isomerase }\end{array}$ & $\begin{array}{l}\text { Rv3274c } \\
\text { Rv3504 }\end{array}$ & $\begin{array}{l}\text { fadE25 } \\
\text { fadE26 }\end{array}$ & acyl-CoA dehydrogenase \\
\hline Rv2486 & echA14 & $\begin{array}{l}\text { enoyl-CoA hydratase/isomerase } \\
\text { superfamily }\end{array}$ & $\begin{array}{l}\text { Rv3504 } \\
\text { Rv3505 }\end{array}$ & $\begin{array}{l}\text { fadE26 } \\
\mathrm{fadE27}\end{array}$ & $\begin{array}{l}\text { acyl-CoA dehydrogenase } \\
\text { acyl-CoA dehydrogenase }\end{array}$ \\
\hline Rv2679 & echA15 & enoyl-CoA hydratase/isomerase & Rv3544c & $\mathrm{fadE28}$ & acyl-CoA dehydrogenase \\
\hline
\end{tabular}

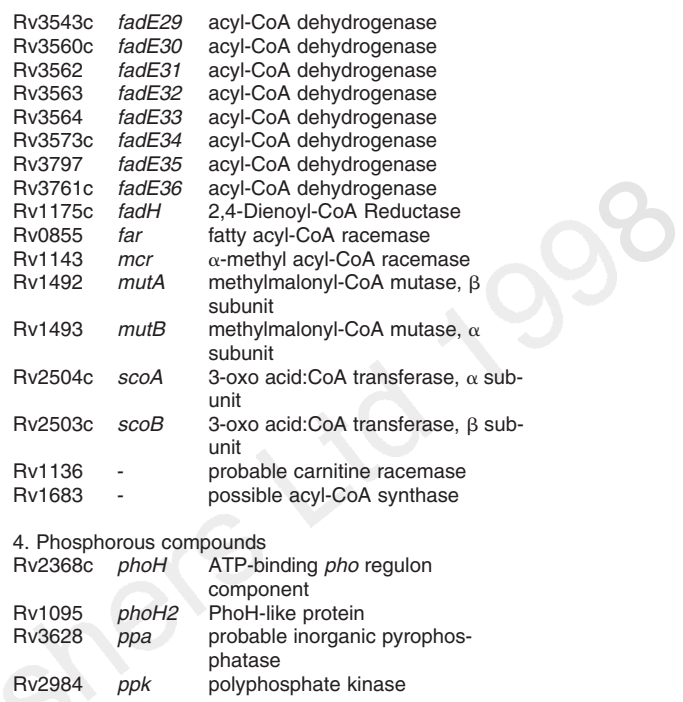

Rv2984 ppk polyphosphate kinase

B. Energy metabolism

1. Glycolysis

Rv1023 eno enolase

Rv0363c fba fructose bisphosphate aldolase

Rv1436 gap glyceraldehyde 3-phosphate dehy-

Rv0489 gpm phosphoglycerate mutase I

Rv3010c pfkA phosphofructokinase I

Rv2029c pfkB phosphofructokinase II

Rv0946c pgi glucose-6-phosphate isomerase

Rv1437 pgk phosphoglycerate kinase

Rv1617 pykA pyruvate kinase

Rv1438 tpi triosephosphate isomerase

Rv2419c - putative phosphoglycerate mutase

Rv3837c - putative phosphoglycerate mutase

2. Pyruvate dehydrogenase

Rv2241 aceE pyruvate dehydrogenase E1 com-

Rv3303c IpdA dihydrolipoamide dehydrogenase

Rv2497c pdhA pyruvate dehydrogenase E1 com-

ponent $\alpha$ subunit

Rv2496c pdhB pyruvate dehydrogenase E1 com-

Rv2495c pdhC ponent $\beta$ subunit

dihydrolipoamide acetyltransferase

Rv0462 - probable dihydrolipoamide dehydrogenase

3. TCA cycle

Rv1475c acn aconitate hydratase

Rv0889c citA citrate synthase 2

Rv2498c cite citrate lyase $\beta$ chain

Rv1098c fum fumarase

Rv1131 gltA1 citrate synthase 3

Rv0896 gltA2 citrate synthase 1

Rv3339c icd1 isocitrate dehydrogenase

Rv0066c icd2 isocitrate dehydrogenase

Rv0794c IpdB dihydrolipoamide dehydrogenase

Rv1240 mdh malate dehydrogenase

Rv2967c pca pyruvate carboxylase

Rv3318 sdhA succinate dehydrogenase A

Rv3319 sdhB succinate dehydrogenase B

Rv3316 sdhC succinate dehydrogenase $\mathrm{C}$ sub-

unit

Rv1248c SUCA

Rv2215 sucB dihydrolipoamide succinyltrans-

ferase

$\begin{array}{lll}\text { Rv0951 } & \text { sucC } & \text { succinyl-CoA synthase } \beta \text { chain } \\ \text { Rv0952 } & \text { sucD } & \text { succinyl-CoA synthase } \alpha \text { chain }\end{array}$

4. Glyoxylate bypass

Rv0467 aceA isocitrate lyase

Rv1915 aceAa isocitrate lyase, $\alpha$ module

Rv1916 aceAb isocitrate lyase, $\beta$ module

$\begin{array}{lll}\text { Rv1916 } & a c e A b & \text { isocitrate lyase, } \\ \text { Rv1837c } & \text { glc } B & \text { malate synthase }\end{array}$

Rv3323c gphA phosphoglycolate phosphatase

5. Pentose phosphate pathway

Rv1445c devB glucose-6-phosphate 1-dehydro-

Rv1844c gnd 6-phosphogluconate dehydroge-

Rv1122 gnd2 6-phosphogluconate dehydroge-

nase (Gram +)
n-phosphogluconat

Rv1446c opcA unknown function, may aid 


\begin{tabular}{|c|c|c|c|c|c|c|c|c|}
\hline Rv2436 & rbsk & ribokinase & Rv3250c & $r u b B$ & rubredoxin $\mathrm{B}$ & Rv1878 & $g \ln A 3$ & probable glutamine synthase \\
\hline Rv1408 & rpe & ribulose-phosphate 3-epimerase & & & & Rv2860c & $g \ln A 4$ & proable glutamine synthase \\
\hline Rv2465c & rpi & phosphopentose isomerase & \multicolumn{3}{|c|}{ 7. Miscellaneous oxidoreductases and oxygenases 171} & Rv2918c & $g \ln D$ & uridylyltransferase \\
\hline Rv1448c & tal & transaldolase & & & & Rv2221c & $g \ln E$ & glutamate-ammonia-ligase \\
\hline Rv1449c & tkt & transketolase & \multicolumn{3}{|c|}{ 8. ATP-proton motive force } & & & adenyltransferase \\
\hline Rv1121 & $z w f$ & $\begin{array}{l}\text { glucose-6-phosphate 1-dehydro- } \\
\text { genase }\end{array}$ & $\begin{array}{l}\text { Rv1308 } \\
\text { Rv1304 }\end{array}$ & $\begin{array}{l}\operatorname{atpA} \\
\operatorname{atp} B\end{array}$ & $\begin{array}{l}\text { ATP synthase } \alpha \text { chain } \\
\text { ATP synthase } \alpha \text { chain }\end{array}$ & Rv3859c & gltB & $\begin{array}{l}\text { ferredoxin-dependent glutamate } \\
\text { synthase }\end{array}$ \\
\hline Rv1447c & $z w f 2$ & $\begin{array}{l}\text { glucose-6-phosphate 1-dehydro- } \\
\text { genase }\end{array}$ & $\begin{array}{l}\text { Rv1311 } \\
\text { Rv1310 }\end{array}$ & $\begin{array}{l}\operatorname{atpC} \\
\operatorname{atpD}\end{array}$ & $\begin{array}{l}\text { ATP synthase } \epsilon \text { chain } \\
\text { ATP synthase } \beta \text { chain }\end{array}$ & Rv3858c & $g l t D$ & $\begin{array}{l}\text { small subunit of NADH-dependent } \\
\text { glutamate synthase }\end{array}$ \\
\hline & & & $\begin{array}{l}\text { Rv1305 } \\
\text { Rv1306 }\end{array}$ & $\begin{array}{l}\operatorname{atp} E \\
\operatorname{atpF}\end{array}$ & $\begin{array}{l}\text { ATP synthase c chain } \\
\text { ATP synthase b chain }\end{array}$ & Rv3704c & $g s h A$ & $\begin{array}{l}\text { possible } \gamma \text {-glutamylcysteine syn- } \\
\text { thase }\end{array}$ \\
\hline $\begin{array}{l}\text { 6. Respirat } \\
\text { a. aerobic }\end{array}$ & & & Rv1309 & atpG & $\begin{array}{l}\text { AlP synthase } D \text { chain } \\
\text { ATP synthase } \gamma \text { chain }\end{array}$ & Rv2427c & proA & $\gamma$-glutamyl phosphate reductase \\
\hline Rv0527 & $\operatorname{ccs} A$ & $\begin{array}{l}\text { cytochrome } c \text {-type biogenesis } \\
\text { protein }\end{array}$ & Rv1307 & atpH & ATP synthase $\delta$ chain & $\begin{array}{l}\text { Rv2439c } \\
\text { Rv0500 }\end{array}$ & $\begin{array}{l}\text { proB } \\
\text { proC }\end{array}$ & $\begin{array}{l}\text { glutamate 5-kinase } \\
\text { pyrroline-5-carboxylate reductase }\end{array}$ \\
\hline Rv0529 & $\operatorname{ccs} B$ & $\begin{array}{l}\text { cytochrome } c \text {-type biogenesis } \\
\text { protein }\end{array}$ & \multicolumn{5}{|c|}{$\begin{array}{l}\text { C. Central intermediary metabolism } \\
\text { 1. General }\end{array}$} & \\
\hline Rv1451 & $\operatorname{ctaB}$ & $\begin{array}{l}\text { cytochrome } c \text { oxidase assembly } \\
\text { factor }\end{array}$ & $\begin{array}{l}\text { Rv2589 } \\
\text { Rv3432c }\end{array}$ & $\begin{array}{l}\operatorname{gabT} T \\
\operatorname{gad} B\end{array}$ & $\begin{array}{l}\text { 4-aminobutyrate aminotransferase } \\
\text { glutamate decarboxylase }\end{array}$ & Rv3708c & asd & $\begin{array}{l}\text { aspartate semialdehyde dehydro- } \\
\text { genase }\end{array}$ \\
\hline Rv2200c & $\operatorname{ctaC}$ & cytochrome $c$ oxidase chain II & Rv1832 & $g c v B$ & glycine decarboxylase & Rv3709c & ask & aspartokinase \\
\hline Rv3043c & $c t a D$ & $\begin{array}{l}\text { cytochrome } c \text { oxidase poly- } \\
\text { peptide I }\end{array}$ & $\begin{array}{l}\text { Rv1826 } \\
\text { Rv2211c }\end{array}$ & $\begin{array}{l}\text { gcvH } \\
\text { gcvT }\end{array}$ & $\begin{array}{l}\text { glycine cleavage system } \mathrm{H} \text { protein } \\
\text { T protein of glycine cleavage }\end{array}$ & $\begin{array}{l}\text { Rv2201 } \\
\text { Rv3565 }\end{array}$ & $\begin{array}{l}\text { asnB } \\
\text { aspB }\end{array}$ & $\begin{array}{l}\text { asparagine synthase } B \\
\text { aspartate aminotransferase }\end{array}$ \\
\hline Rv2193 & $\operatorname{cta} E$ & $\begin{array}{l}\text { cytochrome } c \text { oxidase poly- } \\
\text { peptide III }\end{array}$ & Rv1213 & & $\begin{array}{l}\text { system } \\
\text { glucose-1-phosphate adenylyl- }\end{array}$ & $\begin{array}{l}\text { Rv0337c } \\
\text { Rv2753c }\end{array}$ & $\begin{array}{l}\text { aspC } \\
\text { dapA }\end{array}$ & $\begin{array}{l}\text { aspartate aminotransferase } \\
\text { dihydrodipicolinate synthase }\end{array}$ \\
\hline Rv1542c & $g l b N$ & hemoglobin-like, oxygen carrier & חVIL10 & gige & transferase & Rv2773c & dapB & dihydrodipicolinate reductase \\
\hline $\begin{array}{l}\text { Rv2470 } \\
\text { Rv2249c }\end{array}$ & $\begin{array}{l}\text { glbO } \\
\text { glpD1 }\end{array}$ & $\begin{array}{l}\text { hemoglobin-like, oxygen carrier } \\
\text { glycerol-3-phosphate dehydroge- }\end{array}$ & Rv3842c & glpQ1 & $\begin{array}{l}\text { glycerophosphoryl diester phos- } \\
\text { phodiesterase }\end{array}$ & Rv1202 & dapE & $\begin{array}{l}\text { succinyl-diaminopimelate desuc- } \\
\text { cinylase }\end{array}$ \\
\hline Rv3302c & glpD2 & $\begin{array}{l}\text { nase } \\
\text { glycerol-3-phosphate dehydroge- }\end{array}$ & Rv0317c & glpQ2 & $\begin{array}{l}\text { glycerophosphoryl diester phos- } \\
\text { phodiesterase }\end{array}$ & Rv2141c & dapE2 & $\begin{array}{l}\text { ArgE/DapE/Acy } 1 / \text { Cpg2/yscS } \\
\text { family }\end{array}$ \\
\hline & & nase & Rv3566c & $n h \circ A$ & $\mathrm{~N}$-hydroxyarylamine $o$-acetyltrans- & Rv2726c & dapF & diaminopimelate epimerase \\
\hline Rv0694 & $\| d D 1$ & $\begin{array}{l}\text { L-lactate dehydrogenase } \\
\text { (cytochrome) }\end{array}$ & Rv0155 & pntAA & $\begin{array}{l}\text { ferase } \\
\text { pyridine transhydrogenase sub- }\end{array}$ & $\begin{array}{l}\text { Rv1293 } \\
\text { Rv3341 }\end{array}$ & $\begin{array}{l}\text { lysA } \\
\text { metA }\end{array}$ & $\begin{array}{l}\text { diaminopimelate decarboxylase } \\
\text { homoserine } o \text {-acetyltransferase }\end{array}$ \\
\hline Rv1872c & $1 / d D 2$ & L-lactate dehydrogenase & & & unit $\alpha 1$ & Rv1079 & metB & cystathionine $\gamma$-synthase \\
\hline Rv1854c & $n d h$ & probable NADH dehydrogenase & Rv0156 & pntAB & pyridine transhydrogenase sub- & Rv3340 & metC & cystathionine $\beta$-lyase \\
\hline Rv3145 & пиоA & NADH dehydrogenase chain A & & & unit $\alpha 2$ & Rv1133c & metE & 5-methyltetrahydropteroyltrigluta- \\
\hline Rv3146 & nuoB & NADH dehydrogenase chain $B$ & Rv0157 & pntB & pyridine transhydrogenase & & & mate-homocysteine methyltrans- \\
\hline Rv3147 & nиос & $\mathrm{NADH}$ dehydrogenase chain $\mathrm{C}$ & & & subunit $\beta$ & & & ferase \\
\hline Rv3148 & nuoD & $\mathrm{NADH}$ dehydrogenase chain $\mathrm{D}$ & Rv1127c & ppdK & similar to pyruvate, phosphate & Rv2124c & metH & 5-methyltetrahydrofolate-homo- \\
\hline Rv3149 & nuoE & $\mathrm{NADH}$ dehydrogenase chain $\mathrm{E}$ & & & dikinase & & & \\
\hline Rv3150 & nuof & $\mathrm{NADH}$ dehydrogenase chain $\mathrm{F}$ & & & & Rv1392 & metK & $S$-adenosylmethionine synthase \\
\hline Rv3151 & nuoG & NADH dehydrogenase chain $G$ & 2. Gluconec & oogenesis & & Rv0391 & metZ & $o$-succinylhomoserine sulfhy- \\
\hline Rv3152 & nuoH & $\mathrm{NADH}$ dehydrogenase chain $\mathrm{H}$ & Rv0211 & pckA & phosphoenolpyruvate carboxy- & & & drylase \\
\hline Rv3153 & nuol & NADH dehydrogenase chain I & & & kinase & Rv1294 & thrA & homoserine dehydrogenase \\
\hline Rv3154 & nuoJ & $\mathrm{NADH}$ dehydrogenase chain $\mathrm{J}$ & Rv0069c & $s d a A$ & L-serine dehydratase 1 & Rv1296 & thrB & homoserine kinase \\
\hline Rv3155 & nuok & $\mathrm{NADH}$ dehydrogenase chain $\mathrm{K}$ & & & & Rv1295 & thrC & homoserine synthase \\
\hline Rv3156 & nuol & $\mathrm{NADH}$ dehydrogenase chain $\mathrm{L}$ & 3. Sugar nu & ucleotides & & & & \\
\hline Rv3157 & nиoм & $\mathrm{NADH}$ dehydrogenase chain $\mathrm{M}$ & Rv1512 & epiA & nucleotide sugar epimerase & 3. Serine fo & amily & \\
\hline Rv3158 & nuoN & $\mathrm{NADH}$ dehydrogenase chain $\mathrm{N}$ & Rv3784 & epiB & probable UDP-galactose 4- & Rv0815c & CYsA2 & thiosulfate sulfurtransferase \\
\hline Rv2195 & $q c r A$ & $\begin{array}{l}\text { Rieske iron-sulphur component of } \\
\text { ubiQ-cytB reductase }\end{array}$ & Rv1511 & $g m d A$ & $\begin{array}{l}\text { epimerase } \\
\text { GDP-mannose } 4,6 \text { dehydratase }\end{array}$ & $\begin{array}{l}\text { Rv3117 } \\
\text { Rv2335 }\end{array}$ & $\begin{array}{l}\text { CysA3 } \\
\text { CYSE }\end{array}$ & $\begin{array}{l}\text { thiosulfate sulfurtransferase } \\
\text { serine acetyltransferase }\end{array}$ \\
\hline Rv2196 & $q c r B$ & $\begin{array}{l}\text { cytochrome } \beta \text { component of } u b i Q- \\
\text { cytB reductase }\end{array}$ & Rv0334 & $r m / A$ & $\begin{array}{l}\text { glucose-1-phosphate thymidyl- } \\
\text { transferase }\end{array}$ & Rv0511 & cysG & $\begin{array}{l}\text { uroporphyrin-III c-methyltrans- } \\
\text { ferase }\end{array}$ \\
\hline Rv2194 & $q c r C$ & $\begin{array}{l}\text { cytochrome } b / c \text { component of } \\
\text { ubiQ-cytB reductase }\end{array}$ & Rv3264c & $r m I A 2$ & $\begin{array}{l}\text { glucose-1-phosphate thymidyl- } \\
\text { transferase }\end{array}$ & Rv2847c & cysG2 & $\begin{array}{l}\text { multifunctional enzyme, siroheme } \\
\text { synthase }\end{array}$ \\
\hline & & & Rv3464 & $r m / B$ & dTDP-glucose 4,6-dehydratase & Rv2334 & cysK & cysteine synthase $A$ \\
\hline b. anaerobi & & & Rv3634c & $r m / B 2$ & dTDP-glucose 4,6-dehydratase & Rv1336 & cysM & cysteine synthase B \\
\hline Rv2392 & cysH & $\begin{array}{l}\text { 3'-phosphoadenylylsulfate (PAPS) } \\
\text { reductase }\end{array}$ & $\begin{array}{l}\text { Rv3468c } \\
\text { Rv3465 }\end{array}$ & $\begin{array}{l}r m / B 3 \\
r m / C\end{array}$ & $\begin{array}{l}\text { dTDP-glucose 4,6-dehydratase } \\
\text { dTDP-4-dehydrorhamnose }\end{array}$ & $\begin{array}{l}\text { Rv1077 } \\
\text { Rv0848 }\end{array}$ & $\begin{array}{l}\text { cysM2 } \\
\text { cysM3 }\end{array}$ & $\begin{array}{l}\text { cystathionine } \beta \text {-synthase } \\
\text { putative cysteine synthase }\end{array}$ \\
\hline Rv2899c & $f d h D$ & affects formate dehydrogenase- $\mathrm{N}$ & & & 3,5-epimerase & Rv1093 & glya & serine hydroxymethyltransferase \\
\hline Rv2900c & $f d h F$ & $\begin{array}{l}\text { molybdopterin-containing oxidore- } \\
\text { ductase }\end{array}$ & Rv3266c & $r m / D$ & $\begin{array}{l}\text { dTDP-4-dehydrorhamnose } \\
\text { reductase }\end{array}$ & $\begin{array}{l}\text { Rv0070c } \\
\text { Rv2996c }\end{array}$ & $\begin{array}{l}\text { glyA2 } \\
\text { serA }\end{array}$ & $\begin{array}{l}\text { serine hydroxymethyltransferase } \\
\text { D-3-phosphoglycerate dehydro- }\end{array}$ \\
\hline Rv1552 & $\operatorname{frd} A$ & fumarate reductase flavoprotein & Rv0322 & $u d g A$ & UDP-glucose & & & genase \\
\hline Rv1553 & $\operatorname{frdB}$ & $\begin{array}{l}\text { subunit } \\
\text { fumarate reductase iron sulphur }\end{array}$ & & & $\begin{array}{l}\text { dehydrogenase/GDP-mannose 6- } \\
\text { dehydrogenase }\end{array}$ & Rv0505c & serB & $\begin{array}{l}\text { probable phosphoserine phos- } \\
\text { phatase }\end{array}$ \\
\hline & & protein & Rv3265c & $w b b L$ & dTDP-rhamnosyl transferase & Rv3042c & serB2 & C-term similar to phosphoserine \\
\hline Rv1554 & frdC & fumarate reductase $15 \mathrm{kD}$ anchor & Rv1525 & wbbl2 & dTDP-rhamnosyl transferase & & & phosphatase \\
\hline Rv1555 & $f r d D$ & $\begin{array}{l}\text { protein } \\
\text { fumarate reductase } 13 \mathrm{kD} \text { anchor }\end{array}$ & Rv3400 & - & probable $\beta$-phosphoglucomutase & Rv0884c & $\operatorname{serC}$ & phosphoserine aminotransferase \\
\hline & & protein & 4. Amino su & sugars & & 4. Aromati & & \\
\hline Rv1161 & narG & nitrate reductase $\alpha$ subunit & Rv3436c & glmS & glucosamine-fructose-6- & Rv3227 & $\operatorname{aroA}$ & 3-phosphoshikimate \\
\hline Rv1162 & narH & nitrate reductase $\beta$ chain & & & phosphate aminotransferase & & & nsferase \\
\hline Rv1164 & narl & nitrate reductase $\gamma$ chain & & & & Rv2538c & $\operatorname{aroB}$ & 3-dehydroquinate synthase \\
\hline Rv1163 & narJ & nitrate reductase $\delta$ chain & 5. Sulphur $r$ & metabolis & & Rv2537c & aroD & 3-dehydroquinate dehydratase \\
\hline Rv1736c & narX & fused nitrate reductase & Rv0711 & ats $A$ & arylsulfatase & Rv2552c & aroE & shikimate 5 -dehydrogenase \\
\hline Rv2391 & nirA & $\begin{array}{l}\text { probable nitrite reductase/sulphite } \\
\text { reductase }\end{array}$ & $\begin{array}{l}\text { Rv3299c } \\
\text { Rv0663 }\end{array}$ & ats $B$ & proable arylsulfatase & $\begin{array}{l}\text { Rv2540c } \\
\text { Rv2178c }\end{array}$ & $\begin{array}{l}\operatorname{aro} F \\
\operatorname{aroG}\end{array}$ & $\begin{array}{l}\text { chorismate synthase } \\
\text { DAHP synthase }\end{array}$ \\
\hline Rv0252 & nirB & nitrite reductase flavoprotein & Rv3077 & ats $F$ & $\begin{array}{l}\text { proabile arylsulfatase } \\
\text { proable arylsulfatase }\end{array}$ & Rv2539c & aroK & $\begin{array}{l}\text { DAHP synthase } \\
\text { shikimate kinase I }\end{array}$ \\
\hline Rv0253 & nirD & probable nitrite reductase small & Rv0296c & ats $G$ & proable arylsulfatase & Rv3838c & pheA & prephenate dehydratase \\
\hline & & subunit & Rv3796 & ats $\mathrm{H}$ & proable arylsulfatase & Rv1613 & $\operatorname{trpA}$ & tryptophan synthase $\alpha$ chain \\
\hline & & & Rv1285 & $\operatorname{cys} D$ & ATP:sulphurylase subunit 2 & Rv1612 & $\operatorname{trp} B$ & tryptophan synthase $\beta$ chain \\
\hline c. Electron & transport & & Rv1286 & $\operatorname{cys} N$ & ATP:sulphurylase subunit 1 & Rv1611 & $\operatorname{trpC}$ & indole-3-glycerol phosphate \\
\hline Rv0409 & ackA & acetate kinase & Rv2131c & $\operatorname{cys} Q$ & homologue of M.leprae cys $Q$ & & & \\
\hline Rv1623c & appC & $\begin{array}{l}\text { cytochrome bd-I/ oxidase } \\
\text { subunit I }\end{array}$ & $\begin{array}{l}\text { Rv3248c } \\
\text { Rv3283 }\end{array}$ & $\begin{array}{l}\operatorname{sahH} \\
\operatorname{sse} A\end{array}$ & $\begin{array}{l}\text { adenosylhomocysteinase } \\
\text { thiosulfate sulfurtransferase }\end{array}$ & Rv2192c & $\operatorname{trpD}$ & $\begin{array}{l}\text { anthranilate phosphoribosyltrans- } \\
\text { ferase }\end{array}$ \\
\hline Rv1622c & $c y d B$ & $\begin{array}{l}\text { cytochrome } d \text { ubiquinol oxidase } \\
\text { subunit II }\end{array}$ & $\begin{array}{l}\text { Rv2291 } \\
\text { Rv3118 }\end{array}$ & $\begin{array}{l}s s e B \\
s s e C\end{array}$ & $\begin{array}{l}\text { thiosulfate sulfurtransferase } \\
\text { thiosulfate sulfurtransferase }\end{array}$ & Rv1609 & $\operatorname{trp} E$ & $\begin{array}{l}\text { anthranilate synthase } \\
\text { component I }\end{array}$ \\
\hline Rv1620c & cydC & $A B C$ transporter & Rv0814c & ssec2 & thiosulfate sulfurtransferase & Rv2386c & $\operatorname{trpE2}$ & anthranilate synthase \\
\hline Rv1621c & cydD & $A B C$ transporter & Rv3762c & & probable alkyl sulfatase & & & \\
\hline Rv2007c & $f d x A$ & ferredoxin & & & & Rv3754 & tyrA & prephenate dehydrogenase \\
\hline Rv3554 & $f d x B$ & & D. Amino ac & acid bios & thesis. & & & \\
\hline Rv1177 & $f d x C$ & ferredoxin $4 \mathrm{Fe}-4 \mathrm{~S}$ & 1. Glutamat & ate family & & 5. Histidine & & \\
\hline Rv3503c & $f d x D$ & probable ferredoxin & Rv1654 & $\arg B$ & acetylglutamate kinase & Rv1603 & hisA & phosphoribosylformimino-5- \\
\hline Rv3029c & fixA & $\begin{array}{l}\text { electron transfer flavoprotein } \\
\beta \text { subunit }\end{array}$ & Rv1652 & $\arg C$ & $\begin{array}{l}\mathrm{N} \text {-acetyl- } \gamma \text {-glutamyl-phosphate } \\
\text { reductase }\end{array}$ & & & $\begin{array}{l}\text { aminoimidazole carboxamide } \\
\text { ribonucleotide isomerase }\end{array}$ \\
\hline Rv3028c & $f i x B$ & $\begin{array}{l}\text { electron transfer flavoprotein } \alpha \\
\text { subunit }\end{array}$ & $\begin{array}{l}\text { Rv1655 } \\
\text { Rv1656 }\end{array}$ & $\begin{array}{l}\arg D \\
\arg F\end{array}$ & $\begin{array}{l}\text { acetylornithine aminotransferase } \\
\text { ornithine carbamoyltransferase }\end{array}$ & Rv1601 & hisB & $\begin{array}{l}\text { imidazole glycerol-phosphate } \\
\text { dehydratase }\end{array}$ \\
\hline Rv3106 & fprA & $\begin{array}{l}\text { adrenodoxin and NADPH ferre- } \\
\text { doxin reductase }\end{array}$ & $\begin{array}{l}\text { Rv1658 } \\
\text { Rv1659 }\end{array}$ & $\operatorname{argG}$ & $\begin{array}{l}\text { arginosuccinate synthase } \\
\text { arginosuccinate lyase }\end{array}$ & Rv1600 & hisC & $\begin{array}{l}\text { histidinol-phosphate aminotrans- } \\
\text { ferase }\end{array}$ \\
\hline Rv0886 & $f p r B$ & $\begin{array}{l}\text { ferredoxin, ferredoxin-NADP } \\
\text { reductase }\end{array}$ & $\begin{array}{l}\text { Rv1653 } \\
\text { Rv2220 }\end{array}$ & $\begin{array}{l}\operatorname{argJ} \\
\operatorname{gln} A 1\end{array}$ & $\begin{array}{l}\text { glutamate } \mathrm{N} \text {-acetyltransferase } \\
\text { glutamine synthase class I }\end{array}$ & Rv3772 & hisC2 & $\begin{array}{l}\text { histidinol-phosphate aminotrans- } \\
\text { ferase }\end{array}$ \\
\hline Rv3251c & $r u b A$ & rubredoxin A & Rv2222c & $g \ln A 2$ & glutamine synthase class II & Rv1599 & hisD & histidinol dehydrogenase \\
\hline
\end{tabular}




\begin{tabular}{|c|c|c|}
\hline Rv1605 & hisF & $\begin{array}{l}\text { imidazole glycerol-phosphate } \\
\text { synthase }\end{array}$ \\
\hline Rv2121c & hisG & ATP phosphoribosyltransferase \\
\hline Rv1602 & hisH & amidotransferase \\
\hline Rv2122c & hisl & $\begin{array}{l}\text { phosphoribosyl-AMP cyclohydro- } \\
\text { lase }\end{array}$ \\
\hline Rv1606 & his/2 & $\begin{array}{l}\text { probable phosphoribosyl-AMP 1,6 } \\
\text { cyclohydrolase }\end{array}$ \\
\hline Rv0114 & - & similar to HisB \\
\hline \multicolumn{3}{|c|}{ 6. Pyruvate family } \\
\hline Rv3423c & alr & alanine racemase \\
\hline \multicolumn{3}{|c|}{ 7. Branched amino acid family } \\
\hline Rv1559 & ilvA & threonine deaminase \\
\hline Rv3003c & $i l v B$ & $\begin{array}{l}\text { acetolactate synthase I large sub- } \\
\text { unit }\end{array}$ \\
\hline Rv3470c & ilvB2 & $\begin{array}{l}\text { acetolactate synthase large sub- } \\
\text { unit }\end{array}$ \\
\hline Rv3001c & ilvC & ketol-acid reductoisomerase \\
\hline Rv0189c & $i l v D$ & dihydroxy-acid dehydratase \\
\hline Rv2210c & ilvE & $\begin{array}{l}\text { branched-chain-amino-acid } \\
\text { transaminase }\end{array}$ \\
\hline Rv1820 & $i l v G$ & acetolactate synthase II \\
\hline Rv3002c & $i l v N$ & $\begin{array}{l}\text { acetolactate synthase I small sub- } \\
\text { unit }\end{array}$ \\
\hline Rv3509c & ilvX & $\begin{array}{l}\text { probable acetohydroxyacid syn- } \\
\text { thase I large subunit }\end{array}$ \\
\hline Rv3710 & leuA & $\alpha$-isopropyl malate synthase \\
\hline Rv2995c & leuB & 3-isopropylmalate dehydrogenase \\
\hline Rv2988c & leuC & $\begin{array}{l}\text { 3-isopropylmalate dehydratase } \\
\text { large subunit }\end{array}$ \\
\hline Rv2987c & leuD & $\begin{array}{l}\text { 3-isopropylmalate dehydratase } \\
\text { small subunit }\end{array}$ \\
\hline
\end{tabular}

F. Purines, pyrimidines, nucleosides and nucleotides 1. Purine ribonucleotide biosynthesis

Rv1389 gmk putative guanylate kinase

Rv3396c guaA GMP synthase

Rv1843c guaB1 inosine-5'-monophosphate dehydrogenase

Rv3411c guaB2 inosine-5'-monophosphate dehydrogenase

Rv3410c guaB3 inosine-5'-monophosphate dehy-

Rv1017c prsA $\quad \begin{aligned} & \text { drogenase } \\ & \text { ribose-phosphate pyrophosphoki- }\end{aligned}$

Rv1017c PISA ribose-p nase

Rv0357c purA adenylosuccinate synthase

Rv0777 purB adenylosuccinate lyase

Rv0780 purC phosphoribosylaminoimidazoleRv0772 purD succinocarboxamide synthase

Rv3275c purE phosphoribosylaminoimidazole

Rv0808 purF amidophosphoribosyltransferase-

Rv0957 purH phosphoribosylaminoimidazole-

phosphoribosylaminoimidazole-

Rv3276c purK phosphoribosylaminoimidazole

carboxylase ATPase subunit

Rv0803 purL phosphoribosylformylglycin-

Rv0809 purM 5'-phosphoribosyl-5-aminoimida-

Rv0956 purN phosphoribosylglycinamide

formyltransferase I

Rv0788 purQ phosphoribosylformylglycin-

Rv0389 purT phosphoribosylglycinamide

Rv0389 purT $\begin{aligned} & \text { phosphoribosylglycin } \\ & \text { formyltransferase II }\end{aligned}$

Rv2964 purU formyltetrahydrofolate deformylase

2. Pyrimidine ribonucleotide biosynthesis

Rv1383 carA carbamoyl-phosphate synthase

Rv1384 carB carbamoyl-phosphate synthase

Rv1380 pyrB $\quad \begin{aligned} & \text { subunit } \\ & \text { aspartate carbamoyltransferase }\end{aligned}$

$\begin{array}{lll}\text { Rv1380 } & \text { pyrB } & \text { aspartate carba } \\ \text { Rv1381 } & \text { pyrC } & \text { dihydroorotase }\end{array}$

$\begin{array}{lll}\text { Rv1381 } & \text { pyrC } & \text { dihydroorotase } \\ \text { Rv2139 } & \text { pyrD } & \text { dihydroorotate dehydrogenase }\end{array}$

$\begin{array}{lll}\text { Rv2139 pyrD } & \text { dihydroorotate dehydrogenase } \\ \text { Rv1385 pyrF } & \text { orotidine 5'-phosphate decarboxy- }\end{array}$

Rv1699 lase

$\begin{array}{lll}\text { Rv2883c } & \text { pyrH } & \text { CTP synthase } \\ \text { uridylate kinase }\end{array}$

Rv0382c umpA probable uridine 5'-monophosphate synthase

3. 2'-deoxyribonucleotide metabolism

Rv0321 dcd deoxycytidine triphosphate

deaminase

dut deoxyuridine triphosphatase

$\begin{array}{ll}\text { Rv0233 nrdB ribonucleoside-diphosphate } & \text { reductase B2 (eukaryotic-like) }\end{array}$

Rv3051c nrdE ribonucleoside diphosphate

reductase $\alpha$ chain

Rv1981c nrdF ribonucleotide reductase small subunit

Rv3048c nrdG ribonucleoside-diphosphate small

Rv3053c nrdH glutaredoxin electron transport

component of NrdEF system

Rrdl Nrdl/YgaO/YmaA famly

$\begin{array}{lll}\text { Rv3247c } & \text { tmk } & \text { thymidylate kinase } \\ \text { Rv2764c } & \text { thy } A & \text { thymidylate synthase }\end{array}$

$\begin{array}{lll}\text { Rv2764c } & \text { thy } A & \text { thymidylate synthase } \\ \text { Rv0570 } & n r d Z & \text { ribonucleotide reductase, class II }\end{array}$

Rv3752c - probable cytidine/deoxycytidylate deaminase

4. Salvage of nucleosides and nucleotides

Rv3313c add probable adenosine deaminase

Rv2584c apt adenine phosphoribosyltrans-

Rv3315c cdd probable cytidine deaminase

Rv3314c deoA thymidine phosphorylase

Rv0478 deoC deoxyribose-phosphate aldolase

Rv3307 deoD probable purine nucleoside phos-

Rv3624c hpt probable hypoxanthine-guanine

Rv3393 phosphoribosyltransferase

probable inosine-uridine
preferring nucleoside hydrolase

Rv0535 pnp phosphorylase from Pnp/MtaP

family 2

Rv3309c upp uracil phophoribosyltransferase

5. Miscellaneous nucleoside/nucleotide reaction

Rv0733 adk probable adenylate kinase

Rv2364c bex GTP-binding protein of Era/ThdF

Rv1712 cmk family

Rv2344c dgt probable deoxyguanosine

triphosphate hydrolase

Rv2727c miaA tRNA $\delta(2)$-isopentenylpyrophos-

phate transferase

Rv2445c ndkA nucleoside diphosphate kinase

Rv2440c obg Obg GTP-binding protein

Rv2583c relA (p)ppGpp synthase I

G. Biosynthesis of cofactors, prosthetic groups and

carriers

Rv1568 bioA adenosylmethionine-8-amino-7-

oxononanoate aminotransferase

Rv1589 bioB biotin synthase

Rv1570 bioD dethiobiotin synthase

Rv1569 biof 8-amino-7-oxononanoate

synthase

\section{Biof}

Rv3279c birA biotin apo-protein ligase

Rv1442 bisC biotin sulfoxide reductase

Rv0089 - possible bioC biotin synthesis

gene

2. Folic acid

Rv2763c dfrA dihydrofolate reductase

Rv2447c folC folylpolyglutamate synthase

Rv3356c folD methylenetetrahydrofolate dehydrogenas

Rv3609c folE GTP cyclohydrolase I

Rv3606c folK 7,8-dihydro-6-hydroxymethylpterin pyrophosphokinase

Rv3608c folP dihydropteroate synthase

Rv1207 folP2 dihydropteroate synthase

Rv3607c folX may be involved in folate biosyn-

Rv0013 pabA thesis $p$-aminobenzoate synthase gluta-

$p$-aminobenzoate synth
mine amidotransferase

Rv1005c pabB p-aminobenzoate synthase

Rv0812 pabC aminodeoxychorismate lyase

3. Lipoate

Rv2218 lipA lipoate biosynthesis protein A

Rv2217 lipB lipoate biosynthesis protein B

4. Molybdopterin

Rv3109 moaA molybdenum cofactor biosynthesis, protein $A$

Rv0869c moaA2 molybdenum cofactor biosynthesis, protein $A$

Rv0438c moaA3 molybdenum cofactor biosynthe-

$\begin{array}{ll}\text { Rv3110 moaB } & \begin{array}{l}\text { sis, protein A } \\ \text { molybdenum cofactor biosynthe- }\end{array}\end{array}$ sis, protein B

Rv0984 moaB2 molybdenum cofactor biosynthe-

sis, protein $B$

Rv3111 moaC molybdenum cofactor biosynthe-

sis, protein $\mathrm{C}$

Rv0864 moaC2 molybdenum cofactor biosynthe-

Rv3324c moaC3 sis, protein C

Rv3112 sis, protein C

Rv0868c moaD2 $\begin{aligned} & \text { subunit } 1 \\ & \text { molybdopterin converting factor }\end{aligned}$ subunit 1

Rv3119 moaE molybdopterin-converting factor subunit 2

Rv0866 moaE2 molybdopterin-converting factor subunit 2

Rv3322c moaE3 molybdopterin-converting factor subunit 2

Rv0994 moeA molybdopterin biosynthesis

Rv3116 moeB molybdopterin biosynthesis

Rv2338c moeW molybdopterin biosynthesis

Rv1681 moeX weak similarity to E. coli MoaA

Rv3206c moeZ probably involved in

molybdopterin biosynthesis

5. Pantothenate

Rv1092C CoaA

Rv2225 panB

Rv3602c panC

Rv3601c panD

pantothenate kinase

3-methyl-2-oxobutanoate

hydroxymethyltransferase

pantoate- $\beta$-alanine ligase

6. Pyridoxine

Rv2607 pdxH pyridoxamine 5'-phosphate oxidase

7. Pyridine nucleotide

Rv1594 nadA quinolinate synthase

Rv1595 nadB L-aspartate oxidase

Rv1596 nadC nicotinate-nucleotide pyrophos-

Rv0423c thic thiamine

thiamine synthesis, pyrimidine

8. Thiamine

Rv0422c thiD phosphomethylpyrimidine kinase

Rv0414c thiE thiamine synthesis, thiazole

Rv0417 thig

moiety synthesis, thiazole

Rv2977c thil probable thiamine-monophos-

phate kinase

9. Riboflavin

Rv1940 ribA GTP cyclohydrolase II

Rv1415 ribA2 probable GTP cyclohydrolase II

Rv1412 ribC riboflavin synthase $\alpha$ chain

Rv2671 ribD probable riboflavin deaminase

Rv2786c ribF riboflavin kinase

Rv1409 ribG riboflavin biosynthesis

Rv1416 ribH riboflavin synthase $\beta$ chain

Rv3300c - probable deaminase, riboflavin synthesis

10. Thioredoxin, glutaredoxin and mycothiol

Rv0773c ggtA putative $\gamma$-glutamyl transpeptidase

Rv2394 ggtB $\quad \gamma$-glutamyltranspeptidase

precursor

Rv2855 gorA glutathione reductase homologue

Rv0816c thiX equivalent to M. leprae ThiX

Rv1470 trxA thioredoxin

Rv1471 trxB thioredoxin reductase

Rv3913 trxB2 thioredoxin reductase

Rv3914 trxC thioredoxin

11. Menaquinone, $P Q Q$, ubiquinone and other terpenoids

Rv2682c $d x s$ 1-deoxy-D-xylulose 5-phosphate

synthase

Rv0562 grcC1 heptaprenyl diphosphate

Rv0989c grcCe synthase II

synthase II

Rv3398c idsA geranylgeranyl pyrophosphate

Rv2173 idsA2 geranylgeranyl pyrophosphate

synthase

Rv3383c idsB transfergeranyl, similar geranyl

Rv0534c menA pyrophosphate synthase

octaprenyltransferase

Rv0548c menB naphthoate synthase

Rv0553 menC o-succinylbenzoate-CoA synthase

Rv0555 menD 2-succinyl-6-hydroxy-2,4-cyclo-

Rv0542C menE $\begin{aligned} & \text { hexadiene-1-carboxylate synthase } \\ & \text { o-succinylbenzoic acid-CoA ligase }\end{aligned}$

Rv3853 menG S-adenosylmethionine:

R $3397 \mathrm{C}$ phy phytoene synthase

Rv0693 pqqE coenzyme PQQ synthesis

ubiquinone/menaquinone biosyn-

thesis methyltransferase

12. Heme and porphyrin

Rv0509 hemA glutamyl-tRNA reductase

Rv0512 hemB $\delta$-aminolevulinic acid dehydratas

Rv0510 hemC porphobilinogen deaminase

Rv2678c hemE uroporphyrinogen decarboxylase 


\begin{tabular}{|c|c|c|}
\hline Rv1300 & hemk & protoporphyrinogen oxidase \\
\hline Rv0524 & hemL & $\begin{array}{l}\text { glutamate-1-semialdehyde amino- } \\
\text { transferase }\end{array}$ \\
\hline Rv2388c & $\operatorname{hemN}$ & $\begin{array}{l}\text { oxygen-independent copropor- } \\
\text { phyrinogen III oxidase }\end{array}$ \\
\hline Rv2677c & hem $Y^{\prime}$ & protoporphyrinogen oxidase \\
\hline Rv1485 & hemZ & ferrochelatase \\
\hline \multicolumn{3}{|c|}{ 13. Cobalamin } \\
\hline Rv2849c & $\operatorname{cob} A$ & cob(I)alamin adenosyltransferase \\
\hline Rv2848c & $c o b B$ & $\begin{array}{l}\text { cobyrinic acid a,c-diamide } \\
\text { synthase }\end{array}$ \\
\hline Rv2231c & $c o b C$ & aminotransferase \\
\hline Rv2236c & cobD & cobinamide synthase \\
\hline Rv2064 & $c o b G$ & percorrin reductase \\
\hline Rv2065 & $\mathrm{cobH}$ & precorrin isomerase \\
\hline Rv2066 & cobl & Cobl-CobJ fusion protein \\
\hline Rv2070c & cobK & precorrin reductase \\
\hline Rv2072c & $c o b L$ & probable methyltransferase \\
\hline Rv2071c & cobM & precorrin-3 methylase \\
\hline Rv2062c & $\operatorname{cobN}$ & cobalt insertion \\
\hline Rv2208 & cobs & $\begin{array}{l}\text { cobalamin (5'-phosphate) } \\
\text { synthase }\end{array}$ \\
\hline Rv2207 & cobT & $\begin{array}{l}\text { nicotinate-nucleotide-dimethyl- } \\
\text { benzimidazole transferase }\end{array}$ \\
\hline Rv0254c & $\operatorname{cobU}$ & cobinamide kinase \\
\hline Rv0255c & $c o b Q$ & cobyric acid synthase \\
\hline Rv3713 & $c o b Q 2$ & possible cobyric acid synthase \\
\hline Rv0306 & - & $\begin{array}{l}\text { similar to BluB cobalamin synthe- } \\
\text { sis protein R. capsulatus }\end{array}$ \\
\hline \multicolumn{3}{|c|}{ 14. Iron utilization } \\
\hline Rv1876 & bfrA & bacterioferritin \\
\hline Rv3841 & $b f r B$ & bacterioferritin \\
\hline Rv3215 & entC & probable isochorismate synthase \\
\hline Rv3214 & entD & $\begin{array}{l}\text { weak similarity to many phospho- } \\
\text { glycerate mutases }\end{array}$ \\
\hline Rv2895c & viuB & $\begin{array}{l}\text { similar to proteins involved in } \\
\text { vibriobactin uptake }\end{array}$ \\
\hline Rv3525c & - & $\begin{array}{l}\text { similar to ferripyochelin binding } \\
\text { protein }\end{array}$ \\
\hline
\end{tabular}

H. Lipid biosynthesis

1. Synthesis of fatty and mycolic acids

Rv3285 accA3 acetyl/propionyl CoA carboxylase

Rv0904c accD3 $\begin{aligned} & \alpha \text { subunit } \\ & \text { acetyl/propionyl CoA carboxylase }\end{aligned}$

$\begin{array}{ll}R v 3799 c \quad a c c D 4 & \beta \text { subunit } \\ \text { acetyl/propionyl CoA carboxylase }\end{array}$

Rv3280 accD5 $\begin{aligned} & \beta \text { subunit } \\ & \text { acety//propionyl CoA carboxylase }\end{aligned}$

$\begin{array}{lll}\text { Rv3280 } & \text { accD5 } & \begin{array}{l}\text { acetyl/propionyl CoA carboxylase } \\ \beta \text { subunit }\end{array} \\ \text { Rv2247 } & \text { accD6 } & \text { acetyl/propionyl CoA carboxylase }\end{array}$

$\begin{array}{lll}\text { Rv2247 } & \text { accD6 } & \begin{array}{l}\text { acetyl/propionyl CoA carboxylase } \\ \beta \text { subunit }\end{array} \\ \text { Rv2244 } & \text { acpM } & \begin{array}{l}\text { acyl carrier protein (meromycolate }\end{array}\end{array}$

$\begin{array}{ll}\text { Rv2523c acpS } & \text { CoAtension) } \\ & \text { Potapo-[ACP] pantethienephos- }\end{array}$

$\begin{array}{lll}\text { Rv2243 fabD } & \begin{array}{l}\text { photransferase } \\ \text { malonyl CoA-[ACP] transacylase }\end{array}\end{array}$

Rv0649 fabD2 malonyl CoA-[ACP] transacylase

Rv1483 fabG1 3-oxoacyl-[ACP] reductase (aka

$\begin{array}{lll}\text { Rv1483 fabG1 } & \begin{array}{l}\text { 3-oxoacyl-[ACP] reductase } \\ \text { MabA) }\end{array} \\ \text { Rv1350 fabG2 } & \text { 3-oxoacyl-[ACP] Reductase }\end{array}$

$\begin{array}{lll}\text { Rv1350 } & \text { fabG2 } & \text { 3-oxoacyl-[ACP] Reductase } \\ \text { Rv2002 } & \text { fabG3 } & \text { 3-oxoacyl-[ACP] reductase }\end{array}$

$\begin{array}{lll}\text { Rv2002 } & \text { fabG3 } & \text { 3-oxoacyl-[ACP] reductase } \\ \text { Rv0242c } & \text { fabG4 } & \text { 3-oxoacyl-[ACP] reductase }\end{array}$

Rv2766c fabG5 3-oxoacyl-[ACP] reductase

Rv0533c fabH $\beta$-ketoacyl-ACP synthase III

Rv2524c fas fatty acid synthase

Rv1484 inhA enoyl-[ACP] reductase

Rv2245 kasA $\beta$-ketoacyl-ACP synthase

Rv2246 kasB $\quad \beta$-ketoacyl-ACP synthase

(meromycolate extension)

tesB1 thioesterase

Rv2605c tesB2 thioesterase

Rv0033 - possible acyl carrier protein

Rv1344 - possible acyl carrier protein

Rv1722 - possible biotin carboxylase

Rv3221c - resembles biotin carboxyl carrier

Rv3472 - possible acyl carrier protein

2. Modification of fatty and mycolic acids

Rv3391 acrA1 fatty acyl-CoA reductase

Rv3392c cmaA1 cyclopropane mycolic acid

synthase 1

Rv0503c cmaA2 cyclopropane mycolic acid syn-

thase 2

acyl-[ACP] desaturase

Rv1094 desA2 acyl-[ACP] desaturase

Rv3229c desA3 acyl-[ACP] desaturase

Rv0645c mmaA1 methoxymycolic acid synthase 1

Rv0644c mmaA2 methoxymycolic acid synthase 2

Rv0643c mmaA3 methoxymycolic acid synthase 3

Rv0642c mmaA4 methoxymycolic acid synthase 4

Rv0447c ufaA1 unknown fatty acid methyltrans-

ferase

Rv3538 ufaA2 unknown fatty acid methyltrans-

Rv0469 umaA1 unknown mycolic acid methyltransferase
Rv0470c umaA2 unknown mycolic acid methyltransferase

3. Acyltransferases, mycoloyltransferases and

Rv2289 cdh CDP-diacylglycerol phosphatidyl-

Rv2881c cdsA $\begin{aligned} & \text { hydrolase } \\ & \text { phosphatidate cytidylyltransferase }\end{aligned}$

Rv3804c fbpA antigen 85A, mycolyltransferase

Rv1886c $f b p B$ antigen 85B, mycolyltransferase

Rv3803c fbpC1 antigen 85C, mycolyltransferase

Rv0129c fbpC2 antigen 85C', mycolytransferase

Rv0564c gpdA1 glycerol-3-phosphate dehydroge-

Rv2982c gpdA2 glycerol-3-phosphate dehydroge-

Rv2612c pgsA CDP-diacylglycerol-glycerol-3phosphate phosphatidyltrans ferase

Rv1822 pgsA2 CDP-diacylglycerol-glycerol-3phosphate phosphatidyltrans ferase

Rv2746c pgsA3 CDP-diacylglycerol-glycerol-3phosphate phosphatidyltransferase

Rv1551 plsB1 glycerol-3-phosphate acyltransgerase

Rv2482c plsB2 glycerol-3-phosphate acyltrans-

Rv0437c psd putative phosphatidylserine

decarboxylase

Rv0436c pssA CDP-diacylglycerol-serine

o-phosphatidyltransferase

Rv0045c - possible dihydrolipoamide acetyl-

transferase

Rv1543 - probable fatty-acyl CoA reductase

Rv1627c
Rv1814

Rv1867

lipid carrier protein

possible C-5 sterol desaturase

similar to acetyl CoA

synthase/lipid carriers

Rv2261c - apolipoprotein N-acyltrans-

Rv2262c - $\quad$ apolipoprotein N-acyltrans

ferase-b

Rv3523 - lipid carrier protein

Rv3720 - $\quad$ C-term similar to cyclopropane

fatty acid synthases

1. Polyketide and non-ribosomal peptide synthesis

Rv2940c mas mycocerosic acid synthase

Rv2384 mbtA mycobactin/exochelin synthesis

(salicylate-AMP ligase)

Rv2383c mbtB mycobactin/exochelin synthesis (serine/threonine ligation)

Rv2382c mbtC mycobactin/exochelin synthesis

Rv2381c mbtD mycobactin/exochelin synthesis (polyketide synthase)

Rv2380c mbtE mycobactin/exochelin synthesis (lysine ligation)

Rv2379c mbtF mycobactin/exochelin synthesis

(lysine ligation)

Rv2378c mbtG mycobactin/exochelin synthesis (lysine hydroxylase)

Rv2377c mbth mycobactin/exochelin synthesis

Rv0101 nrp unknown non-ribosomal peptid synthase

Rv1153c omt PKS o-methyltransferase

Rv3824c papA1 PKS-associated protein, unknown function

Rv3820c рарA2 PKS-associated protein, unknown

function

Rv1182 рарАЗ PKS-associated protein, unknown function

Rv1528c papA4 PKS-associated protein, unknown function

Rv2939 рарA5 PKS-associated protein, unknown function

Rv2946c pks1 polyketide synthase

Rv1660 pks10 polyketide synthase (chalcone

synthase-like)

synthase-like)

Rv1665 pks11 $\begin{aligned} & \text { polyketide syn } \\ & \text { synthase-like) }\end{aligned}$

Rv2048c pks12 polyketide synthase (erythronolide synthase-like)

Rv3800c pks13 polyketide synthase

Rv1342c pks14 polyketide synthase (chalcone synthase-like)

Rv2947c pks15 polyketide synthase

Rv1013 pks16 polyketide synthase

Rv1663 pks17 polyketide synthase

Rv1372 pks18 polyketide synthase

Rv3825c pks2 polyketide synthase

Rv1180 pks3 polyketide synthase

Rv1181 pks4 polyketide synthase

Rv1527c pks5 polyketide synthase

Rv0405 pks6 polyketide synthase

Rv1661 pks7 polyketide synthase

$\begin{array}{lll}\mathrm{Rv} 1662 & p k s 8 & \text { polyketide synthase } \\ \mathrm{Rv} 1664 & \text { pks9 } & \text { polyketide synthase }\end{array}$
Rv2931 ppsA phenolpthiocerol synthesis ( $p k s B)$ Rv2932 pps $B$ phenolpthiocerol synthesis (pksC) Rv2933 ppsC phenolpthiocerol synthesis ( $p k s D)$ Rv2934 ppsD phenolpthiocerol synthesis ( $p k s E)$

Rv2935 ppsE phenolpthiocerol synthesis (pksF)

Rv2928 tesA thioesterase

Rv1544 - probable ketoacyl reductase

J. Broad regulatory functions

1. Repressors/activators

Rv1657 argR arginine represso

Rv1267c embR regulator of embAB genes (AfsR/Dndl/RedD family)

Rv1909c furA ferric uptake regulatory protein

Rv2359 furB ferric uptake regulatory protein

Rv2919c glnB nitrogen regulatory protein

Rv2711 ideR iron dependent repressor, IdeR

Rv2720 IexA LexA, SOS repressor protein

Rv1479 moxR transcriptional regulator, MoxR homologue

Rv3692 moxR2 transcriptional regulator, MoxR homologue

Rv3164c moxR3 transcriptional regulator, MoxR homologue

Rv0212c nadR similar to Ecoli NadR

Rv0117 oxyS transcriptional regulator (LysR

family)

Rv1379 pyrR regulatory protein pyrimidine

Rv2788 sirR iron-dependent transcriptional

repressor

Rv3082c virS putative virulence regulating protein (AraC/XylS family)

Rv3219 whiB1 WhiB transcriptional activator

homologue

WhiB transcriptional activator

homologue

Rv3681c whiB4 WhiB transcriptional activator

Rv0023 - $\quad \begin{aligned} & \text { homologue } \\ & \text { putative transcriptional regulator }\end{aligned}$

Rv0043c - transcriptional regulator (GntR

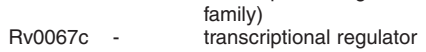

(TetR/AcrR family)

$\begin{array}{ll}\text { (TetR/AcrR family) } & \\ \text { (Tanscriptonal regulato }\end{array}$

Rv0081 - $\quad$ transcriptional regulator (ArsR

Rv0135c - putative transcriptional regulator

Rv0144 - putative transcriptional regulator

Rv0158 - transcriptional regulato

(TetR/AcrR family)

Rv0165c - transcriptional regulator (GntR

Rv0195 - $\quad \begin{aligned} & \text { family) } \\ & \text { transcriptional regulator }\end{aligned}$

(LuxR/UhpA family)

transcriptional regulator

$\begin{array}{ll} & \text { (TetR/AcrR family) } \\ \text { Rv0232 - } & \text { transcriptional regulato }\end{array}$

(TetR/AcrR family)

Rv0238 - transcriptional regulator

Rv0273c - putative transcriptional regulato

Rv0302 - transcriptional regulator

(TetR/AcrR family)

Rv0324 - putative transcriptional regulator

Rv0328 - transcriptional regulator

(TetR/AcrR family)

Rv0348 - putative transcriptional regulato

transcriptional regulator (LysR

family)

Rv0386 - transcriptional regulato

(LuxR/UhpA family)

Rv0452 - putative transcriptional regulato

Rv0465c - transcriptional regulator

(PbsX/Xre family)

$\begin{array}{ll}\text { Rv0472c - } & \begin{array}{l}\text { transcriptional regulator } \\ \text { (TetR/AcrR family) }\end{array}\end{array}$

Rv0474 - transcriptional regulator

Rv0485 - $\quad$ (PbsX/Xre family)

family)

transcriptional regulator (GntR

framily)

Rv0552 - putative transcriptional regulator

putative transcriptional regulato

transcriptional regulator (GntR

family)

Rv0650 - t transcriptional regulator (ROK

Rv0653c - $\quad$ putative transcriptional regulator

Rv0681 - transcriptional regulator

(TetR/AcrR family)

transcriptional regulato

$\begin{array}{ll}\text { Rv0691c - } & \text { transcriptional regulator } \\ \text { (TetR/AcrR family) }\end{array}$

Rv0737 - putative transcriptional regulator

Rv0744c - putative transcriptional regulato

Rv0792C - t transcriptional regulator (GntR 


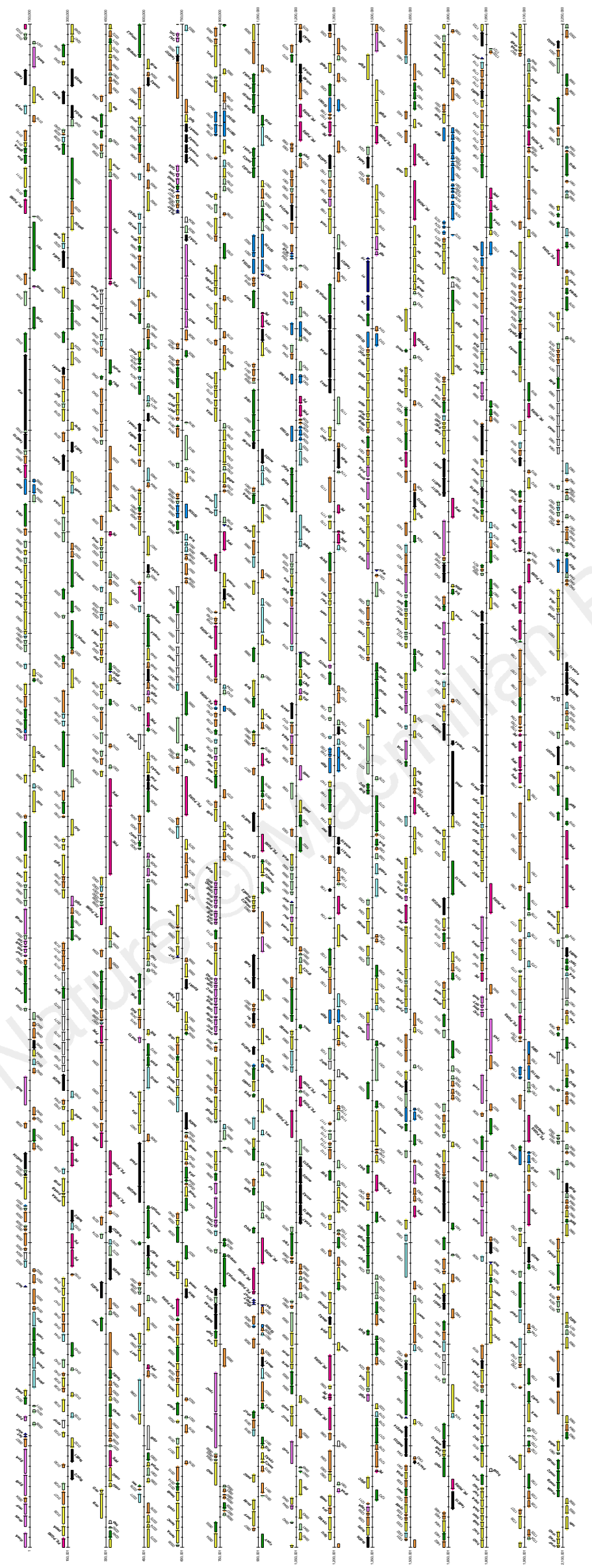

Nature ๑ Macmillan Publishers Ltd 1998 


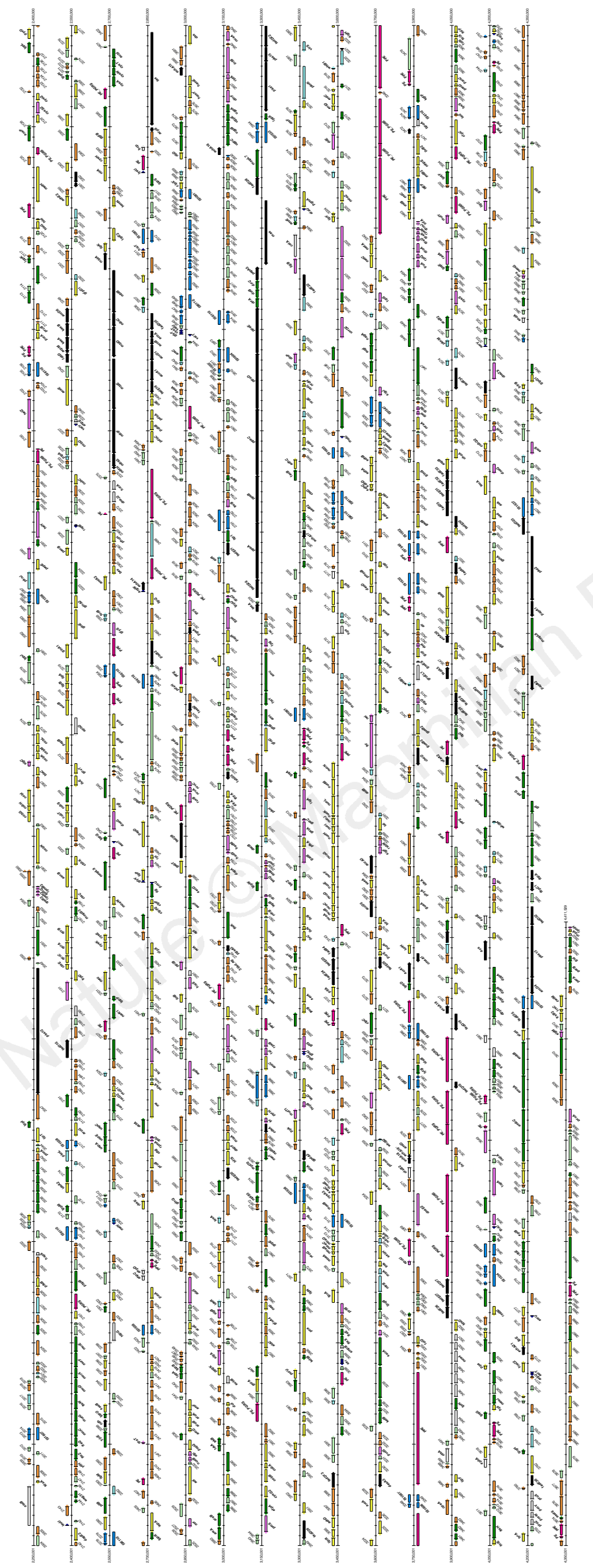




\begin{tabular}{|c|c|c|c|c|c|c|c|c|}
\hline \multirow[b]{2}{*}{ Rv0823c } & \multirow[b]{2}{*}{ - } & family) & \multirow{2}{*}{$\begin{array}{l}\text { Rv3160c } \\
\text { Rv3167c } \\
\text { Rv3173c }\end{array}$} & \multirow{2}{*}{-} & putative transcriptional regulator & & & truncated \\
\hline & & $\begin{array}{l}\text { transcriptional regulator } \\
\text { (NifR3/Smm1 family) }\end{array}$ & & & $\begin{array}{l}\text { putative transcriptional regulator } \\
\text { transcriptional regulator }\end{array}$ & Rv0018c & ppp & $\begin{array}{l}\text { putative phosphoprotein phos- } \\
\text { phatase }\end{array}$ \\
\hline Rv0827c & - & $\begin{array}{l}\text { transcriptional regulator (ArsR } \\
\text { family) }\end{array}$ & Rv3183 & - & $\begin{array}{l}\text { (TetR/AcrR family) } \\
\text { putative transcriptional regulator }\end{array}$ & Rv2234 & ptpA & $\begin{array}{l}\text { low molecular weight protein-tyro- } \\
\text { sine-phosphatase }\end{array}$ \\
\hline Rv0890c & - & $\begin{array}{l}\text { transcriptional regulator } \\
\text { (LuxR/UhpA family) }\end{array}$ & Rv3208 & - & $\begin{array}{l}\text { transcriptional regulator } \\
\text { (TetR/AcrR family) }\end{array}$ & Rv0153c & - & $\begin{array}{l}\text { putative protein-tyrosine-phos- } \\
\text { phatase }\end{array}$ \\
\hline Rv0891c & - & putative transcriptional regulator & Rv3249c & - & transcriptional regulator & & & \\
\hline Rv0894 & - & putative transcriptional regulator & & & (TetR/AcrR family) & II. Macrom & holecule r & netabolism \\
\hline Rv1019 & - & $\begin{array}{l}\text { transcriptional regulator } \\
\text { (TetR/AcrR family) }\end{array}$ & Rv3291c & - & $\begin{array}{l}\text { transcriptional regulator } \\
\text { (Lrp/AsnC family) }\end{array}$ & $\begin{array}{l}\text { A. Synthes } \\
\text { 1. Riboson }\end{array}$ & $\begin{array}{l}\text { sis and } m \\
\text { nal proteir }\end{array}$ & $\begin{array}{l}\text { odification of macromolecules } \\
\text { synthesis and modification }\end{array}$ \\
\hline Rv1049 & - & $\begin{array}{l}\text { transcriptional regulator (MarR } \\
\text { family) }\end{array}$ & Rv3295 & - & $\begin{array}{l}\text { transcriptional regulator } \\
\text { (TetR/AcrR family) }\end{array}$ & Rv3420c & riml & $\begin{array}{l}\text { ribosomal protein S18 acetyl } \\
\text { transferase }\end{array}$ \\
\hline Rv1129c & - & $\begin{array}{l}\text { transcriptional regulator } \\
\text { (PbsX/Xre family) }\end{array}$ & Rv3334 & - & $\begin{array}{l}\text { transcriptional regulator (MerR } \\
\text { family) }\end{array}$ & $\begin{array}{l}\text { Rv0995 } \\
\text { Rv0641 }\end{array}$ & $\begin{array}{l}\operatorname{rimJ} \\
\operatorname{rplA}\end{array}$ & $\begin{array}{l}\text { acetylation of } 30 \mathrm{~S} S 5 \text { subunit } \\
50 \mathrm{~S} \text { ribosomal protein } \mathrm{L} 1\end{array}$ \\
\hline Rv1151c & - & putative transcriptional regulator & Rv3405c & - & putative transcriptional regulator & Rv0704 & $r p / B$ & 50 S ribosomal protein L2 \\
\hline Rv1152 & - & $\begin{array}{l}\text { transcriptional regulator (GntR } \\
\text { family) }\end{array}$ & $\begin{array}{l}\text { Rv3522 } \\
\text { Rv3557c }\end{array}$ & - & $\begin{array}{l}\text { putative transcriptional regulator } \\
\text { transcriptional regulator }\end{array}$ & $\begin{array}{l}\text { Rv0701 } \\
\text { Rv0702 }\end{array}$ & $\begin{array}{l}r p / C \\
r p / D\end{array}$ & $\begin{array}{l}50 \text { S ribosomal protein L3 } \\
50 \text { S ribosomal protein L4 }\end{array}$ \\
\hline Rv1167c & - & putative transcriptional regulator & & & (TetR/AcrR family) & Rv0716 & rplE & $50 S$ ribosomal protein L5 \\
\hline Rv1219c & - & putative transcriptional regulator & Rv3574 & - & transcriptional regulator & Rv0719 & $r p / F$ & 50 S ribosomal protein L6 \\
\hline Rv1255c & - & $\begin{array}{l}\text { transcriptional regulator } \\
\text { (TetR/AcrR family) }\end{array}$ & Rv3575c & - & $\begin{array}{l}\text { (TetR/AcrR family) } \\
\text { transcriptional regulator (Lacl }\end{array}$ & $\begin{array}{l}\text { Rv0056 } \\
\text { Rv0651 }\end{array}$ & $\begin{array}{l}\text { rpll } \\
\text { rplJ }\end{array}$ & $\begin{array}{l}50 \text { S ribosomal protein L9 } \\
50 \text { r ribosomal protein L10 }\end{array}$ \\
\hline Rv1332 & - & putative transcriptional regulator & & & family) & Rv0640 & rplk & $50 \mathrm{~S}$ ribosomal protein L11 \\
\hline Rv1353c & - & $\begin{array}{l}\text { transcriptional regulator } \\
\text { (TetR/AcrR family) }\end{array}$ & $\begin{array}{l}\text { Rv3583c } \\
\text { Rv3676 }\end{array}$ & - & $\begin{array}{l}\text { putative transcriptional regulator } \\
\text { transcriptional regulator (Crp/Fnr }\end{array}$ & $\begin{array}{l}\text { Rv0652 } \\
\text { Rv3443c }\end{array}$ & $\begin{array}{l}\text { rp/L } \\
\text { rp/M }\end{array}$ & $\begin{array}{l}50 S \text { ribosomal protein } L 7 / L 12 \\
50 S \text { ribosomal protein } L 13\end{array}$ \\
\hline Rv1358 & - & transcriptional regulator & & & family) & Rv0714 & $r p / N$ & 50 S ribosomal protein L14 \\
\hline & & (LuxR/UnpA family) & Rv3678c & - & transcriptional regulator (LysR & Rv0723 & rplO & 50 S ribosomal protein L15 \\
\hline Rv1359 & - & putative transcriptional regulator & & & family) & Rv0708 & rplP & 50 S ribosomal protein L16 \\
\hline Rv1395 & - & $\begin{array}{l}\text { transcriptional regulator } \\
\text { (AraC/XylS family) }\end{array}$ & Rv3736 & - & $\begin{array}{l}\text { transcriptional regulator } \\
\text { (AraC/XylS family) }\end{array}$ & $\begin{array}{l}\text { Rv3456c } \\
\text { Rv0720 }\end{array}$ & $\begin{array}{l}r p / Q \\
r p / R\end{array}$ & $\begin{array}{l}50 \text { ribosomal protein L17 } \\
50 \text { S ribosomal protein L18 }\end{array}$ \\
\hline Rv1404 & - & $\begin{array}{l}\text { transcriptional regulator (MarR } \\
\text { family) }\end{array}$ & Rv3744 & - & $\begin{array}{l}\text { transcriptional regulator (ArsR } \\
\text { family) }\end{array}$ & $\begin{array}{l}\text { Rv2904c } \\
\text { Rv1643 }\end{array}$ & $r p / S$ & $\begin{array}{l}50 \text { S ribosomal protein L19 } \\
50 \text { S ribosomal protein L20 }\end{array}$ \\
\hline Rv1423 & - & putative transcriptional regulator & Rv3830c & - & transcriptional regulator & Rv2442c & rp/U & $50 S$ ribosomal protein L21 \\
\hline Rv1460 & - & putative transcriptional regulator & & & (TetR/AcrR family) & Rv0706 & $r p / V$ & 50 S ribosomal protein L22 \\
\hline Rv1474c & - & $\begin{array}{l}\text { transcriptional regulator } \\
\text { (TetR/AcrR family) }\end{array}$ & Rv3833 & - & $\begin{array}{l}\text { transcriptional regulator } \\
\text { (AraC/XylS family) }\end{array}$ & $\begin{array}{l}\text { Rv0703 } \\
\text { Rv0715 }\end{array}$ & $\begin{array}{l}r p / W \\
r p / X\end{array}$ & $\begin{array}{l}50 \text { S ribosomal protein L23 } \\
50 \text { ribosomal protein L24 }\end{array}$ \\
\hline Rv1534 & - & transcriptional regulator & $\begin{array}{l}\text { Rv3840 } \\
\text { Rv3855 }\end{array}$ & - & putative transcriptional regulator & Rv1015c & $r p / Y$ & 50 S ribosomal protein L25 \\
\hline Rv1556 & - & $\begin{array}{l}\text { (letR/AcrR family) } \\
\text { putative transcriptional regulator }\end{array}$ & Rv3855 & - & putative transcriptional regulator & $\begin{array}{l}\text { Rv2441c } \\
\text { Rv0105c }\end{array}$ & $\begin{array}{l}r p m A \\
r p m B\end{array}$ & $\begin{array}{l}50 \text { S ribosomal protein L27 } \\
50 S \text { ribosomal protein L28 }\end{array}$ \\
\hline Rv1674c & - & putative transcriptional regulator & 2. Two con & nponent s & jstems & Rv2058c & rpmB2 & 50 S ribosomal protein L28 \\
\hline Rv1675c & - & putative transcriptional regulator & Rv1028c & $k d p D$ & sensor histidine kinase & Rv0709 & $r p m C$ & 50 S ribosomal protein L29 \\
\hline Rv1719 & - & $\begin{array}{l}\text { transcriptional regulator (IclR } \\
\text { family) }\end{array}$ & Rv1027c & $k d p E$ & $\begin{array}{l}\text { two-component response } \\
\text { regulator }\end{array}$ & $\begin{array}{l}\text { Rv0722 } \\
\text { Rv1298 }\end{array}$ & $\begin{array}{l}\text { rpmD } \\
\text { rpmE }\end{array}$ & $\begin{array}{l}50 \text { S ribosomal protein L30 } \\
50 \text { S ribosomal protein L31 }\end{array}$ \\
\hline Rv1773c & - & $\begin{array}{l}\text { transcriptional regulator (ICIR } \\
\text { family) }\end{array}$ & Rv3246c & $m t r A$ & $\begin{array}{l}\text { two-component response } \\
\text { regulator }\end{array}$ & $\begin{array}{l}\text { Rv2057c } \\
\text { Rv3924c }\end{array}$ & $\begin{array}{l}\text { rpmG } \\
\text { rpmH }\end{array}$ & $\begin{array}{l}50 \text { S ribosomal protein L33 } \\
50 \text { S ribosomal protein L34 }\end{array}$ \\
\hline Rv1776c & - & putative transcriptional regulator & Rv3245c & $m t r B$ & sensor histidine kinase & Rv1642 & rpml & 50 S ribosomal protein L35 \\
\hline Rv1816 & - & putative transcriptional regulator & Rv0844c & narL & two-component response & Rv3461c & rpmJ & 50 S ribosomal protein L36 \\
\hline Rv1846c & - & putative transcriptional regulator & & & regulator & Rv1630 & $r p s A$ & $30 \mathrm{~S}$ ribosomal protein $\mathrm{S} 1$ \\
\hline Rv1931c & - & $\begin{array}{l}\text { transcriptional regulator } \\
\text { (AraC/XylS family) }\end{array}$ & Rv0757 & phoP & $\begin{array}{l}\text { two-component response } \\
\text { regulator }\end{array}$ & $\begin{array}{l}\text { Rv2890c } \\
\text { Rv0707 }\end{array}$ & $\begin{array}{l}r p s B \\
r p s C\end{array}$ & $\begin{array}{l}30 \text { S ribosomal protein S2 } \\
30 \text { S ribosomal protein S3 }\end{array}$ \\
\hline Rv1956 & - & putative transcriptional regulator & Rv0758 & phoR & sensor histidine kinase & Rv3458c & $r p s D$ & $30 \mathrm{~S}$ ribosomal protein $\mathrm{S} 4$ \\
\hline Rv1963c & - & putative transcriptional regulator & Rv0491 & $\operatorname{reg} X 3$ & two-component response & Rv0721 & rpsE & $30 \mathrm{~S}$ ribosomal protein S5 \\
\hline Rv1985c & - & $\begin{array}{l}\text { transcriptional regulator (LysR } \\
\text { family) }\end{array}$ & Rv0490 & $\operatorname{sen} X 3$ & $\begin{array}{l}\text { regulator } \\
\text { sensor histidine kinase }\end{array}$ & $\begin{array}{l}\text { Rv0053 } \\
\text { Rv0683 }\end{array}$ & $\begin{array}{l}r p s F \\
r p s G\end{array}$ & $\begin{array}{l}30 \text { S ribosomal protein S6 } \\
30 \text { S ribosomal protein S7 }\end{array}$ \\
\hline Rv1990c & - & putative transcriptional regulator & Rv0602c & tcrA & two-component response & Rv0718 & rpsH & $30 \mathrm{~S}$ ribosomal protein S8 \\
\hline Rv1994c & - & transcriptional regulator (MerR & & & regulator & Rv3442c & $r p s l$ & 30 S ribosomal protein S9 \\
\hline & & family) & Rv0260c & - & two-component response & Rv0700 & rps & $30 \mathrm{~S}$ ribosomal protein $\mathrm{S} 10$ \\
\hline Rv2017 & - & putative transcriptional regulator & & & regulator & Rv3459c & rpsK & $30 \mathrm{~S}$ ribosomal protein $\mathrm{S} 11$ \\
\hline & & (PbsX/Xre family) & Rv0600c & - & sensor histidine kinase & Rv0682 & $r p s L$ & $30 \mathrm{~S}$ ribosomal protein $\mathrm{S} 12$ \\
\hline Rv2021c & - & putative transcriptional regulator & Rv0601c & - & sensor histidine kinase & Rv3460c & $r p s M$ & $30 S$ ribosomal protein $\mathrm{S} 13$ \\
\hline Rv2034 & - & $\begin{array}{l}\text { transcriptional regulator (ArsR } \\
\text { family) }\end{array}$ & Rv0818 & - & $\begin{array}{l}\text { two-component response } \\
\text { regulator }\end{array}$ & $\begin{array}{l}\text { Rv0717 } \\
\text { Rv2056c }\end{array}$ & $\begin{array}{l}r p s N \\
r p s N 2\end{array}$ & $\begin{array}{l}30 \mathrm{~S} \text { ribosomal protein } \mathrm{S} 14 \\
30 \mathrm{~S} \text { ribosomal protein } \mathrm{S} 14\end{array}$ \\
\hline Rv2175c & - & putative transcriptional regulator & Rv0845 & - & sensor histidine kinase & Rv2785c & rpsO & 30 S ribosomal protein $\mathrm{S} 15$ \\
\hline Rv2250c & & putative transcriptional regulator & Rv0902c & - & sensor histidine kinase & Rv2909c & $r p s P$ & 30 S ribosomal protein $\mathrm{S} 16$ \\
\hline Rv2258c & - & putative transcriptional regulator & Rv0903c & - & two-component response & Rv0710 & $r p s Q$ & 30 S ribosomal protein $\mathrm{S} 17$ \\
\hline Rv2282c & & transcriptional regulator (LysR & & & regulator & Rv0055 & $r p s R$ & $30 \mathrm{~S}$ ribosomal protein $\mathrm{S} 18$ \\
\hline & & family) & Rv0981 & - & two-component response & Rv2055c & rpsR2 & $30 \mathrm{~S}$ ribosomal protein $\mathrm{S} 18$ \\
\hline Rv2308 & - & putative transcriptional regulator & & & regulator & Rv0705 & rpsS & $30 \mathrm{~S}$ ribosomal protein $\mathrm{S} 19$ \\
\hline Rv2324 & - & transcriptional regulator & Rv0982 & - & sensor histidine kinase & Rv2412 & rpst & 30 S ribosomal protein $\mathrm{S} 20$ \\
\hline & & (Lrp/AsnC family) & Rv1032c & - & sensor histidine kinase & Rv3241c & - & member of S30AE ribosomal \\
\hline Rv2358 & - & $\begin{array}{l}\text { transcriptional regulator (ArsR } \\
\text { family) }\end{array}$ & Rv1033c & - & $\begin{array}{l}\text { two-component response } \\
\text { regulator }\end{array}$ & & & protein family \\
\hline Rv2488c & - & transcriptional regulator & Rv1626 & - & two-component response & 2. Riboson & ne modific & ation and maturation \\
\hline & & (LuxR/UhpA family) & & & regulator & Rv1010 & $k s g A$ & 16S rRNA dimethyltransferase \\
\hline Rv2506 & - & transcriptional regulator & Rv2027c & - & sensor histidine kinase & Rv2838c & $r b f a$ & ribosome-binding factor $\mathrm{A}$ \\
\hline & & (TetR/AcrR family) & Rv2884 & - & two-component response & Rv2907c & rimM & 16S rRNA processing protein \\
\hline Rv2621c & - & putative transcriptional regulator & & & regulator & & & \\
\hline Rv2640c & - & transcriptional regulator (ArsR & Rv3132c & - & sensor histidine kinase & 3. Aminoac & cyl tRNA : & ynthases and their modification \\
\hline & & family) & Rv3133c & - & two-component response & Rv2555c & alas & alanyl-tRNA synthase \\
\hline Rv2642 & - & transcriptional regulator (ArsR & & & regulator & Rv1292 & args & arginyl-tRNA synthase \\
\hline & & family) & Rv3143 & - & putative sensory transduction & Rv2572c & asps & aspartyl-tRNA synthase \\
\hline Rv2669 & - & putative transcriptional regulator & & & protein & Rv3580c & cyss & cysteinyl-tRNA synthase \\
\hline Rv2745c & - & putative transcriptional regulator & Rv3220c & - & sensor histidine kinase & Rv2130c & cysS2 & cysteinyl-tRNA synthase \\
\hline Rv2779c & - & transcriptional regulator & Rv3764c & - & sensor histidine kinase & Rv1406 & fmt & methionyl-tRNA formyltransferase \\
\hline Rv2887 & - & $\begin{array}{l}\text { (Lrp/AsnC family) } \\
\text { transcriptional regulator (MarR }\end{array}$ & Rv3765c & - & $\begin{array}{l}\text { two-component response } \\
\text { regulator }\end{array}$ & Rv3011c & gatA & $\begin{array}{l}\text { glu-tRNA-gln amidotransferase, } \\
\text { subunit B }\end{array}$ \\
\hline & & family) & & & & Rv3009c & gatB & glu-tRNA-gln amidotransferase, \\
\hline Rv2912c & - & transcriptional regulator & 3. Serine & רreonine & rotein kinases and phosphoprotein & & & subunit $A$ \\
\hline & & (TetR/AcrR family) & & & & Rv3012c & gatC & glu-tRNA-gln amidotransferase, \\
\hline Rv2989 & - & transcriptional regulator (IcIR & Rv0015c & $p k n A$ & serine-threonine protein kinase & & & subunit $C$ \\
\hline & & family) & Rv0014c & $p k n B$ & serine-threonine protein kinase & Rv2992c & gltS & glutamyl-tRNA synthase \\
\hline Rv3050c & - & putative transcriptional regulator & Rv0931c & pknD & serine-threonine protein kinase & Rv2357c & glys & glycyl-tRNA synthase \\
\hline Rv3055 & - & putative transcriptional regulator & Rv1743 & $p k n E$ & serine-threonine protein kinase & Rv2580c & hiss & histidyl-tRNA synthase \\
\hline Rv3058c & - & putative transcriptional regulator & Rv1746 & $p k n F$ & serine-threonine protein kinase & Rv1536 & iles & isoleucyl-tRNA synthase \\
\hline Rv3060c & - & transcriptional regulator (GntR & Rv0410c & pknG & serine-threonine protein kinase & Rv0041 & leus & leucyl-tRNA synthase \\
\hline & & & Rv1266c & pknH & serine-threonine protein kinase & Rv3598c & lyss & lysyl-tRNA synthase \\
\hline Rv3066 & - & putative transcriptional regulator & Rv2914c & pknl & serine-threonine protein kinase & Rv1640c & lys $X$ & C-term lysyl-tRNA synthase \\
\hline Rv3095 & - & putative transcriptional regulator & Rv2088 & $p k n J$ & serine-threonine protein kinase & Rv1007c & mets & methionyl-tRNA synthase \\
\hline Rv3124 & - & transcriptional regulator & Rv3080c & pknk & serine-threonine protein kinase & Rv1649 & phes & phenylalanyl-tRNA synthase $\alpha$ \\
\hline
\end{tabular}




\begin{tabular}{|c|c|c|c|c|c|c|c|c|}
\hline Rv1650 & pheT & $\begin{array}{l}\text { phenylalanyl-tRNA synthase } \beta \\
\text { subunit }\end{array}$ & Rv2090 & - & $\begin{array}{l}\text { partially similar to DNA poly- } \\
\text { merase I }\end{array}$ & $\begin{array}{l}\text { 2. DNA } \\
\text { Rv0670 }\end{array}$ & end & endonuclease IV (apurinase) \\
\hline Rv2845c & pros & prolyl-tRNA synthase & Rv2191 & - & similar to both PolC and UvrC & Rv1108c & $x s e A$ & exonuclease VII large subunit \\
\hline Rv3834c & sers & seryl-tRNA synthase & & & proteins & Rv1107c & $x s e B$ & exonuclease VII small subunit \\
\hline Rv2614c & thrs & threonyl-tRNA synthase & Rv2464c & - & probable DNA glycosylase, & & & \\
\hline Rv2906c & $\operatorname{trm} D$ & tRNA (guanine-N1)-methyltrans- & & & endonuclease VIII & \multicolumn{3}{|c|}{ 3. Proteins, peptides and glycopeptides } \\
\hline Rv3336c & $\operatorname{trps}$ & $\begin{array}{l}\text { ferase } \\
\text { tryptophanyl tRNA synthase }\end{array}$ & Rv3201c & - & $\begin{array}{l}\text { probable ATP-dependent DNA } \\
\text { helicase }\end{array}$ & $\begin{array}{l}\text { Rv3305c } \\
\text { Rv3306c }\end{array}$ & amiA & $\begin{array}{l}\text { probable aminohydrolase } \\
\text { probable aminohydrolase }\end{array}$ \\
\hline Rv1689 & tyrs & tyrosyl-tRNA synthase & Rv3202c & - & similar to UvrD proteins & Rv3596c & $c / p C$ & ATP-dependent Clp protease \\
\hline Rv2448c & vals & valyl-tRNA synthase & $\begin{array}{l}\text { Rv3263 } \\
\text { Rv3644c }\end{array}$ & - & $\begin{array}{l}\text { probable DNA methylase } \\
\text { similar in N-term to DNA poly- }\end{array}$ & Rv2461c & $c / p P$ & $\begin{array}{l}\text { ATP-dependent Clp protease pro- } \\
\text { teolytic subunit }\end{array}$ \\
\hline \multicolumn{3}{|c|}{ 4. Nucleoproteins } & & & merase III & Rv2460c & $c l p P 2$ & $\begin{array}{l}\text { ATP-dependent Clp protease pro- } \\
\text { teolytic subunit }\end{array}$ \\
\hline $\begin{array}{l}\text { Rv1407 } \\
\text { Rv3852 }\end{array}$ & $\begin{array}{l}\text { fmu } \\
h n s\end{array}$ & $\begin{array}{l}\text { similar to Fmu protein } \\
\text { HU-histone protein }\end{array}$ & \multicolumn{3}{|c|}{ 6. Protein translation and modification } & Rv2457c & $c / p X$ & $\begin{array}{l}\text { teolytic subunit } \\
\text { ATP-dependent Clp protease }\end{array}$ \\
\hline Rv2986c & hupB & DNA-binding protein II & Rv0429c & def & polypeptide deformylase & & & ATP-binding subunit ClpX \\
\hline Rv1388 & mIHF & integration host factor & $\begin{array}{l}\text { Rv2534c } \\
\text { Rv2882c }\end{array}$ & $\begin{array}{l}\text { efp } \\
\text { frr }\end{array}$ & $\begin{array}{l}\text { elongation factor } \mathrm{P} \\
\text { ribosome recycling factor }\end{array}$ & Rv2667 & $c / p X^{\prime}$ & $\begin{array}{l}\text { similar to ClpC from M. leprae but } \\
\text { shorter }\end{array}$ \\
\hline \multirow{2}{*}{\multicolumn{3}{|c|}{$\begin{array}{l}\text { 5. DNA replication, repair, recombination and restric- } \\
\text { tion/modification }\end{array}$}} & Rv0684 & fusA & elongation factor $\mathrm{G}$ & Rv3419c & $g c p$ & glycoprotease \\
\hline & & & Rv0120c & fusA2 & elongation factor $\mathrm{G}$ & Rv2725c & $h f I X$ & GTP-binding protein \\
\hline Rv1317c & alkA & $\begin{array}{l}\text { DNA-3-methyladenine glycosi- } \\
\text { dase II }\end{array}$ & $\begin{array}{l}\text { Rv1080c } \\
\text { Rv3462c }\end{array}$ & $\begin{array}{l}\text { greA } \\
\text { infA }\end{array}$ & $\begin{array}{l}\text { transcription elongation factor } \mathrm{G} \\
\text { initiation factor IF-1 }\end{array}$ & $\begin{array}{l}\text { Rv1223 } \\
\text { Rv2861c }\end{array}$ & $\begin{array}{l}\text { htrA } \\
\text { map }\end{array}$ & $\begin{array}{l}\text { serine protease } \\
\text { methionine aminopeptidase }\end{array}$ \\
\hline $\begin{array}{l}\text { Rv2836c } \\
\text { Rv1329c }\end{array}$ & $\begin{array}{l}\operatorname{din} F \\
\operatorname{din} G\end{array}$ & $\begin{array}{l}\text { DNA-damage-inducible protein } \mathrm{F} \\
\text { probable ATP-dependent helicase }\end{array}$ & $\begin{array}{l}\text { Rv2839c } \\
\text { Rv1641 }\end{array}$ & $\begin{array}{l}\operatorname{infB} \\
\operatorname{infC}\end{array}$ & $\begin{array}{l}\text { initiation factor IF-2 } \\
\text { initiation factor IF-3 }\end{array}$ & Rv0734 & map' & $\begin{array}{l}\text { probable methionine aminopepti- } \\
\text { dase }\end{array}$ \\
\hline Rv3056 & $\operatorname{din} P$ & DNA-damage-inducible protein & Rv0009 & ppiA & peptidyl-prolyl cis-trans isomerase & Rv0319 & $p c p$ & pyrrolidone-carboxylate peptidase \\
\hline Rv1537 & $\operatorname{din} x$ & $\begin{array}{l}\text { probable DNA-damage-inducible } \\
\text { protein }\end{array}$ & $\begin{array}{l}\text { Rv2582 } \\
\text { Rv1299 }\end{array}$ & $\begin{array}{l}\text { ppiB } \\
\text { prfa }\end{array}$ & $\begin{array}{l}\text { peptidyl-prolyl cis-trans isomerase } \\
\text { peptide chain release factor } 1\end{array}$ & $\begin{array}{l}\text { Rv0125 } \\
\text { Rv2213 }\end{array}$ & $\begin{array}{l}\text { pepA } \\
\text { pepB }\end{array}$ & $\begin{array}{l}\text { probable serine protease } \\
\text { aminopeptidase A/l }\end{array}$ \\
\hline Rv0001 & $d n a A$ & $\begin{array}{l}\text { chromosomal replication initiator } \\
\text { protein }\end{array}$ & $\begin{array}{l}\text { Rv3105c } \\
\text { Rv2889c }\end{array}$ & $\begin{array}{l}\text { prfB } \\
\text { tsf }\end{array}$ & $\begin{array}{l}\text { peptide chain release factor } 2 \\
\text { elongation factor EF-Ts }\end{array}$ & $\begin{array}{l}\text { Rv0800 } \\
\text { Rv2467 }\end{array}$ & $\begin{array}{l}\text { pepC } \\
\text { pepD }\end{array}$ & $\begin{array}{l}\text { aminopeptidase I } \\
\text { probable aminopeptidase }\end{array}$ \\
\hline Rv0058 & $d n a B$ & DNA helicase (contains intein) & Rv0685 & tuf & elongation factor EF-Tu & Rv2089c & pepE & cytoplasmic peptidase \\
\hline Rv1547 & dnaE1 & DNA polymerase III, $\alpha$ subunit & & & & Rv2535c & pepQ & cytoplasmic peptidase \\
\hline Rv3370c & dnaE2 & DNA polymerase III $\alpha$ chain & 7. RNA syr & nthesis, & NA modification and DNA & Rv2782c & pepR & \\
\hline Rv2343c & dnaG & DNA primase & $\begin{array}{l}\text { transcriptic } \\
\text { Rv1253 }\end{array}$ & deaD & ATP-dependent DNA/RNA & Rv2109c & & $\begin{array}{l}\text { (insulinase) } \\
\text { proteasome } \alpha \text {-type subunit } 1\end{array}$ \\
\hline $\begin{array}{l}\text { Rv0002 } \\
\text { Rv3711c }\end{array}$ & $\begin{array}{l}\text { dnaN } \\
\text { dnaQ }\end{array}$ & $\begin{array}{l}\text { DNA polymerase III, } \beta \text { subunit } \\
\text { DNA polymerase } I I I \epsilon \text { chain }\end{array}$ & mivicus & & helicase & Rv2110c & $\begin{array}{l}\text { prcA } \\
\text { prcB }\end{array}$ & \\
\hline Rv3721c & $d n a Z X$ & $\begin{array}{l}\text { DNA polymerase III, } \gamma(\text { dnaZ) and } \\
\tau(\text { dnaX) }\end{array}$ & Rv2783c & gpsl & $\begin{array}{l}\text { pppGpp synthase and polyribo- } \\
\text { nucleotide phosphorylase }\end{array}$ & $\begin{array}{l}\text { Rv0782 } \\
\text { Rv0781 }\end{array}$ & $\begin{array}{l}\text { ptrBa } \\
\text { ptrBb }\end{array}$ & $\begin{array}{l}\text { protease II, } \alpha \text { subunit } \\
\text { protease II, } \beta \text { subunit }\end{array}$ \\
\hline Rv2924c & $f p g$ & $\begin{array}{l}\text { formamidopyrimidine-DNA glyco- } \\
\text { sylase }\end{array}$ & $\begin{array}{l}\text { Rv2841c } \\
\text { Rv2533c }\end{array}$ & $\begin{array}{l}\text { nusA } \\
\text { nusB }\end{array}$ & $\begin{array}{l}\text { transcription termination factor } \\
\mathrm{N} \text {-utilization substance protein } \mathrm{B}\end{array}$ & Rv0724 & sppA & $\begin{array}{l}\text { protease IV, signal peptide pepti- } \\
\text { dase }\end{array}$ \\
\hline Rv0006 & gyrA & DNA gyrase subunit $A$ & Rv0639 & nusG & transcription antitermination & Rv0198c & - & probable zinc metalloprotease \\
\hline Rv0005 & gyrB & DNA gyrase subunit B & & & protein & Rv0457c & - & probable peptidase \\
\hline Rv2092c & helY & probable helicase, Ski2 subfamily & Rv3907c & pcnA & polynucleotide polymerase & Rv0840c & - & probable proline iminopeptidase \\
\hline Rv2101 & helz & $\begin{array}{l}\text { probable helicase, Snf2/Rad54 } \\
\text { family }\end{array}$ & Rv3232c & pvdS & $\begin{array}{l}\text { alternative sigma factor for } \\
\text { siderophore production }\end{array}$ & $\begin{array}{l}\text { Rv0983 } \\
\text { Rv1977 }\end{array}$ & - & $\begin{array}{l}\text { probable serine protease } \\
\text { probable zinc metallopeptidase }\end{array}$ \\
\hline Rv2756c & $h s d M$ & type I restriction/modification sys- & Rv3211 & rhIE & $\begin{array}{l}\text { probable ATP-dependent } \\
\text { RNA helicase }\end{array}$ & $\begin{array}{l}\text { Rv3668c } \\
\text { Rv3671c }\end{array}$ & - & $\begin{array}{l}\text { probable alkaline serine protease } \\
\text { probable serine protease }\end{array}$ \\
\hline Rv2755c & $h s d S^{\prime}$ & $\begin{array}{l}\text { type I restriction/modification sys- } \\
\text { tem specificity determinant }\end{array}$ & Rv1297 & rho & $\begin{array}{l}\text { transcription termination } \\
\text { factor rho }\end{array}$ & $\begin{array}{l}\text { Rv3883c } \\
\text { Rv3886c }\end{array}$ & - & $\begin{array}{l}\text { probable secreted protease } \\
\text { protease }\end{array}$ \\
\hline Rv3296 & Ihr & ATP-dependent helicase & Rv3457c & rpoA & $\alpha$ subunit of RNA polymerase & & & \\
\hline Rv3014c & $\operatorname{lig} A$ & DNA ligase & Rv0667 & rpoB & $\beta$ subunit of RNA polymerase & 4. Polysac & charides, & lipopolysaccharides and phospho- \\
\hline Rv3062 & $\operatorname{lig} B$ & DNA ligase & Rv0668 & rpoc & $\beta^{\prime}$ subunit of RNA polymerase & lipids & & \\
\hline Rv3731 & $\operatorname{lig} C$ & probable DNA ligase & Rv1364c & $r s b U$ & SigB regulation protein & Rv0062 & celA & cellulase/endoglucanase \\
\hline Rv1020 & mfd & transcription-repair coupling factor & Rv3287c & rsbW & anti-sigma B factor & Rv3915 & cwIM & hydrolase \\
\hline Rv2528c & $m r r$ & restriction system protein & Rv2703 & $\operatorname{sig} A$ & RNA polymerase sigma factor & Rv0315 & - & probable $\beta$-1,3-glucanase \\
\hline Rv2985 & mutT1 & MutT homologue & & & (aka MysA, RpoV) & Rv1090 & - & probable inactivated \\
\hline Rv1160 & mutT2 & MutT homologue & Rv2710 & $\operatorname{sig} B$ & RNA polymerase sigma factor & & & cellulase/endoglucanase \\
\hline Rv0413 & mutT3 & MutT homologue & & & (aka MysB) & Rv1327c & - & probable glycosyl hydrolase, $\alpha-$ \\
\hline Rv3589 & mutY & probable DNA glycosylase & Rv2069 & $\operatorname{sig} C$ & ECF subfamily sigma subunit & & & amylase family \\
\hline Rv3297 & nei & probable endonuclease VIII & Rv3414c & $\operatorname{sig} D$ & ECF subfamily sigma subunit & Rv1333 & - & probable hydrolase \\
\hline Rv3674c & nth & probable endonuclease III & Rv1221 & sigE & ECF subfamily sigma subunit & Rv3463 & - & probable neuraminidase \\
\hline Rv1316c & ogt & $\begin{array}{l}\text { methylated-DNA-protein-cysteine } \\
\text { methyltransferase }\end{array}$ & $\begin{array}{l}\text { Rv3286c } \\
\text { Rv0182c }\end{array}$ & $\begin{array}{l}\text { sigF } \\
\text { sigG }\end{array}$ & $\begin{array}{l}\text { ECF subfamily sigma subunit } \\
\text { sigma-70 factors ECF subfamily }\end{array}$ & Rv3717 & - & $\begin{array}{l}\text { possible } \mathrm{N} \text {-acetylmuramoyl-L-ala- } \\
\text { nine amidase }\end{array}$ \\
\hline Rv1629 & polA & DNA polymerase I & Rv3223c & $\mathrm{sigH}$ & ECF subfamily sigma subunit & & & \\
\hline Rv1402 & pria & putative primosomal protein $n^{\prime}$ & Rv1189 & sigl & ECF family sigma factor & 5. Esterase & es and & ases \\
\hline & & (replication factor $\mathrm{Y}$ ) & Rv3328c & sigJ & similar to Sigl, ECF family & Rv0220 & $\operatorname{lipC}$ & probable esterase \\
\hline Rv3585 & $\operatorname{rad} A$ & probable DNA repair RadA homo- & Rv0445c & sigk & ECF-type sigma factor & Rv1923 & $\operatorname{lip} D$ & probable esterase \\
\hline & & logue & Rv0735 & $\operatorname{sigh}$ & sigma-70 factors ECF subfamily & Rv3775 & lipE & probable hydrolase \\
\hline Rv2737c & recA & recombinase (contains intein) & Rv3911 & sigM & probable sigma factor, similar to & Rv3487c & lipF & probable esterase \\
\hline Rv0630c & rec $B$ & exodeoxyribonuclease $\mathrm{V}$ & & & SigE & Rv0646c & lipG & probable hydrolase \\
\hline Rv0631c & recC & exodeoxyribonuclease $\mathrm{V}$ & Rv3366 & spou & probable rRNA methylase & Rv1399c & $\mathrm{lipH}$ & probable lipase \\
\hline Rv0629c & recD & exodeoxyribonuclease $\mathrm{V}$ & Rv3455c & truA & probable pseudouridylate syn- & Rv1400c & lipl & probable lipase \\
\hline Rv0003 & $\mathrm{rec} F$ & $\begin{array}{l}\text { DNA replication and SOS induc- } \\
\text { tion }\end{array}$ & Rv2793c & $\operatorname{truB}$ & $\begin{array}{l}\text { thase } \\
\text { tRNA pseudouridine } 55 \text { synthase }\end{array}$ & $\begin{array}{l}\text { Rv1900c } \\
\text { Rv2385 }\end{array}$ & $\begin{array}{l}\text { lipJ } \\
\text { lipK }\end{array}$ & $\begin{array}{l}\text { probable esterase } \\
\text { probable acetyl-hydrolase }\end{array}$ \\
\hline Rv2973c & recG & ATP-dependent DNA helicase & Rv1644 & $\operatorname{tsn} R$ & putative $23 \mathrm{~S}$ rRNA methyltrans- & Rv1497 & $\operatorname{lipL}$ & esterase \\
\hline Rv1696 & recN & recombination and DNA repair & & & ferase & Rv2284 & $\operatorname{lipM}$ & probable esterase \\
\hline Rv3715c & rech & $\begin{array}{l}\text { RecBC-Independent process of } \\
\text { DNA repair }\end{array}$ & Rv3649 & - & $\begin{array}{l}\text { ATP-dependent DNA/RNA heli- } \\
\text { case }\end{array}$ & $\begin{array}{l}\text { Rv2970c } \\
\text { Rv1426c }\end{array}$ & $\begin{array}{l}\operatorname{lipN} \\
\operatorname{lipO}\end{array}$ & $\begin{array}{l}\text { probable lipase/esterase } \\
\text { probable esterase }\end{array}$ \\
\hline Rv2736c & recX & regulatory protein for RecA & & & & Rv2463 & lipP & probable esterase \\
\hline Rv2593c & ruvA & Holliday junction binding protein, & 8. Polysac & charides & cytoplasmic) & Rv2485c & $\operatorname{lip} Q$ & probable carboxlyesterase \\
\hline & & DNA helicase & Rv1326c & $g / g B$ & $1,4-\alpha$-glucan branching enzyme & Rv3084 & lipR & probable acetyl-hydrolase \\
\hline Rv2592c & $r u v B$ & Holliday junction binding protein & Rv1328 & glgP & probable glycogen phosphory- & Rv3176c & lips & probable esterase/lipase \\
\hline Rv2594c & ruve & Holliday junction resolvase, endo- & & & lase & Rv2045c & lipt & probable carboxylesterase \\
\hline & & deoxyribonuclease & Rv1564c & $\operatorname{glg} X$ & probable glycogen debranching & Rv1076 & lipU & probable esterase \\
\hline Rv0054 & $s s b$ & single strand binding protein & & & enzyme & Rv3203 & $\operatorname{lip} V$ & probable lipase \\
\hline Rv1210 & $\operatorname{tag} A$ & DNA-3-methyladenine glycosi- & Rv1563c & $g \lg Y$ & putative $\alpha$-amylase & Rv0217c & lipW & probable esterase \\
\hline & & dase I & Rv1562c & glgz & maltooligosyltrehalose trehalohy- & Rv2351c & plcA & phospholipase $\mathrm{C}$ precursor \\
\hline & topA & DNA topoisomerase & & & drolase & Rv2350c & $p / c B$ & phospholipase $\mathrm{C}$ precursor \\
\hline Rv2976c & ung & uracil-DNA glycosylase & Rv0126 & - & probable glycosyl hydrolase & Rv2349c & $\mathrm{plcC}$ & phospholipase $\mathrm{C}$ precursor \\
\hline Rv1638 & uvrA & excinuclease $A B C$ subunit $A$ & Rv1781c & - & probable 4 - $\alpha$-glucanotransferase & Rv1755c & plcD & partial CDS for phospholipase $C$ \\
\hline Rv1633 & uvrB & excinuclease $A B C$ subunit $B$ & Rv2471 & - & probable maltase $\alpha$-glucosidase & Rv1104 & - & probable esterase pseudogene \\
\hline Rv1420 & uvrC & excinuclease $A B C$ subunit $C$ & & & & Rv1105 & - & probable esterase pseudogene \\
\hline Rv0949 & uvrD & DNA-dependent ATPase I and & B. Degrad & ation of & acromolecules & & & \\
\hline & & helicase II & & & & & & \\
\hline Rv3198c & uvrD2 & putative UvrD & Rv1014c & pth & peptidyl-tRNA hydrolase & Rv3469c & $m h p E$ & probable 4-hydroxy-2-oxovalerate \\
\hline Rv0427c & xthA & exodeoxyribonuclease III & Rv2925c & $r n c$ & RNAse III & & & aldolase \\
\hline Rv0071 & - & group II intron maturase & Rv2444c & rne & similar at C-term to ribo- & Rv0316 & - & probable muconolactone iso- \\
\hline Rv0861c & - & probable DNA helicase & & & nuclease $\mathrm{E}$ & & & merase \\
\hline Rv0944 & - & $\begin{array}{l}\text { possible formamidopyrimidine- } \\
\text { DNA glycosylase }\end{array}$ & $\begin{array}{l}\text { Rv2902c } \\
\text { Rv3923c }\end{array}$ & $\begin{array}{l}r n h B \\
r n p A\end{array}$ & $\begin{array}{l}\text { ribonuclease } \mathrm{HII} \\
\text { ribonuclease } \mathrm{P} \text { protein compo- }\end{array}$ & Rv0771 & - & $\begin{array}{l}\text { probable 4-carboxymuconolac- } \\
\text { tone decarboxylase }\end{array}$ \\
\hline & - & probable 3-methylpurine DNA & & & & Rv0939 & - & probable dehydrase \\
\hline & & glycosylase & Rv1340 & $\operatorname{rph} A$ & ribonuclease $\mathrm{PH}$ & Rv1723 & - & 6-aminohexanoate-dimer hydro- \\
\hline
\end{tabular}




\begin{tabular}{|c|c|c|c|c|c|c|c|c|}
\hline \multirow{3}{*}{ Rv2715 } & \multirow[b]{2}{*}{ - } & lase & Rv1367c & - & probable penicillin binding protein & Rv1030 & $k d p B$ & \multirow{2}{*}{$\begin{array}{l}\text { potassium-transporting ATPase B } \\
\text { chain }\end{array}$} \\
\hline & & 2-hydroxymuconic semialdehyde & Rv1730c & - & probable penicillin binding protein & & & \\
\hline & & hydrolase & Rv1922 & - & probable penicillin binding protein & Rv1031 & $k d p C$ & potassium-transporting ATPase $C$ \\
\hline Rv3530c & $\mathrm{pr}$ & probable cis-diol dehydrogenase & Rv2864c & - & probable penicillin binding protein & & & chain \\
\hline Rv3534c & - & 4-hydroxy-2-oxovalerate aldolase & Rv3330 & - & probable penicillin binding protein & Rv3236c & kefB & probable glutathione-regulated \\
\hline Rv3536c & tic & $\begin{array}{l}\text { aromatic hydrocarbon degrada- } \\
\text { tion }\end{array}$ & $\begin{array}{l}\text { Rv3627c } \\
\text { 4. Conserve }\end{array}$ & ved membra & probable penicillin binding protein & Rv2877c & merT & $\begin{array}{l}\text { potassium-efflux protein } \\
\text { possible mercury resistance } \\
\text { transport system }\end{array}$ \\
\hline C. Cell en & velope & & Rv0402c & $m m p L 1$ & conserved large membrane & Rv1811 & $m g t C$ & probable magnesium transport \\
\hline 1. Lipoprot & teins (IppA-Ip & (pro) 65 & Rv0507 & $m m p L 2$ & $\begin{array}{l}\text { protein } \\
\text { conserved large membrane }\end{array}$ & Rv0362 & mgtE & $\begin{array}{l}\text { ATPase protein C } \\
\text { putative magnesium ion }\end{array}$ \\
\hline teins and & $\begin{array}{l}\text { polysacc } \\
\text { antigens }\end{array}$ & & Rv0206c & $m m p L 3$ & conserved large membrane & Rv2856 & nict & probable nickel transport protein \\
\hline Rv0806c & cpsY & $\begin{array}{l}\text { probable UDP-glucose-4- } \\
\text { epimerase }\end{array}$ & & & $\begin{array}{l}\text { protein } \\
\text { conserved large membrane }\end{array}$ & Rv0924c & nramp & $\begin{array}{l}\text { transmembrane protein belonging } \\
\text { to Nramp family }\end{array}$ \\
\hline Rv3811 & $\operatorname{csp} p$ & secreted protein & & & protein & Rv2691 & $\operatorname{trk} A$ & probable potassium uptake pro- \\
\hline Rv1677 & $d s b F$ & highly similar to C-term Mpt53 & Rv0676c & $m m p L 5$ & conserved large membrane & & & \\
\hline Rv3794 & $e m b A$ & $\begin{array}{l}\text { involved in arabinogalactan syn- } \\
\text { thesis }\end{array}$ & Rv1557 & $m m p L 6$ & $\begin{array}{l}\text { protein } \\
\text { conserved large membrane }\end{array}$ & Rv2692 & $\operatorname{trkB}$ & $\begin{array}{l}\text { probable potassium uptake pro- } \\
\text { tein }\end{array}$ \\
\hline Rv3795 & $e m b B$ & $\begin{array}{l}\text { involved in arabinogalactan syn- } \\
\text { thesis } \\
\text { involved in arabinogalactan syn- }\end{array}$ & Rv2942 & $m m p L 7$ & $\begin{array}{l}\text { protein } \\
\text { conserved large membrane } \\
\text { protein }\end{array}$ & $\begin{array}{l}\text { Rv2287 } \\
\text { Rv2723 }\end{array}$ & $y j c E$ & $\begin{array}{l}\text { probable } \mathrm{Na}+/ \mathrm{H}+\text { exchanger } \\
\text { probable membrane protein, } \\
\text { tellurium resistance }\end{array}$ \\
\hline Rv3793 & $e m b C$ & $\begin{array}{l}\text { Involved in arabinogalactan syn- } \\
\text { thesis }\end{array}$ & Rv3823c & $m m p L 8$ & conserved large membrane & Rv3162c & - & $\begin{array}{l}\text { tellurium resistance } \\
\text { probable membrane protein }\end{array}$ \\
\hline Rv3875 & esat6 & early secretory antigen target & & & protein & Rv3237c & - & possible potassium channel \\
\hline Rv0112 & gca & $\begin{array}{l}\text { probable GDP-mannose dehy- } \\
\text { dratase }\end{array}$ & Rv2339 & $m m p L 9$ & $\begin{array}{l}\text { conserved large membrane } \\
\text { protein }\end{array}$ & & & $\begin{array}{l}\text { protein } \\
\text { probable cation-transporting }\end{array}$ \\
\hline $\begin{array}{l}\text { Rv0113 } \\
\text { Rv2965c }\end{array}$ & $\underset{k d t B}{\operatorname{gmh} A}$ & phosphoheptose isomerase & Rv1183 & $m m p L 10$ & conserved large membrane & & & ATPase \\
\hline & & thesis protein & Rv0202c & $m m p L 11$ & conserved large membrane & 3. Carbohy & ydrates, $c$ & rganic acids and alcohols \\
\hline Rv2878c & mpt53 & secreted protein Mpt53 & & & protein & Rv2443 & $d c t A$ & C4-dicarboxylate transport protein \\
\hline Rv1980c & mpt64 & $\begin{array}{l}\text { secreted immunogenic protein } \\
\text { Mpb64/Mpt64 }\end{array}$ & Rv1522c & $m m p L 12$ & $\begin{array}{l}\text { conserved large membrane } \\
\text { protein }\end{array}$ & $\begin{array}{l}\text { Rv3476c } \\
\text { Rv1902c }\end{array}$ & $\begin{array}{l}\mathrm{kgtP} \\
\text { nant }\end{array}$ & $\begin{array}{l}\text { sugar transport protein } \\
\text { probable sialic acid transporter }\end{array}$ \\
\hline Rv2875 & mpt70 & $\begin{array}{l}\text { major secreted immunogenic pro- } \\
\text { tein Mpt70 precursor }\end{array}$ & Rv0403c & $m m p S 1$ & $\begin{array}{l}\text { conserved small membrane } \\
\text { protein }\end{array}$ & Rv1236 & $\operatorname{sug} A$ & $\begin{array}{l}\text { membrane protein probably } \\
\text { involved in sugar transport }\end{array}$ \\
\hline $\begin{array}{l}\text { Rv2873 } \\
\text { Rv0899 }\end{array}$ & $\begin{array}{l}\text { mpt83 } \\
\text { ompA }\end{array}$ & $\begin{array}{l}\text { surface lipoprotein Mpt83 } \\
\text { member of OmpA family }\end{array}$ & Rv0506 & $m m p S 2$ & $\begin{array}{l}\text { conserved small membrane } \\
\text { protein }\end{array}$ & $\begin{array}{l}\text { Rv1237 } \\
\text { Rv1238 }\end{array}$ & $\begin{array}{l}\operatorname{sug} B \\
\operatorname{sug} C\end{array}$ & $\begin{array}{l}\text { sugar transport protein } \\
\text { ABC transporter component of }\end{array}$ \\
\hline $\begin{array}{l}\text { Rvo899 } \\
\text { Rv3810 }\end{array}$ & $\begin{array}{l}\text { OmpA } \\
\text { pirG }\end{array}$ & $\begin{array}{l}\text { cell surface protein precursor (Erp } \\
\text { protein) }\end{array}$ & Rv2198c & $m m p S 3$ & $\begin{array}{l}\text { proten } \\
\text { conserved small membrane } \\
\text { protein }\end{array}$ & Rv3331 & $\begin{array}{l}\text { sugc } \\
\text { sugl }\end{array}$ & $\begin{array}{l}\text { ABC transporter component of } \\
\text { sugar uptake system } \\
\text { probable sugar transport protein }\end{array}$ \\
\hline $\begin{array}{l}\text { Rv3782 } \\
\text { Rv1302 }\end{array}$ & $\begin{array}{l}r f b E \\
r f e\end{array}$ & $\begin{array}{l}\text { similar to rhamnosyl transferase } \\
\text { undecaprenyl-phosphate } \alpha-\mathrm{N} \text { - }\end{array}$ & Rv0451c & $m m p S 4$ & $\begin{array}{l}\text { conserved small membrane } \\
\text { protein }\end{array}$ & Rv2835c & ugpA & $\begin{array}{l}\text { sn-glycerol-3-phosphate } \\
\text { permease }\end{array}$ \\
\hline Rv2145c & wag31 & $\begin{array}{l}\text { acetylglucosaminyltransferase } \\
\text { antigen } 84 \text { (aka wag31) }\end{array}$ & Rv0677c & $m m p S 5$ & $\begin{array}{l}\text { conserved small membrane } \\
\text { protein }\end{array}$ & Rv2833c & ugp $B$ & $\begin{array}{l}\text { sn-glycerol-3-phosphate-binding } \\
\text { periplasmic lipoprotein }\end{array}$ \\
\hline Rv0431 & - & tuberculin related peptide (AT103) & & & & Rv2832c & ugpC & $s n$-glycerol-3-phosphate transport \\
\hline Rv0954 & $\mathrm{ce}$ & cell envelope antigen & 5. Other $\mathrm{me}$ & Tembrane pr & proteins 211 & & & ATP-binding protein \\
\hline Rv1514c & $\begin{array}{l}\text { in } \\
\text { th }\end{array}$ & $\begin{array}{l}\text { involved in polysaccharide syn- } \\
\text { thesis }\end{array}$ & III. Cell pro & ocesses & & Rv2834c & ugpE & $\begin{array}{l}\text { sn-glycerol-3-phosphate transport } \\
\text { system protein }\end{array}$ \\
\hline Rv1518 & $\begin{array}{l}\text { in } \\
\text { sy }\end{array}$ & $\begin{array}{l}\text { involved in exopolysaccharide } \\
\text { synthesis }\end{array}$ & $\begin{array}{l}\text { A. Transpo } \\
\text { 1. Amino ac }\end{array}$ & $\begin{array}{l}\text { ort/binding } p \\
\text { acids }\end{array}$ & proteins & $\begin{array}{l}\text { Rv2316 } \\
\text { Rv2318 }\end{array}$ & $\begin{array}{l}\text { uspA } \\
\text { uspC }\end{array}$ & $\begin{array}{l}\text { sugar transport protein } \\
\text { sugar transport protein }\end{array}$ \\
\hline Rv1758 & pa & partial cutinase & Rv2127 & ansP & L-asparagine permease & Rv2317 & uspE & sugar transport protein \\
\hline Rv1910c & $\mathrm{pr}$ & probable secreted protein & Rv0346c & aroP2 & probable aromatic amino acid & Rv1200 & - & probable sugar transporter \\
\hline Rv1919c & we & weak similarity to pollen antigens & & & permease & Rv2038c & - & probable $A B C$ sugar transporter \\
\hline Rv1984c & pr & probable secreted protein & Rv0917 & betP & betaine transport & Rv2039c & - & ugar transporter \\
\hline Rv1987 & pr & probable secreted protein & Rv1704c & сусA & transport of $\mathrm{D}$-alanine, $\mathrm{D}$-serine & Rv2040c & - & ar transporter \\
\hline Rv2223c & pr & probable exported protease & & & and glycine & Rv2041c & - & probable sugar transporter \\
\hline Rv2224c & $\mathrm{pr}$ & probable exported protease & Rv3666c & $d p p A$ & probable peptide transport system & & & \\
\hline Rv2301 & - & probable cutinase & & & permease & 4. Anions & & \\
\hline Rv2345 & pr & $\begin{array}{l}\text { precursor of probable membrane } \\
\text { protein }\end{array}$ & Rv3665c & $d p p B$ & $\begin{array}{l}\text { probable peptide transport system } \\
\text { permease }\end{array}$ & $\begin{array}{l}\text { Rv2684 } \\
\text { Rv2685 }\end{array}$ & $\begin{array}{l}\operatorname{ars} A \\
\operatorname{ars} B\end{array}$ & $\begin{array}{l}\text { probable arsenical pump } \\
\text { probable arsenical pump }\end{array}$ \\
\hline Rv2672 & pu & putative exported protease & Rv3664c & $d p p C$ & probable peptide transport system & Rv3578 & arsB2 & probable arsenical pump \\
\hline Rv3019c & sir & similar to Esat6 & & & permease & Rv2643 & arsC & probable arsenical pump \\
\hline Rv3036c & pr & probable secreted protein & Rv3663c & $d p p D$ & probable ABC-transporter & Rv2397c & cysA & sulphate transport ATP-binding \\
\hline Rv3449 & $\begin{array}{l}\text { pr } \\
\text { te }\end{array}$ & $\begin{array}{l}\text { probable precursor of serine pro- } \\
\text { tease }\end{array}$ & Rv0522 & $g a b P$ & $\begin{array}{l}\text { probable 4-amino butyrate trans- } \\
\text { porter }\end{array}$ & & cyst & $\begin{array}{l}\text { protein } \\
\text { sulphate transport system perme- }\end{array}$ \\
\hline Rv3451 & & probable cutinase & Rv0411c & $g \operatorname{lnH}$ & putative glutamine binding protein & & & \\
\hline Rv3452 & & probable cutinase precursor & Rv2564 & $g \ln Q$ & probable ATP-binding transport & Rv2398c & cysW & sulphate transport system perme- \\
\hline & & & Rv1280c & oppA & probable oligopeptide transport & Rv1857 & $\bmod A$ & molybdate binding protein \\
\hline 3. Murein & sacculus and & d peptidoglycan & & & & Rv1858 & $\bmod B$ & transport system permease, \\
\hline Rv2911 & $d a c B$ & penicillin binding protein & Rv1283c & $o p p B$ & oligopeptide transport protein & & & \\
\hline $\begin{array}{l}\text { Rv2981c } \\
\text { Rv3809c }\end{array}$ & $\begin{array}{l}\text { ddlA } \\
\text { glf }\end{array}$ & $\begin{array}{l}\text { D-alanine-D-alanine ligase } A \\
\text { UDP-galactopyranose mutase }\end{array}$ & Rv1282c & oppC & $\begin{array}{l}\text { oligopeptide transport system per- } \\
\text { mease }\end{array}$ & Rv1859 & $\bmod C$ & $\begin{array}{l}\text { molybdate uptake ABC- } \\
\text { transporter }\end{array}$ \\
\hline Rv1018c & $g / m U$ & $\begin{array}{l}\text { UDP-N-acetylglucosamine } \\
\text { pyrophosphorylase }\end{array}$ & $\begin{array}{l}\text { Rv1281c } \\
\text { Rv2320c }\end{array}$ & $\begin{array}{l}\text { oppD } \\
\text { rocE }\end{array}$ & $\begin{array}{l}\text { probable peptide transport protein } \\
\text { arginine/ornithine transporter }\end{array}$ & Rv1860 & $\bmod D$ & $\begin{array}{l}\text { precursor of Apa ( } 45 / 47 \\
\text { kD secreted protein) }\end{array}$ \\
\hline $\begin{array}{l}\text { Rv3382c } \\
\text { Rv1110 }\end{array}$ & $\begin{array}{l}\text { lytB } \\
\text { lytB' }\end{array}$ & $\begin{array}{l}\text { LytB protein homologue } \\
\text { very similar to LytB }\end{array}$ & Rv3253c & - & $\begin{array}{l}\text { probable cationic amino acid } \\
\text { transport }\end{array}$ & $\begin{array}{l}\text { Rv2329c } \\
\text { Rv1737c }\end{array}$ & $\begin{array}{l}\text { narK1 } \\
\text { narK2 }\end{array}$ & $\begin{array}{l}\text { probable nitrite extrusion protein } \\
\text { nitrite extrusion protein }\end{array}$ \\
\hline Rv1315 & murA & $\begin{array}{l}\text { UDP-N-acetylglucosamine-1-car- } \\
\text { boxyvinyltransferase }\end{array}$ & Rv3454 & - & possible proline permease & $\begin{array}{l}\text { Rv0261c } \\
\text { Rv0267 }\end{array}$ & $\begin{array}{l}\text { nark3 } \\
\text { narU }\end{array}$ & $\begin{array}{l}\text { nitrite extrusion protein } 1 \\
\text { similar to nitrite extrusion }\end{array}$ \\
\hline Rv0482 & murB & UDP-N-acetylenolpyruvoylglu- & 2. Cations & & & & & protein 2 \\
\hline Rv2152c & murC & $\begin{array}{l}\text { cosamine reductase } \\
\text { UDP-N-acetyl-muramate-alanine }\end{array}$ & $\begin{array}{l}\text { Rv2920c } \\
\text { Rv1607 }\end{array}$ & amt & putative ammonium transporter & Rv0934 & phos1 & PstS component of phosphate \\
\hline & & $\begin{array}{l}\text { UDF-N-acetyl-muramate-alanine } \\
\text { ligase }\end{array}$ & Rv1239c & $\begin{array}{l}\text { CnaA } \\
\text { corA }\end{array}$ & probable magnesium and cobalt & Rv0928 & phos2 & $\begin{array}{l}\text { Uplake } \\
\text { PstS component of phosphate }\end{array}$ \\
\hline Rv2155c & murD & $\begin{array}{l}\text { UDP-N-acetylmuramoylalanine-D- } \\
\text { glutamate liqase }\end{array}$ & Rv0092 & $\operatorname{ctp} A$ & $\begin{array}{l}\text { transport protein } \\
\text { cation-transporting ATPase }\end{array}$ & Rv0820 & phot & $\begin{array}{l}\text { uptake } \\
\text { phosphate transport system } A B C\end{array}$ \\
\hline Rv2158c & murE & $\begin{array}{l}\text { meso-diaminopimelate-adding } \\
\text { enzyme }\end{array}$ & $\begin{array}{l}\text { Rv0103c } \\
\text { Rv3270 }\end{array}$ & $\begin{array}{l}\operatorname{ctpB} \\
\operatorname{ctp} C\end{array}$ & $\begin{array}{l}\text { cation transport ATPase } \\
\text { cation transport ATPase }\end{array}$ & Rv3301c & phoY1 & transporter \\
\hline Rv2157c & murF & D-alanine:D-alanine-adding & Rv1469 & $c t p D$ & probable cadmium-transporting & & & regulator \\
\hline Rv2153c & murG & $\begin{array}{l}\text { enzyme } \\
\text { transferase in peptidoglycan syn- }\end{array}$ & Rv0908 & $\operatorname{ctp} E$ & ion transport ATPase & Rv0821c & phoY2 & $\begin{array}{l}\text { phosphate transport system } \\
\text { regulator }\end{array}$ \\
\hline & & & Rv1997 & ctpF & probable cation transport ATPase & Rv0545c & pita & low-affinity inorganic phosphate \\
\hline Rv1338 & murl & & Rv1992c & $c t p G$ & probable cation transport ATPase & & & \\
\hline Rv2156c & murX & $\begin{array}{l}\text { phospho-N-acetylmuramoyl- } \\
\text { petapeptide transferase }\end{array}$ & Rv0425c & $\mathrm{ctpH}$ & $\begin{array}{l}\text { C-terminal region putative cation- } \\
\text { transporting ATPase }\end{array}$ & $\begin{array}{l}\text { Rv2281 } \\
\text { Rv0930 }\end{array}$ & $\begin{array}{l}\text { pitB } \\
\text { pstA1 }\end{array}$ & $\begin{array}{l}\text { phosphate permease } \\
\text { PstA component of phosphate }\end{array}$ \\
\hline Rv3332 & nagA & $\begin{array}{l}\mathrm{N} \text {-acetylglucosamine-6-P- } \\
\text { deacetylase }\end{array}$ & Rv0107c & ctpl & $\begin{array}{l}\text { probable magnesium transport } \\
\text { ATPase }\end{array}$ & Rv0936 & pstA2 & $\begin{array}{l}\text { uptake } \\
\text { PstA component of phosphate }\end{array}$ \\
\hline Rv0016c & pbpA & penicillin-binding protein & Rv0969 & $\operatorname{ctpV}$ & cation transport ATPase & & & uptake \\
\hline Rv2163c & $p b p B$ & penicillin-binding protein 2 & Rv3044 & $f e c B$ & putative Felll-dicitrate transporter & Rv0933 & pstB & $A B C$ transport component of \\
\hline Rv0050 & ponA & penicillin-bonding protein & Rv0265c & fecB2 & iron transport protein Felll dici- & & & phosphate uptake \\
\hline Rv3682 & ponA & class A penicillin binding protein & trate & & transporter & Rv0935 & pstC & PstC component of phosphate \\
\hline Rv0017c & $\operatorname{rod} A$ & FtsW/RodA/SpovE family & Rv1029 & kdpA & potassium-transporting ATPase A & & & uptake \\
\hline Rv0907 & pr & probable penicillin binding protein & & & chain & Rv0929 & pstC2 & membrane-bound component of \\
\hline
\end{tabular}




\begin{tabular}{|c|c|c|c|c|c|c|c|c|c|}
\hline & & phosphate transport system & & & unit & Rv3500c & - & part of mce 4 opero & \\
\hline Rv0932c & pstS & $\begin{array}{l}\text { PstS component of phosphate } \\
\text { uptake }\end{array}$ & Rv1821 & $\sec A 2$ & $\begin{array}{l}\text { SecA, preprotein translocase sub- } \\
\text { unit }\end{array}$ & $\begin{array}{l}\text { Rv3501c } \\
\text { Rv3896c }\end{array}$ & - & $\begin{array}{l}\text { part of } m c e 4 \text { opero } \\
\text { putative p60 homol }\end{array}$ & $\begin{array}{l}\text { on } \\
\text { ologue }\end{array}$ \\
\hline Rv2400c & subl & sulphate binding precursor & Rv2587c & $\sec D$ & protein-export membrane protein & Rv3922c & - & possible hemolysin & \\
\hline Rv0143c & - & probable chloride channel & Rv0638 & secE & SecE preprotein translocase & & & & \\
\hline Rv1707 & - & probable sulphate permease & Rv2586c & $\sec F$ & protein-export membrane protein & B. IS eleme & ents, Repe & eated sequences, ar & ind Phage \\
\hline Rv1739c & - & possible sulphate transporter & Rv1440 & $\sec G$ & protein-export membrane protein & 1. IS eleme & ents & & \\
\hline Rv3679 & - & possible anion transporter & & & SecG & IS6110 & & 16 copies & \\
\hline Rv3680 & - & probable anion transporter & Rv0732 & $\sec Y$ & $\begin{array}{l}\text { SecY subunit of preprotein translo- } \\
\text { case }\end{array}$ & $\begin{array}{l}\text { IS } 1081 \\
\text { Others }\end{array}$ & & $\begin{array}{l}6 \text { copies } \\
37 \text { copies }\end{array}$ & \\
\hline 5. Fatty ac & id transpo & & Rv2462c & tig & chaperone protein, similar to & & & & \\
\hline Rv2790c & Itp1 & non-specific lipid transport protein & & & trigger factor & 2. REP $13 E$ & 12 family & 7 copies & \\
\hline Rv3540c & Itp2 & non-specific lipid transport protein & Rv2813 & - & $\begin{array}{l}\text { probable general secretion path- } \\
\text { way protein }\end{array}$ & 3. Phage-re & elated func & ctions & \\
\hline 6. Efflux pr & roteins & & & & & Rv2894c & xerC & integrase/recombin & nase \\
\hline Rv2936 & drra & similar daunorubicin resistance & E. Adaptati & tions and & atypical conditions & Rv1701 & xerD & integrase/recombin & nase \\
\hline & & ABC-transporter & Rv1901 & $\operatorname{cin} A$ & competence damage protein & Rv1054 & - & integrase-a & \\
\hline Rv2937 & $d r r B$ & $\begin{array}{l}\text { similar daunorubicin resistance } \\
\text { transmembrane protein }\end{array}$ & Rv3648c & $\operatorname{csp} A$ & $\begin{array}{l}\text { cold shock protein, transcriptional } \\
\text { requlator }\end{array}$ & Rv1055 & - & integrase-b & \\
\hline Rv2938 & $d r r C$ & $\begin{array}{l}\text { transmembrane protein } \\
\text { similar daunorubicin resistance }\end{array}$ & Rv0871 & $\operatorname{csp} B$ & $\begin{array}{l}\text { regulator } \\
\text { probable cold shock protein }\end{array}$ & $\begin{array}{l}\text { Rv15/3 } \\
\text { Rv1574 }\end{array}$ & - & $\begin{array}{l}\text { phiRV1 phage rela } \\
\text { phiRV1 phage rela }\end{array}$ & ated protein \\
\hline 年 & and & transmembrane protein & Rv3063 & cstA & $\begin{array}{l}\text { probable cold snock proteln } \\
\text { starvation-induced stress }\end{array}$ & Rv1575 & - & phiRV1 phage rela & ated protein \\
\hline Rv2846c & efpA & putative efflux protein & & & response protein & Rv1576c & - & phiRV1 phage rela & ted protein \\
\hline Rv3065 & emrE & resistance to ethidium bromide & Rv3490 & otsA & probable $\alpha, \alpha$-trehalose-phosphate & Rv1577c & - & phiRV1 possible pr & rohead protease \\
\hline Rv0783c & - & multidrug resistance protein & & & synthase & Rv1578c & - & phiRV1 phage rela & ated protein \\
\hline Rv0849 & - & possible quinolone efflux pump & Rv2006 & otsB & trehalose-6-phosphate phos- & Rv1579c & - & phiRV1 phage rela & ated protein \\
\hline Rv1145 & - & probable drug transporter & & & phatase & Rv1580c & - & phiRV1 phage rela & ated protein \\
\hline Rv1146 & - & probable drug transporter & Rv3372 & otsB2 & trehalose-6-phosphate phos- & Rv1581c & - & phiRV1 phage rela & ated protein \\
\hline Rv1250 & - & probable drug efflux protein & & & phatase & Rv1582c & - & phiRV1 phage rela & ated protein \\
\hline Rv1258c & - & probable multidrug resistance & Rv3758c & prov & osmoprotection $\mathrm{ABC}$ transporter & Rv1583c & & phiRV1 phage rela & ated protein \\
\hline & & pump & Rv3757c & prow & transport system permease & Rv1584c & - & phiRV1 phage rela & ated protein \\
\hline Rv1410c & - & probable drug efflux protein & Rv3759c & proX & similar to osmoprotection proteins & Rv1585c & - & phiRV1 phage rela & ated protein \\
\hline Rv1634 & - & probable drug efflux protein & Rv3756c & proZ & transport system permease & Rv1586c & - & phiRV1 integrase & \\
\hline Rv1819c & - & $\begin{array}{l}\text { probable multidrug resistance } \\
\text { pump }\end{array}$ & Rv1026 & - & $\begin{array}{l}\text { probable pppGpp-5'phosphohydro- } \\
\text { lase }\end{array}$ & $\begin{array}{l}\text { Rv2309c } \\
\text { Rv2310 }\end{array}$ & - & $\begin{array}{l}\text { integrase } \\
\text { excisionase }\end{array}$ & \\
\hline Rv2136c & - & $\begin{array}{l}\text { putative bacitracin resistance pro- } \\
\text { tein }\end{array}$ & F. Detoxific & cation & & $\begin{array}{l}\text { Rv2646 } \\
\text { Rv2647 }\end{array}$ & - & $\begin{array}{l}\text { phiRV2 integrase } \\
\text { phiRV2 phage rela }\end{array}$ & ted protein \\
\hline Rv2209 & - & probable drug efflux protein & Rv2428 & $a h p C$ & alkyl hydroperoxide reductase & Rv2650c & - & phiRV2 phage rela & ted protein \\
\hline Rv2333c & - & $\begin{array}{l}\text { probable tetracenomycin C resis- } \\
\text { tance protein }\end{array}$ & $\begin{array}{l}\text { Rv2429 } \\
\text { Rv2238c }\end{array}$ & $\begin{array}{l}\text { ahpD } \\
\text { ahpE }\end{array}$ & $\begin{array}{l}\text { member of AhpC/TSA family } \\
\text { member of AhpC/TSA family }\end{array}$ & $\begin{array}{l}\text { Rv2651c } \\
\text { Rv2652c }\end{array}$ & - & $\begin{array}{l}\text { phiRV2 prohead pr } \\
\text { phiRV2 phage rela }\end{array}$ & rotease \\
\hline Rv2994 & - & $\begin{array}{l}\text { probable fluoroquinolone efflux } \\
\text { protein }\end{array}$ & $\begin{array}{l}\text { Rv2521 } \\
\text { Rv1608c }\end{array}$ & $\begin{array}{l}b c p \\
b c p B\end{array}$ & $\begin{array}{l}\text { bacterioferritin comigratory protein } \\
\text { probable bacterioferritin comigra- }\end{array}$ & $\begin{array}{l}\text { Rv2653c } \\
\text { Rv2654c }\end{array}$ & - & $\begin{array}{l}\text { phiRV2 phage rela } \\
\text { phiRV2 phage rela }\end{array}$ & $\begin{array}{l}\text { ated protein } \\
\text { ated protein }\end{array}$ \\
\hline Rv1877 & - & probable drug efflux protein & & & tory protein & Rv2655c & - & phiRV2 phage rela & ated protein \\
\hline Rv2459 & - & probable drug efflux protein & Rv3473c & bpoA & $\begin{array}{l}\text { probable non-heme bromoperoxi- } \\
\text { dase }\end{array}$ & Rv2656c & - & phiRV2 phage rela & ted protein \\
\hline B. Chaper & ones/He & shock & Rv1123c & bpoB & probable non-heme bromoperoxi- & $\mathrm{RV} 265 / \mathrm{C}$ & & phage L5 & \\
\hline Rv0384c & $c / p B$ & heat shock protein & & & dase & Rv2658c & - & phiRV2 phage rela & ated protein \\
\hline Rv0352 & dnaJ & acts with GrpE to stimulate DnaK & Rv0554 & bpoc & probable non-heme bromoperoxi- & Rv2659c & - & phiRV2 integrase & \\
\hline & & ATPase & & & dase & Rv2830c & - & similar to phage $P$ & 1 phd gene \\
\hline Rv2373c & dnaJ2 & DnaJ homologue & Rv3617 & ephA & probable epoxide hydrolase & Rv3750c & - & excisionase & \\
\hline Rv0350 & dnaK & $\begin{array}{l}70 \mathrm{kD} \text { heat shock protein, chromo- } \\
\text { some replication }\end{array}$ & $\begin{array}{l}\text { Rv1938 } \\
\text { Rv1124 }\end{array}$ & $\begin{array}{l}\text { ephB } \\
\text { ephC }\end{array}$ & $\begin{array}{l}\text { probable epoxide hydrolase } \\
\text { probable epoxide hydrolase }\end{array}$ & Rv3751 & - & putative integrase & \\
\hline Rv3417c & groEL1 & $60 \mathrm{kD}$ chaperonin 1 & Rv2214c & ephD & probable epoxide hydrolase & C. PE and & PPE famili & & \\
\hline Rv0440 & groEL2 & $60 \mathrm{kD}$ chaperonin 2 & Rv3670 & ephE & probable epoxide hydrolase & 1. PE famil & & & \\
\hline Rv3418c & groES & $10 \mathrm{kD}$ chaperone & Rv0134 & ephF & probable epoxide hydrolase & PE subfam & & 38 members & \\
\hline Rv0351 & grpE & stimulates DnaK ATPase activity & Rv3171c & hpx & probable non-heme haloperoxi- & PE_PGRS & subfamily & 61 members & \\
\hline Rv2374c & hrcA & heat-inducible transcription & & & & & & & \\
\hline & & repressor & Rv1908c & katG & catalase-peroxidase & 2. PPE fam & & 68 members & \\
\hline Rv0251c & $h s p$ & possible heat shock protein & Rv3846 & sodA & superoxide dismutase & & & & \\
\hline Rv0353 & $h s p R$ & heat shock regulator & Rv0432 & sodC & superoxide dismutase precursor - & D. Antibioti & ic productio & ion and resistance & \\
\hline Rv2031c & $h s p X$ & $14 \mathrm{kD}$ antigen, heat shock protein & & & (Cu-Zn) & Rv2068c & blac & class $\mathrm{A} \beta$-lactamas & \\
\hline & & Hsp20 family & Rv1932 & $\operatorname{tpx}$ & thiol peroxidase & Rv3290c & lat & lysine $-\epsilon$ aminotran & sferase \\
\hline Rv2299c & htpG & heat shock protein Hsp90 family & Rv0634c & - & putative glyoxylase II & Rv2043c & $p \cap c A$ & pyrazinamide resis & stance/sensitivity \\
\hline Rv0563 & $h t p X$ & $\begin{array}{l}\text { probable (transmembrane) heat } \\
\text { shock protein }\end{array}$ & $\begin{array}{l}\text { Rv2581c } \\
\text { Rv3177 }\end{array}$ & - & $\begin{array}{l}\text { putative glyoxylase II } \\
\text { probable non-heme haloperoxi- }\end{array}$ & Rv0133 & - & $\begin{array}{l}\text { possible puromycir } \\
\text { ferase }\end{array}$ & n N-acetyltrans- \\
\hline Rv2701c & $\operatorname{suh} B$ & $\begin{array}{l}\text { putative extragenic suppressor } \\
\text { protein }\end{array}$ & & & dase & Rv0262c & - & $\begin{array}{l}\text { aminoglycoside 2'- } \\
\text { ferase }\end{array}$ & - N-acetyltrans- \\
\hline Rv3269 & & probable heat shock protein & IV. Other & & & Rv0802c & - & acetyltransferase & \\
\hline & & & A. Virulenc & & & Rv1082 & - & similar to $S$. lincoln & nensis ImbE \\
\hline C. Cell div & ision & & Rv0169 & mce1 & cell invasion protein & Rv1170 & - & similar to S. lincoln & nensis ImbE \\
\hline Rv3641c & fic & possible cell division protein & Rv0589 & mce2 & cell invasion protein & Rv1347c & - & possible aminoglyc & coside 6'-N- \\
\hline Rv3102c & ftsE & membrane protein & Rv1966 & mce3 & cell invasion protein & & & acetyltransferase & \\
\hline Rv3610c & $\mathrm{ftsH}$ & $\begin{array}{l}\text { inner membrane protein, } \\
\text { chaperone }\end{array}$ & $\begin{array}{l}\text { Rv3499c } \\
\text { Rv3100c }\end{array}$ & $\begin{array}{l}m c e 4 \\
s m p B\end{array}$ & $\begin{array}{l}\text { cell invasion protein } \\
\text { probable small protein } b\end{array}$ & Rv2036 & - & $\begin{array}{l}\text { similar to lincomyc } \\
\text { genes }\end{array}$ & in production \\
\hline Rv2748c & ftsK & chromosome partitioning & Rv1694 & tlyA & cytotoxin/hemolysin homologue & Rv2303c & - & similar to $S$. griseu & is macrotetrolide \\
\hline Rv2151c & $f t s Q$ & ingrowth of wall at septum & Rv0024 & - & putative p 60 homologue & & & resist & \\
\hline Rv2154c & $f t s W$ & $\begin{array}{l}\text { membrane protein (shape determi- } \\
\text { nation) }\end{array}$ & $\begin{array}{l}\text { Rv0167 } \\
\text { Rv0168 }\end{array}$ & - & $\begin{array}{l}\text { part of } m c e 1 \text { operon } \\
\text { part of } m c e 1 \text { operon }\end{array}$ & Rv3225c & - & $\begin{array}{l}\text { probable aminogly } \\
\text { photransferases }\end{array}$ & coside 3'-phos- \\
\hline Rv3101c & fts $X$ & membrane protein & Rv0170 & - & part of $m c e 1$ operon & Rv3700c & - & probable acetyltrar & nsferase \\
\hline Rv2921c & $f t s Y$ & cell division protein FtsY & Rv0171 & - & part of mce 1 operon & Rv3817 & - & probable aminogly & coside 3'-phos- \\
\hline Rv2150c & fts $Z$ & circumferential ring, GTPase & Rv0172 & - & part of mce 1 operon & & & photransferase & 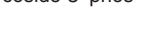 \\
\hline Rv3919c & gid & glucose inhibited division protein B & Rv0174 & - & part of $m c e 1$ operon & & & & \\
\hline Rv3625c & mesJ & probable cell cycle protein & Rv0587 & - & part of mce2 operon & E. Bacterio & cin-like pro & roteins & 3 \\
\hline Rv3917c & parA & chromosome partitioning; DNA - & Rv0588 & - & part of mce2 operon & & & & \\
\hline & & binding & Rv0590 & - & part of mce2 operon & F. Cytochro & pme P450 & enzymes & 22 \\
\hline Rv3918c & parB & possibly involved in chromosome & Rv0591 & - & part of $m c e 2$ operon & & & & \\
\hline & & partitioning & Rv0592 & - & part of mce2 operon & G. Coenzy & me $F 420-d$ & dependent & \\
\hline Rv2922c & $s m c$ & member of Smc1/Cut3/Cut14 & Rv0594 & - & part of $m c e 2$ operon & enzyme & & & 3 \\
\hline Rv0012 & - & $\begin{array}{l}\text { family } \\
\text { possible cell division protein }\end{array}$ & $\begin{array}{l}\text { Rv1085c } \\
\text { Rv1477 }\end{array}$ & $\begin{array}{l}- \\
-\end{array}$ & $\begin{array}{l}\text { possible hemolysin } \\
\text { putative exported p } 60 \text { protein }\end{array}$ & H. Miscella & neous tran & insferases & 61 \\
\hline Rv0435c & - & ATPase of AAA-family & & & homologue & & & & \\
\hline Rv2115c & - & ATPase of AAA-family & Rv1478 & - & putative exported $\mathrm{p} 60$ protein & I. Miscellan & heous phos & sphatases, lyases, & \\
\hline Rv3213c & - & $\begin{array}{l}\text { possible role in chromosome seg- } \\
\text { regation }\end{array}$ & & _- & $\begin{array}{l}\text { homologue } \\
\text { putative exported } \mathrm{p} 60 \text { protein }\end{array}$ & and hydrol & lases & & 18 \\
\hline Rv1708 & - & & & & $\begin{array}{l}\text { putative exported pou protein } \\
\text { homologue }\end{array}$ & J. Cyclases & & & 6 \\
\hline & & tioning & Rv1964 & - & part of $m c e 3$ operon & & & & \\
\hline & & & & - & part of $m c e 3$ operon & K. Chelatas & & & 2 \\
\hline D. Protein & and pep & de secretion & Rv1967 & - & part of $m c e 3$ operon & & & & \\
\hline Rv2916c & ffh & signal recognition particle protein & Rv1968 & - & part of $m c e 3$ operon & V. Conserv & red hypothe & heticals & 912 \\
\hline Rv2903c & lepB & signal peptidase I & Rv1969 & - & part of $m c e 3$ operon & & & & \\
\hline Rv1614 & lgt & $\begin{array}{l}\text { prolipoprotein diacylglyceryl trans- } \\
\text { ferase }\end{array}$ & $\begin{array}{l}\text { Rv1971 } \\
\text { Rv2190c }\end{array}$ & - & $\begin{array}{l}\text { part of } m c e 3 \text { operon } \\
\text { putative p60 homologue }\end{array}$ & VI. Unknon & & & 606 \\
\hline Rv1539 & IspA & lipoprotein signal peptidase & Rv3494c & - & part of $m c e 4$ operon & TOTAL & & & 3924 \\
\hline Rv0379 & sec & probable transport protein & Rv3496c & - & part of mce 4 operon & & & & \\
\hline & & SecE/Sec61- $\gamma$ family & Rv3497c & - & part of mce 4 operon & & & & \\
\hline Rv3240c & $\sec A$ & SecA, preprotein translocase sub- & Rv3498c & - & 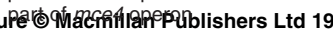 & & & & \\
\hline
\end{tabular}

